Kamila Almeida dos Reis

Desempenho Operacional em Pequenas Empresas: Revisão sistemática da literatura e uma proposta de estudo empírico

Dissertação apresentada ao Programa de Pós-Graduação em Engenharia de Produção da PUC-Rio como requisito parcial para obtenção do grau de Mestre em Engenharia de Produção.

Orientador: Prof. Antônio Márcio Tavares Thomé. 


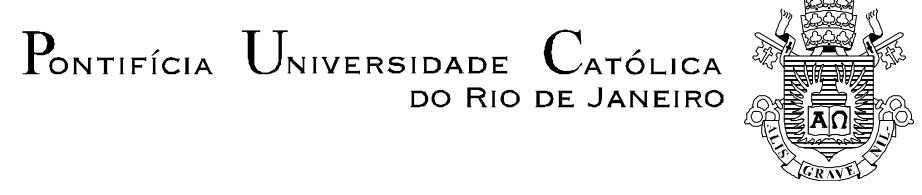

Kamila Almeida dos Reis

\section{Desempenho Operacional em Pequenas Empresas: Revisão sistemática da literatura e uma proposta de estudo empírico}

Dissertação apresentada como requisito parcial para obtenção do grau de Mestre pelo Programa de Pós-Graduação em Engenharia de Produção da PUC-Rio. Aprovada pela Comissão Examinadora abaixo assinada.

Prof. Antônio Márcio Tavares Thomé Orientador Departamento de Engenharia Industrial - PUC-Rio

Prof. Luiz Felipe Roris Rodriguez Scavarda do Carmo Departamento de Engenharia Industrial - PUC-Rio

Prof. Antonio Batista Ribeiro Neto Universidade do Estado do Pará- UEPa

Prof. Márcio da Silveira Carvalho Coordenador Setorial do Centro Técnico Científico - PUC-Rio

Rio de Janeiro, 10 de setembro de 2018 
Todos os direitos reservados. É proibida a reprodução total ou parcial do trabalho sem autorização da universidade, da autora e do orientador.

\section{Kamila Almeida dos Reis}

Graduou-se em Engenharia de Produção pela Universidade do Estado do Pará - UEPA em 2015. Participou ativamente de projetos em diversas organizações adquirindo experiência nas áreas de Logística e Cadeia de Suprimentos, Gerenciamento de Projetos, Gestão da Qualidade e Gerência de Operações.

Ficha Catalográfica

Reis, Kamila Almeida dos

Desempenho operacional em pequenas empresas : revisão sistemática da literatura e uma proposta de estudo empírico / Kamila Almeida dos Reis ; orientador: Antônio Márcio Tavares Thomé. 2018.

102 f. : il. ; $30 \mathrm{~cm}$

Dissertação (mestrado)-Pontifícia Universidade Católica do Rio de Janeiro, Departamento de Engenharia Industrial, 2018.

Inclui bibliografia

1. Engenharia Industrial - Teses. 2. RBV. 3. Desempenho operacional. 4. Revisão sistemática. 5. Inovação. 6. Pequenas empresas. I. Thomé, Antônio Márcio Tavares. II. Pontifícia Universidade Católica do Rio de Janeiro. Departamento de Engenharia Industrial. III. Título. 


\section{Agradecimentos}

A Deus, por ter me concedido a capacidade de ter fé. Por acalmar minha ansiedade em situações fora do meu controle. Por me fazer entender que tudo que nos acontece deixa uma lição. Por me ajudar a encarar os meus desafios com esperança de que tudo se resolveria. Por me dar forças para não desistir.

Aos meus pais, Adelson e Karla, pelo incentivo, apoio e participação em todos os projetos que me envolvo. Por me lembrarem do meu valor quando eu mesma esqueço. Por me lembrarem de que, aonde quer que eu esteja, sempre tenho com quem contar.

Aos meus colegas de classe Ana Paula, Luiza, Lucas, Pierry, Andrew, luri e a todos os outros que compartilharam horas de estudo, provas, trabalhos e todos os desafios do caminho para se tornar um mestre pela PUC-Rio.

Aos meus amigos Leonardo, Leidi, Breno, Júlia, Soraida, Diego e Kayza por terem sido minha família no Rio de Janeiro. Por terem me proporcionado os melhores momentos durante esta jornada.

Aos meus amigos Ludmylla, Narley, Brenda, Vinícius, D’ávila, Jéssica, Pedro e Dalma com quem tive a oportunidade de compartilhar bons momentos. Aos meus companheiros de toda vida Elizabeth, Vitor Rahel e Priscila, por estarem presentes, mesmo de longe, em qualquer situação que eu me envolva.

À minha amiga Nathália, cujo apoio me permitiu finalizar esta dissertação.

Aos meus familiares Carlos, Isabel, Ana Lúcia e Cecília, por renovarem minhas energias a cada visita. Aos meus tios Milton, Ana Clara, Rita e Mariinha cujo suporte e amor me lembram que eu nunca estou sozinha aonde quer que eu esteja, e que eu sempre serei bem-vinda de volta.

Aos meus avós, tios e tias, primos e primas, que acompanharam minha trajetória, dessa vez de longe, mas sempre torcendo pelo meu sucesso e fazendo o que thes era possível para contribuir de alguma forma.

Ao meu eterno professor e amigo Antônio Batista, pelas importantes contribuições e palavras de apoio.

Ao CNPq e à PUC-Rio, pelos auxílios concedidos, sem os quais este trabalho não poderia ter sido realizado. A todos os funcionários do Departamento por não medirem esforços para ajudar os alunos. Ao meu orientador por ter me ensinado a acreditar em mim mesma.

Agradeço, enfim, a todos que de alguma forma contribuíram para que eu concretizasse mais uma etapa do meu desenvolvimento de muitas que virão. 


\section{Resumo}

Reis, Kamila Almeida dos; Thomé, Antônio Márcio Tavares (Orientador). Desempenho Operacional em Pequenas Empresas: Revisão sistemática da literatura e uma proposta de estudo empírico. Rio de Janeiro, 2018. 102p. Dissertação de Mestrado - Departamento de Engenharia Industrial, Pontifícia Universidade Católica do Rio de Janeiro.

Pequenos empreendimentos são muito importantes para a economia de um país, especialmente daqueles em desenvolvimento, como o Brasil. Assim como as grandes empresas, as pequenas precisam encontrar formas de medir o seu desempenho operacional. Contudo, existem poucos trabalhos que abordem esse tema, devido principalmente à grande diversidade de indicadores que não se adaptam às realidades destas pequenas empresas. Este estudo tem por objetivo classificar estes indicadores por meio de uma revisão sistemática da literatura propondo uma taxonomia dos indicadores de desempenho operacional e dos determinantes, moderadores, mediadores e variáveis de controle do desempenho operacional de pequenas empresas e um framework para elaboração de pesquisas mais amplas com as diferentes variantes causais encontradas. Após a realização da revisão verificou-se que existem diversas nomenclaturas para o mesmo termo e que vários autores abordam os mesmos indicadores. Identificouse ainda que o desempenho operacional em pequenas empresas é mensurado através de uma ou mais de suas cinco dimensões como escala do Desempenho Operacional, como escala de outros indicadores (Qualidade como escala de Desempenho organizacional), ou ainda sendo as próprias dimensões os indicadores de Desempenho (Inovação). Os resultados foram organizados em tabelas e dispostos no framework com as diferentes variáveis. A partir do framework, é proposto um modelo causal relacionando algumas das variáveis, para teste de survey aplicado a serviços em pequenas e médias empresas. Devido ao tempo de pesquisa e à generalização das palavras-chave, sugerem-se propostas de trabalhos futuros para a continuação da pesquisa.

\section{Palavras-chave}

RBV; desempenho operacional; revisão sistemática; inovação; pequenas empresas; MPE 


\section{Abstract}

Reis, Kamila Almeida dos; Thomé, Antônio Márcio Tavares (Advisor). Operational Performance in Small Companies: A systematic literature review and a proposal for an empirical study. Rio de Janeiro, 2018. 102p. Dissertação de Mestrado - Departamento de Engenharia Industrial, Pontifícia Universidade Católica do Rio de Janeiro.

Small enterprises are very important to a country's economy, especially those in development, such as Brazil. Like large companies, small companies need to find ways to measure their operational performance. However, there are few studies that address this issue, mainly due to the great diversity of indicators that do not adapt to the realities of these small companies. This study aims to classify these indicators through a systematic literature review proposing a taxonomy of operational performance indicators and determinants, moderators, mediators and control variables of the operational performance of small companies and a framework for elaboration of broader research with the different causal variants found. After the review, it was verified that there are several nomenclatures for the same term and that several authors address the same indicators. It was also identified that operational performance in small companies is measured through one or more of its five dimensions as an Operational Performance scale, as a scale of other indicators (Quality as an Organizational Performance scale), or even the dimensions themselves the indicators of Performance (Innovation). The results were organized in tables and arranged in the framework with the different variables. From the framework, it is proposed a causal model relating some of the variables, for test of survey applied to services in small and medium enterprises. Due to the research time and the generalization of the keywords, future work proposals are suggested for the continuation of the research.

\section{Keywords}

RBV; operational performance; systematic review; innovation; small companies; SME. 


\section{Sumário}

1 Introdução 11

1.1 Justificativa e motivação 11

1.2 Objetivos 12

1.3 Delimitação da pesquisa 13

$\begin{array}{ll}1.4 \text { Estrutura da Dissertação } & 13\end{array}$

2 Referencial teórico $\quad 15$

2.1 Pequenas empresas $\quad 15$

2.1.1 Definição de pequena empresa $\quad 15$

2.1.2 Quantificação de pequenas empresas $\quad 17$

2.2 Teorias da vantagem competitiva 21

2.2.1 Teoria da visão baseada em recursos 23

2.2.2 Desempenho operacional 24

2.2.3 Recursos VRIN em desempenho operacional $\quad 29$

3 Procedimentos metodológicos $\quad 35$

3.1 Revisão sistemática da literatura $\quad 35$

3.1.1 Planejamento e formulação do problema 36

3.1.2 Busca na literatura $\quad 36$

3.1.3 Coleta de dados e avaliação da qualidade da coleta de dados 38

3.1.4 Análise, síntese e interpretação dos dados 39

3.1.5 Apresentação dos resultados e atualização da revisão 40

3.2 Surveys 40

3.2.1 Relação com a teoria $\quad 41$

3.2.2 Design 43

3.2.3 Teste piloto $\quad 44$

4 Resultados e discussões $\quad 46$

4.1 Análise descritiva da RSL 46

4.2 Taxonomia $\quad 49$

4.3 Framework 58

4.4 Novo modelo estrutural $\quad 58$

5 Conclusão 60

5.1 Considerações sobre os resultados obtidos 60

5.2 Limitações da pesquisa e propostas de trabalhos futuros 61

6 Referências bibliográficas 63

APÊNDICE I - Operacionalização dos construtos a partir da literatura $\quad 78$

$\begin{array}{ll}\text { APÊNDICE II - Taxonomia } & 81\end{array}$

APÊNDICE III - Questionário 90

APÊNDICE IV - Escalas de fatores de desempenho operacional 99 


\section{Lista de Figuras}

Figura 1 - Perspectivas de análise da vantagem competitiva

Figura 2 - A relação entre heterogeneidade e imobilidade de recursos, valor, raridade, imitabilidade imperfeita, não-substituibilidade, e vantagem competitiva sustentável

Figura 3 - Passos para a seleção dos artigos 38

Figura 4 - Processo de teste de teoria através de survey 41

Figura 5 - Modelo estrutural 42

Figura 6 - Publicações por ano - artigos selecionados $\quad 47$

Figura 7 - Maiores acervos $\quad 47$

Figura 8 - Resumo das variáveis encontradas na RSL 58

Figura 9 - Novo modelo estrutural 59

Figura 10 - Apresentação do questionário 90

Figura 11 - Perfil do respondente $\quad 91$

Figura 12 - Perfil da empresa $\quad 92$

Figura 13 - Caracterização da empresa quanto à orientação ao mercado 93

Figura 14 - Caracterização da empresa quanto aos esforços de inovação 94

Figura 15 - Ordenamento dos objetivos de desempenho 95

Figura 16 - Avaliação do desempenho operacional 96

Figura 17 - Agradecimento pela participação na pesquisa 97

Figura 18 - Oferta de retorno dos resultados da pesquisa 98 


\section{Lista de Tabelas}

Tabela 1 - Definição de MPME segundo a Comissão Europeia 16

Tabela 2 - Definição de MPME segundo o Banco Mundial 16

Tabela 3 - Definição de MPE no Brasil 16

Tabela 4 - Distribuição de empresas por número de funcionários nos

$\begin{array}{ll}\text { países } & 17\end{array}$

Tabela 5 - Porcentagem de micro, pequenos e médio negócios de $\begin{array}{ll}\text { classificados na categoria MPME } & 17\end{array}$

Tabela 6 - Percentual de microempresas segundo os setores considerados na classificação MPME 18

Tabela 7 - Percentual de pequenas e médias empresas segundo os setores $\begin{array}{ll}\text { considerados na classificação MPME } & 19\end{array}$

Tabela 8 - Valor agregado gerado pelas MPE por Unidade de Federação (em milhões de reais)

Tabela 9 - Valor agregado em \% das MPE por atividade econômica (2009-

Tabela 10 - Composição percentual do número de empresas, por região, nas $\begin{array}{ll}\text { atividades selecionadas } & 20\end{array}$

Tabela 11 - Comparação entre as teorias sobre vantagem competitiva 22

Tabela 12 - Dimensões da qualidade em serviços 27

Tabela 13 - Níveis de inovação em serviços 28

Tabela 14 - Queries de busca 37

Tabela 15 - Parâmetros de informação geral 39

Tabela 16 - Parâmetros de informação específica 39

Tabela 17 - Métodos de síntese da literatura 40

Tabela 18 - Palavras-chave mais utilizadas $\quad 48$

Tabela 19 - 10 publicações mais citadas 49

Tabela 20 - Principais indicadores de desempenho que apresentam dimensões de desempenho operacional em pequenas empresas 50

Tabela 21 - Dimensões do desempenho operacional em desempenho organizacional 51

Tabela 22 - Principais determinantes encontrados e os autores que abordam o tema

Tabela 23 - Principais mediadores encontrados e os autores que abordam o tema 
Tabela 24 - Principais moderadores encontrados e os autores que abordam o tema

Tabela 25 - Principais indicadores de controle encontrados e os autores que abordam o tema

Tabela 26 - Dimensões do desempenho operacional em pequenas empresas

Tabela 27 - Dimensões do desempenho operacional em pequenas empresas

Tabela 28 - Escalas de fatores de desempenho operacional 


\section{Introdução}

O presente capítulo tem como objetivo apresentar a justificativa e a motivação da pesquisa, bem como os objetivos que devem ser alcançados com a realização do trabalho e a forma como a pesquisa foi organizada.

\section{1 \\ Justificativa e motivação}

Nos últimos anos, a participação das pequenas empresas na economia tem crescido ao ponto que em países em desenvolvimento, os pequenos e médios empreendimentos contribuem com até $60 \%$ dos empregos e $40 \%$ da renda nacional (exceto os trabalhadores autônomos e as microempresas), sendo responsáveis por uma geração de empregos formais maior que a de grandes empresas (AIRAKSINEN et al., 2015; BELL, 2017; GONZALEZ, 2016).

No Brasil, as MPEs respondem por $52 \%$ dos empregos com carteira assinada no setor privado (SEBRAE, 2018). Enquanto as grandes empresas criam uma maior parcela de valor agregado em atividades de manufatura, pequenas e médias empresas se destacam no setor de serviços desempenhando um papel importante na economia de diversos países (AIRAKSINEN et al., 2015).

Segundo OECD (2000) Em comparação com grandes empresas, as pequenas empresas são menos propensas a realizar atividades de pesquisas e desenvolvimento (P\&D). Entretanto, pequenas empresas utilizam a inovação para criar novos produtos ou serviços e desenvolver novas técnicas, a fim de ganhar participação no mercado, ou diferentes abordagens organizacionais para aumentar a produtividade (OECD, 2000).

Esforços de inovar em métodos e tecnologias oferecem oportunidades para o desenvolvimento de produtos/serviços totalmente novos e/ou aprimorados, assim como adaptações dos já existentes. Os produtos/serviços já existentes podem ser melhorados para atrair novos clientes e aumentar a lealdade dos clientes atuais, o que pode contribuir para a redução de custo e crescimento nas vendas (SMITH, FISCHBACHER e WILSON, 2007). Para o desenvolvimento de 
vantagem competitiva uma postura inovadora pode ser fundamental (DOSI, 1988; KNIGHT e CAVUSGIL, 2004; OTTENBACHER, 2005; RADAS e BOŽIĆ, 2009).

Empresas orientadas ao mercado tendem a investir no desenvolvimento da inovação (i.e., esforços de inovação) a fim de acompanhar as mudanças no mercado, o que geralmente resulta em um aprimoramento de seu desempenho (AGARWAL, ERRAMILLI e DEV, 2003; MEGICKS, MISHRA e LEAN, 2005; RADAS e BOŽIĆ, 2009).

Como a inovação é influenciada pelo contexto em que a organização está inserida, pesquisas evidenciam que países que investem mais em inovação, não apenas desenvolvem mais serviços e produtos, como também se tornam mais competitivos (CORNELL UNIVERSITY, INSEAD e WIPO, 2016; RADAS e BOŽIĆ, 2009).

Ao se considerar a relevância do tema, o baixo volume de publicações a respeito do desempenho operacional em pequenas empresas e a fim de se criar um maior entendimento sobre o assunto, as seguintes perguntas de pesquisa foram elaboradas com objetivo de nortear este trabalho, sendo as determinantes as variáveis que influenciam positiva ou negativamente o desempenho operacional, as mediadoras as que bloqueiam parcialmente ou completam a relação entre os determinantes e o desempenho operacional e as moderadoras as que afetam a direção e/ou a força da relação entre os determinantes e o desempenho operacional e variáveis de controle as que controlam os grupos analisados:

Pergunta de pesquisa 1 - Como é mensurado o desempenho operacional em pequenas empresas?

Pergunta de pesquisa 2 - Quais os determinantes, mediadores, moderadores e variáveis de controle do desempenho operacional em pequenas empresas?

\section{2 \\ Objetivos}

Para responder as perguntas de pesquisa, determina-se como objetivo geral deste estudo classificar os determinantes, moderadores, mediadores variáveis de controle e desempenho operacional de pequenas empresas, propondo uma taxonomia e um framework para pesquisas empíricas com estas variáveis.

Os objetivos específicos seguintes deverão servir de apoio à consecução do objetivo geral: 
- Identificar na literatura as principais variáveis de controle, determinantes, moderadores, mediadores, e medidas de desempenho com ênfase em pequenas empresas;

- Identificar como estas medidas de desempenho operacional são mensuradas na literatura;

- Propor uma taxonomia e um framework

\section{3}

\section{Delimitação da pesquisa}

O escopo da pesquisa restringe-se a pequenos negócios e não considera limitações geográficas.

A revisão sistemática da literatura analisa as publicações feitas até outubro de 2017 em língua inglesa. A pesquisa não compreende todos os métodos possíveis para um levantamento na literatura, assim não foi realizada a busca de citações feitas aos artigos selecionados (tanto nas buscas backward quanto nas buscas forward), chamada de snowball.

A fim de viabilizar uma aplicação prática, são propostas hipóteses para teste com a aplicação de um survey, desenvolvidas a partir do levantamento preliminar da literatura. Entretanto, o modelo de survey proposto não compreende um teste piloto completo, nem as etapas de Coleta de dados, Análise de dados, e Relatório, portanto estas hipóteses não serão testadas.

\section{4 \\ Estrutura da Dissertação}

Esta dissertação é composta por 5 capítulos. No Capítulo 1 são apresentadas a justificativa e motivação dessa pesquisa, objetivos geral e específicos bem como a delimitação da pesquisa e estrutura proposta para essa dissertação.

No Capítulo 2 é desenvolvido o referencial teórico pertinente para a elaboração do trabalho, abordando conceitos relacionados à pequenas empresas e desempenho operacional.

No Capítulo 3 são abordados os procedimentos metodológicos adotados nesta pesquisa e suas respectivas etapas.

No Capítulo 4 são expostos os resultados e discussões dessa dissertação, através da análise descritiva, da taxonomia e do framework. 
No Capítulo 5 apresentam-se as considerações finais deste trabalho, expondo as conclusões sobre os resultados obtidos, bem como as limitações de pesquisa e sugestões de trabalhos futuros. 


\section{2 Referencial teórico}

Neste capítulo será realizada uma revisão de literatura com temas relevantes para o desenvolvimento do trabalho, como a definição de pequenas empresas, bem como alguns assuntos pertinentes ao tema de desempenho operacional.

Deve-se ressaltar que o objetivo deste capítulo não é realizar uma longa discussão acerca dos temas citados, mas sim, situar o leitor nos assuntos mais relevantes ao desenvolvimento da pesquisa.

\section{1}

\section{Pequenas empresas}

Esta seção tem como objetivo fornecer esclarecimentos gerais acerca da definição e quantificação de pequenas empresas no Brasil e no mundo.

\subsection{1 \\ Definição de pequena empresa}

A definição de micro, pequenos e médios empreendimentos (MPME) pode ser feita a partir de diferentes parâmetros, o que resulta na inexistência de uma definição universal do porte de uma empresa. Esta definição é importante para diversos fatores como: elaboração de estatísticas e monitoramento do setor ao longo do tempo, benchmarking contra outras economias e entre regiões dentro de uma economia, fornecimento de limiares arbitrários para aplicação de impostos ou outros regulamentos e determinação da elegibilidade para formas específicas de apoio público (BERISHA e PULA, 2015).

A Comissão Europeia e o Banco Mundial classificam o porte da empresa a partir de três critérios quantitativos, o número de funcionários, e pelo menos um de dois critérios financeiros, conforme expresso nas Tabelas 1 e 2. 
Tabela 1 - Definição de MPME segundo a Comissão Europeia

\begin{tabular}{|c|c|c|c|c|}
\hline CATEGORIA & $\begin{array}{c}\mathrm{N}^{\circ} \mathrm{DE} \\
\text { FUNCIONÁRIOS }\end{array}$ & $\begin{array}{c}\text { FATURAMENTO } \\
\text { ANUAL }\end{array}$ & OU & $\begin{array}{c}\text { BALANÇO } \\
\text { ANUAL TOTAL }\end{array}$ \\
\hline Micro & $<10$ & $\leq € 2 \mathrm{mi}$ & & $\leq € 2 \mathrm{mi}$ \\
\hline \multirow{2}{*}{ Pequena } & $>10$ & $>€ 2 \mathrm{mi}$ & & $>€ 2 \mathrm{mi}$ \\
\hline & $\leq 50$ & $\leq € 10 \mathrm{mi}$ & & $\leq € 10 \mathrm{mi}$ \\
\hline \multirow{2}{*}{ Média } & $>50$ & $>€ 10 \mathrm{mi}$ & & $>€ 10 \mathrm{mi}$ \\
\hline & $<250$ & $\leq € 50 \mathrm{mi}$ & & $\leq € 50 \mathrm{mi}$ \\
\hline \multicolumn{5}{|c|}{ Fonte: Adaptado de Berisha e Pula (2015). } \\
\hline \multicolumn{5}{|c|}{ Tabela 2 - Definição de MPME segundo o Banco Mundial } \\
\hline CATFGORIA & $\mathrm{N}^{\circ} \mathrm{DE}$ & FATURAMENTO & Qu & BALANÇO \\
\hline CAITEGTA & FUNCIONÁRIOS & ANUAL & 0 & ANUAL TOTAL \\
\hline Micro & $<10$ & $\leq \$ 100.000$ & & $\leq \$ 100.000$ \\
\hline \multirow{2}{*}{ Pequena } & $>10$ & $>\$ 100.000$ & & $>\$ 100.000$ \\
\hline & $\leq 50$ & $\leq \$ 3 \mathrm{mi}$ & & $\leq \$ 3 \mathrm{mi}$ \\
\hline \multirow{2}{*}{ Média } & $>50$ & $>\$ 3 \mathrm{mi}$ & & $>\$ 3 \mathrm{mi}$ \\
\hline & $\leq 300$ & $\leq \$ 15 \mathrm{mi}$ & & $\leq \$ 15 \mathrm{mi}$ \\
\hline
\end{tabular}

Fonte: Adaptado de Berisha e Pula (2015).

No Brasil, destacam-se as definições no âmbito da Lei Geral da Micro e da Pequena Empresa (MPE) que adota a definição em função da sua receita bruta anual, como pode ser observado na Tabela 3.

\begin{tabular}{cc} 
Tabela 3 - Definição de MPE no Brasil \\
\hline CATEGORIA & $\begin{array}{c}\text { RERAL DA MPE } \\
\text { ANUAL }\end{array}$ \\
\hline Micro & $\leq \mathrm{R} \$ 360.000$ \\
Pequena & $>\mathrm{R} \$ 360.000$ \\
& $\leq \mathrm{R} \$ 4,8 \mathrm{mi}$
\end{tabular}

O intervalo do número de funcionários para a definição de MPME também pode variar. Em 46 dos 132 países abrangidos pelo estudo realizado pelo Banco Mundial, este parâmetro deve ser inferior a 250 funcionários (KUSHNIR, MIRMULSTEIN e RAMALHO, 2010). Na Tabela 4 são apresentadas as classificações de alguns países. 
Tabela 4 - Distribuição de empresas por número de funcionários nos países

\begin{tabular}{cccc}
\hline Países & Micro & Pequena & Média \\
\hline Países EU, Islândia, Noruega e Suiça & $1-9$ & $10-49$ & $50-249$ \\
\hline Austrália & $0-9$ & $10-49$ & $50-199$ \\
\hline Canadá & $0-9$ & $10-49$ & $50-249$ \\
\hline Japão & $4-9$ & $10-49$ & $50-199$ \\
\hline Coreia & $5-9$ & $10-49$ & $51-199$ \\
\hline México & $0-10$ & $11-50$ & $51-250$ \\
\hline Nova Zelândia & $1-9$ & $10-49$ & $50-99$ \\
\hline Turquia & $1-19$ & $20-49$ & $50-249$ \\
\hline Estados Unidos & $1-9$ & $10-99$ & $100-499$ \\
\hline Fonte: Adaptado de Berisha e Pula (2015) &
\end{tabular}

Conforme observado na Tabela 4, quase todos os países analisados possuem uma classificação similar em relação ao tamanho das empresas, o único com uma grande diferença são os Estados Unidos, cuja divisão para média empresa em relação ao número de funcionário varia de 100 a 499, enquanto que os outros países citados como exemplo variam entre 50 e 250. Apesar dessa diferença, a similaridade entre o número de funcionários é algo positivo, pois significa que os estudos realizados, mesmo que em países diferentes, possuem algo em comum no que diz respeito ao tamanho da empresa analisada.

Em função da maioria dos artigos analisados por esta dissertação serem de língua estrangeira, foi considerada a classificação MPME apresentada anteriormente.

\subsection{2}

\section{Quantificação de pequenas empresas}

Segundo a WTO (World Trade Organization) (2016), os pequenos negócios constituem a maioria das empresas em todas as 132 economias estudadas em seu relatório anual. Em média, 83\% de mais de 12 milhões de negócios enquadrados na categoria de MPME mundial são microempresas (WTO, 2016). $\mathrm{Na}$ Tabela 5 estão expressas as porcentagens de micro, pequenos e médios negócios de acordo com a classificação dos países. 


\begin{tabular}{cccc}
\hline Categoria & \% Microempresas & $\begin{array}{c}\text { \% Pequenas } \\
\text { Empresas }\end{array}$ & \% Médias Empresas \\
\hline $\begin{array}{c}\text { Países } \\
\text { Desenvolvidos }\end{array}$ & 87,1 & 10,7 & 2,2 \\
\hline $\begin{array}{c}\text { Países em } \\
\text { Desenvolvimento }\end{array}$ & 80,5 & 15,6 & 3,9 \\
\hline $\begin{array}{c}\text { Desenvolvimento no } \\
\text { Ritmo do G20 }\end{array}$ & 82,1 & 13,2 & 4,7 \\
\hline $\begin{array}{c}\text { Outro Ritmo de } \\
\text { Desenvolvimento }\end{array}$ & 80,5 & 14,9 & 4,5 \\
\hline $\begin{array}{c}\text { Países Menos } \\
\text { Desenvolvidos }\end{array}$ & 78,6 & 20,7 & $\mathbf{3 , 3}$ \\
\hline Total & $\mathbf{8 2 , 9}$ & $\mathbf{1 3 , 8}$ & \\
\hline & Fonte: Adaptado de WTO $(2016)$. &
\end{tabular}

É possível observar na Tabela 5 que existe uma lacuna nos países menos desenvolvidos em relação as empresas de médio porte na população dos MPME desses países. Contudo, de acordo com o estudo de Hsieh e Olken (2014), que avaliaram a distribuição de empresas de manufatura do setor formal e informal na Índia, Indonésia e México, não existe uma lacuna apenas nas empresas de médio porte, mas também, nas de grande porte, ou seja, o número de firmas de um dado tamanho decrescem à medida que esse tamanho aumenta.

Fernandes, Freund e Pierola (2016), também afirmam que existe um gap maior de grandes empresas do que de médios empreendimentos nos 45 países analisados no seu estudo, sendo que em todos os países a população de empresas é, em sua maioria, composta de pequenos empreendimentos. As micro, pequenas e médias empresas correspondem a um total de mais de $95 \%$ de todas as organizações nos 17 países da Organização para Cooperação Econômica e Desenvolvimento (OECD) mais o Brasil (CRISCUOLO, GAL e MENON, 2014).

Na Tabela 6 é possível visualizar a distribuição de microempresas de acordo com o grupo do país em relação a quatro setores principais: manufatura, comércio, serviços e agricultura/outro.

Tabela 6 - Percentual de microempresas segundo os setores considerados na classificação MPME

\begin{tabular}{ccccc}
\hline Categoria & Manufatura & Comércio & Serviços & Agricultura/Outro \\
\hline $\begin{array}{c}\text { Países } \\
\text { Desenvolvidos }\end{array}$ & 8 & 35 & 56 & 1 \\
\hline $\begin{array}{c}\text { Países em } \\
\text { Desenvolvimento }\end{array}$ & 11,5 & 44,3 & 38,9 & 5,3 \\
\hline $\begin{array}{c}\text { Desenvolvimento no } \\
\text { Ritmo do G20 }\end{array}$ & 14 & 33 & 40 & 14 \\
\hline $\begin{array}{c}\text { Outro Ritmo de } \\
\text { Desenvolvimento }\end{array}$ & 10 & 46 & 40 & 3 \\
\hline $\begin{array}{c}\text { Países Menos } \\
\text { Desenvolvidos }\end{array}$ & 15 & 45 & 31 & $\mathbf{5}$ \\
\hline Total & $\mathbf{1 1}$ & $\mathbf{4 3}$ & $\mathbf{4 2}$ &
\end{tabular}

A Tabela 7 utiliza a mesma divisão da Tabela 6 , porém considera as empresas de pequeno e médio porte. 
Tabela 7 - Percentual de pequenas e médias empresas segundo os setores considerados na

\begin{tabular}{ccccc}
\hline Categoria & Manufatura & Comércio & Serviços & Agricultura/Outro \\
\hline $\begin{array}{c}\text { Países } \\
\text { Desenvolvidos }\end{array}$ & 22 & 25 & 52 & 1 \\
\hline $\begin{array}{c}\text { Países em } \\
\text { Desenvolvimento }\end{array}$ & 19,9 & 30,6 & 41 & 8,5 \\
\hline $\begin{array}{c}\text { Desenvolvimento no } \\
\text { Ritmo do G20 }\end{array}$ & 21 & 31 & 44 & 3 \\
\hline $\begin{array}{c}\text { Outro Ritmo de } \\
\text { Desenvolvimento }\end{array}$ & 18 & 32 & 41 & 8 \\
\hline $\begin{array}{c}\text { Países Menos } \\
\text { Desenvolvidos }\end{array}$ & 24 & 23 & 37 & 16 \\
\hline Total & $\mathbf{2 0}$ & $\mathbf{3 0}$ & $\mathbf{4 2}$ & $\mathbf{8}$ \\
\hline
\end{tabular}

Fonte: Adaptado de WTO (2016).

Analisando as Tabelas 6 e 7 é possível perceber que a maioria das MPME ( $85 \%$ das microempresas e $72 \%$ das pequenas e médias) atuam no comércio e no setor de serviços, $11 \%$ das microempresas e $20 \%$ das pequenas e médias estão no setor de manufatura e $5 \%$ micro e $8 \%$ das pequenas e médias estão na agricultura/outro. Além disso, pode-se perceber que os países em desenvolvimento possuem parcelas maiores de microempresas e pequenas e médias no setor de agricultura ou outro, sendo que esse fato pode ser explicado em função da representatividade desse setor para os países em desenvolvimento.

Segundo o SEBRAE (2015), as MPE, ao logo dos últimos 30 anos, vem aumentando sua relevância econômica para o país, visto que sua participação no PIB brasileiro passou de 21\% em 1985 para 23,2\% em 2001 e, mais recentemente para 27\% em 2011.

O valor agregado gerado pelas MPE também aumentou ao longo dos anos, conforme expresso na Tabela 8.

\begin{tabular}{|c|c|c|c|c|c|}
\hline $\begin{array}{l}\text { Unidade da } \\
\text { Federação }\end{array}$ & 2009 & 2010 & 2011 & 2012 & 2013 \\
\hline Norte & 15.567 & 17.800 & 18.644 & 19.994 & 32.807 \\
\hline Nordeste & 54.443 & 61.956 & 67.332 & 72.524 & 78.956 \\
\hline Centro-Oeste & 36.517 & 38.220 & 44.196 & 48.758 & 55.035 \\
\hline Sudeste & 248.913 & 289.852 & 323.347 & 335.869 & 339.284 \\
\hline Sul & 95.243 & 108.918 & 115.844 & 120.778 & 133.392 \\
\hline Total Brasil & 450.683 & 516.746 & 569.363 & 597.923 & 639.473 \\
\hline
\end{tabular}
país somente aumentou no período de 2009 - 2013, mostrando a importância das MPE para a economia do país, podendo representar uma alternativa nos tempos 
de crise em que o país está vivendo. O SEBRAE (2015) também estudou o valor agregado gerado pelas MPE em função do tipo de atividade econômica, sendo os resultados expressos na Tabela 9.

Tabela 9 - Valor agregado em \% das MPE por atividade econômica (2009-2011)

\begin{tabular}{ccccc}
\hline Região & Indústria & Comércio & Serviços & Total das Atividades \\
\hline Norte & 7,5 & 7,2 & 3,9 & 18,5 \\
\hline Nordeste & 7,5 & 10,7 & 8 & 26,3 \\
\hline Centro-Oeste & 9,9 & 12,4 & 9 & 31,3 \\
\hline Sudeste & 7,7 & 7,9 & 10,1 & 25,7 \\
\hline Sul & 10,9 & 12,2 & 9,9 & 32,9 \\
\hline Total Brasil & $\mathbf{8 , 3}$ & $\mathbf{9 , 3}$ & $\mathbf{9 , 4}$ & $\mathbf{2 7}$
\end{tabular}

Fonte: Adaptado de SEBRAE (2015).

Ao analisar a Tabela 9, é possível perceber que as regiões Norte, Nordeste e Sudeste possuem uma participação menor do que a participação nacional em relação as MPE, logo, nessas regiões ainda existe uma lacuna no setor que ainda pode ser expandido. Além disso, pode-se perceber que a atividade econômica com mais porcentagem de participação das MPE varia de região para região, por exemplo, na região Norte a maior participação é do setor industrial, enquanto que na região Sul é do setor comercial, sendo que para o país a atividade econômica com maior participação de MPE são os serviços.

Apesar da maior porcentagem do valor agregado de MPE vir do setor de serviços, a maioria das MPE existentes no Brasil no mesmo período estudado (2009-2011) são do setor de comércio, conforme expresso na Tabela 10.

Tabela 10 - Composição percentual do número de empresas, por região, nas atividades selecionadas

\begin{tabular}{cccc}
\hline Região & Indústria & Comércio & Serviços \\
\hline Norte & 12,1 & 56,6 & 31,3 \\
\hline Nordeste & 11,3 & 56,5 & 32,2 \\
\hline Centro-Oeste & 12,5 & 52,3 & 35,1 \\
\hline Sudeste & 12,5 & 45,5 & 42 \\
\hline Sul & 16,3 & 47,2 & 36,5 \\
\hline Total Brasil & $\mathbf{1 3 , 1}$ & $\mathbf{4 8 , 5}$ & $\mathbf{3 8 , 3}$
\end{tabular}

Fonte: Adaptado de SEBRAE (2015).

Por meio das Tabelas 8, 9 e 10 pode-se entender a importância das MPE para a economia do país e ainda visualizar como estão divididas, em função das atividades econômicas, o percentual de MPE existentes. 


\section{2}

\section{Teorias da vantagem competitiva}

Uma empresa possui vantagem competitiva quando implementa uma estratégia de criação de valor não utilizada pelos seus concorrentes atuais ou potenciais, resultando em desempenho acima da média do mercado (BARNEY, 1991).

Vasconcelos e Cyrino (2000) dividem as teorias de estratégia empresarial que tratam da questão da vantagem competitiva em dois eixos principais resumidos na Figura 1: o que classifica as abordagens quanto à origem da vantagem competitiva e o que classifica as abordagens quanto às premissas sobre o comportamento do ambiente competitivo.
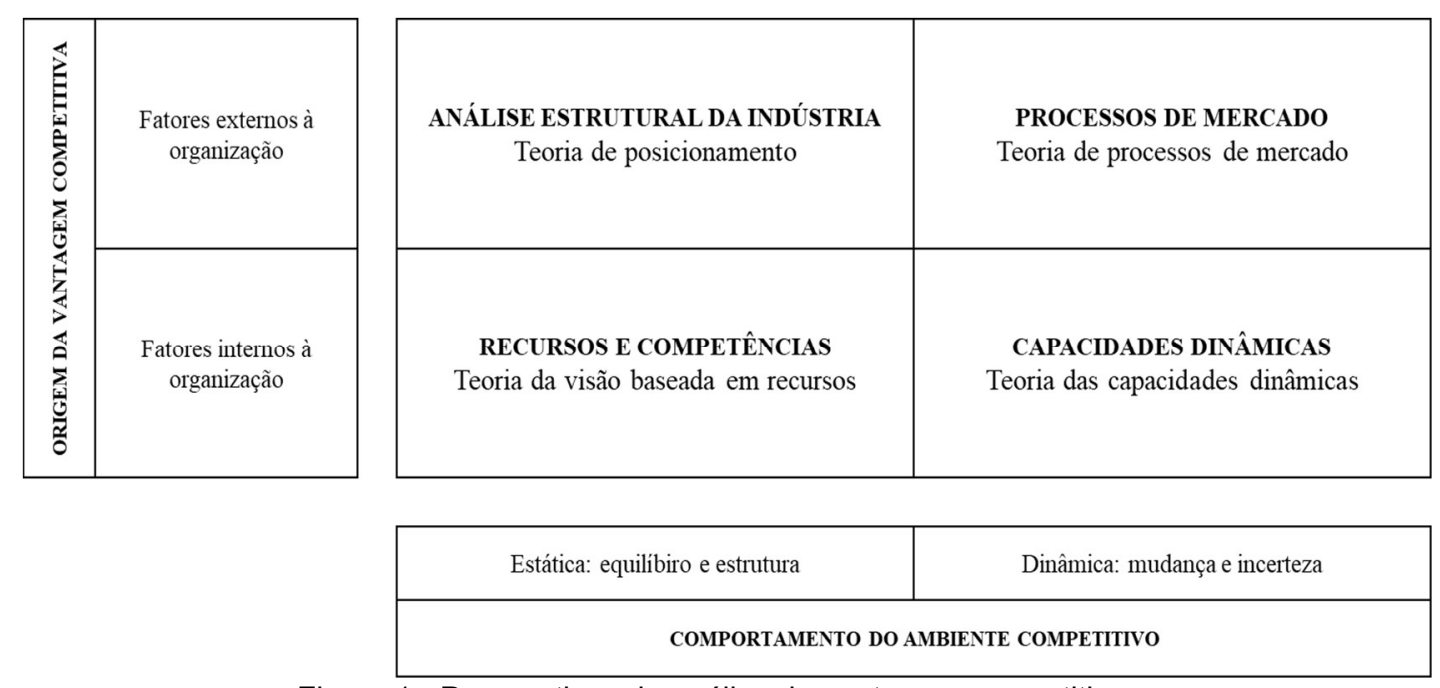

Figura 1 - Perspectivas de análise da vantagem competitiva Fonte: Adaptado de Vasconcelos e Cyrino (2000).

O primeiro eixo pode ser subdivido em duas correntes teóricas: a que considera a vantagem competitiva como resultado de fatores externos à organização, como a estrutura da indústria e processos de mercado; e a que considera a vantagem competitiva como resultado de fatores internos à organização. O segundo eixo também é divido em duas correntes teóricas: a que visualiza a concorrência de forma essencialmente estática, economicamente equilibrada e estruturada, e a que considera seus aspectos dinâmicos e mutáveis.

$\mathrm{Na}$ Tabela 11 está apresentado um resumo das quatro correntes da estratégia empresarial que explicam a vantagem competitiva: teoria de posicionamento estratégico, a teoria baseada nos processos de mercado, a teorias de competências dinâmicas e a teoria da visão baseada em recursos. 
Tabela 11 - Comparação entre as teorias sobre vantagem competitiva

\begin{tabular}{|c|c|c|c|c|}
\hline & $\begin{array}{l}\text { Teoria de } \\
\text { posicionamento }\end{array}$ & $\begin{array}{l}\text { Teoria da visão } \\
\text { baseada em } \\
\text { recursos }\end{array}$ & $\begin{array}{l}\text { Teoria de } \\
\text { processos de } \\
\text { mercado }\end{array}$ & $\begin{array}{l}\text { Teoria das } \\
\text { capacidades } \\
\text { dinâmicas }\end{array}$ \\
\hline $\begin{array}{l}\text { Unidade de } \\
\text { análise }\end{array}$ & Indústria & $\begin{array}{lr}\text { Estoques } & \text { de } \\
\text { recursos } & \text { e } \\
\text { competências } & \\
\text { específicas } & \end{array}$ & $\begin{array}{l}\text { Dinâmica do } \\
\text { mercado, ciclos } \\
\text { de criação e } \\
\text { destruição, } \\
\text { inovação imitação } \\
\text { e seleção }\end{array}$ & $\begin{array}{lr}\text { Processos } & \text { e } \\
\text { rotinas } & \\
\text { organizacionais; } \\
\text { fluxos } \\
\text { recursos } \\
\text { competências } \\
\text { específicas }\end{array}$ \\
\hline $\begin{array}{l}\text { Concepção da } \\
\text { firma }\end{array}$ & $\begin{array}{l}\text { Função técnica de } \\
\text { produção } \\
\text { Conjunto de } \\
\text { atividades } \\
\text { complementares }\end{array}$ & $\begin{array}{l}\text { Conjunto estável } \\
\text { de recursos, } \\
\text { competências e } \\
\text { capacidades }\end{array}$ & \begin{tabular}{l}
\multicolumn{2}{l}{ Empreendedora: } \\
produção de \\
inovações, \\
criação \\
conhecimento
\end{tabular} & $\begin{array}{l}\text { Conjunto } \\
\text { evolutivo de } \\
\text { recursos, } \\
\text { competências e } \\
\text { capacidades }\end{array}$ \\
\hline $\begin{array}{l}\text { Natureza da } \\
\text { vantagem } \\
\text { competitiva }\end{array}$ & \begin{tabular}{ll}
\multicolumn{2}{l}{ Sustentável, } \\
fundada & no \\
exercício & de \\
situações & de \\
quase monopólio
\end{tabular} & $\begin{array}{l}\text { Sustentável, } \\
\text { fundada sobre } \\
\text { recursos estáveis } \\
\text { Rendas } \\
\text { ricardianas* }\end{array}$ & $\begin{array}{l}\text { Transitória e } \\
\text { cíclica, fundada } \\
\text { em rendas de } \\
\text { empreendedor }\end{array}$ & $\begin{array}{l}\text { Sustentável, } \\
\text { fundada sobre } \\
\text { recursos em } \\
\text { evolução } \\
\text { Rendas } \\
\text { ricardianas e de } \\
\text { empreendedor }\end{array}$ \\
\hline $\begin{array}{l}\text { Fonte de } \\
\text { vantagem } \\
\text { competitiva }\end{array}$ & $\begin{array}{l}\text { Atratividade e } \\
\text { posicionamento } \\
\text { da firma na } \\
\text { indústria }\end{array}$ & $\begin{array}{l}\text { Acesso } \\
\text { privilegiado a } \\
\text { recursos únicos } \\
\text { de difícil imitação }\end{array}$ & $\begin{array}{l}\text { Inovação } \\
\text { "destruição } \\
\text { criadora" }\end{array}$ & $\begin{array}{l}\text { Rotinas } \\
\text { processos } \\
\text { organizacionais } \\
\text { capazes de } \\
\text { regenerar a base } \\
\text { de recursos da } \\
\text { firma }\end{array}$ \\
\hline Estratégia & 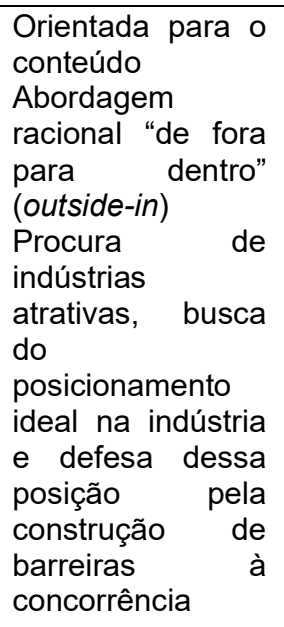 & $\begin{array}{l}\text { Orientada para o } \\
\text { conteúdo } \\
\text { Abordagem "de } \\
\text { racional } \\
\text { dentro para fora" } \\
\text { (inside-out) } \\
\text { Desenvolvimento } \\
\text { e exploração de } \\
\text { competências } \\
\text { existentes }\end{array}$ & $\begin{array}{l}\text { Orientada para o } \\
\text { processo } \\
\text { Procura contínua } \\
\text { de oportunidades } \\
\text { de inovação } \\
\text { Esforços de } \\
\text { imitação das } \\
\text { inovações bem- } \\
\text { sucedidas }\end{array}$ & $\begin{array}{l}\text { Orientada para o } \\
\text { processo e o } \\
\text { conteúdo } \\
\text { Interação entre } \\
\text { competências e } \\
\text { oportunidades do } \\
\text { mercado } \\
\text { Reconfiguração } \\
\text { de competências } \\
\text { e know-how } \\
\text { Racionalidade } \\
\text { limitada, } \\
\text { incerteza, } \\
\text { complexidade e } \\
\text { conflito }\end{array}$ \\
\hline Fundadores & $\begin{array}{l}\text { Mason (1939) } \\
\text { Bain (1956) }\end{array}$ & $\begin{array}{l}\text { Selznick (1957) } \\
\text { Penrose (1959, } \\
1963) \\
\text { Andrews (1980) }\end{array}$ & $\begin{array}{l}\text { Mises (1920) } \\
\text { Hayek (1937) } \\
\text { Schumpeter } \\
(1934,1955)\end{array}$ & $\begin{array}{l}\text { Teece (1984) } \\
\text { Nelson (1991) } \\
\text { Winter (1988) }\end{array}$ \\
\hline
\end{tabular}




\begin{tabular}{|c|c|c|c|c|}
\hline & $\begin{array}{l}\text { Teoria de } \\
\text { posicionamento }\end{array}$ & $\begin{array}{l}\text { Teoria da visão } \\
\text { baseada em } \\
\text { recursos }\end{array}$ & $\begin{array}{l}\text { Teoria de } \\
\text { processos de } \\
\text { mercado }\end{array}$ & $\begin{array}{l}\text { Teoria das } \\
\text { capacidades } \\
\text { dinâmicas }\end{array}$ \\
\hline $\begin{array}{l}\text { Autores } \\
\text { representativos }\end{array}$ & $\begin{array}{l}\text { M. Porter } \\
\text { P. Ghemawat } \\
\text { C. Shapiro }\end{array}$ & $\begin{array}{l}\text { R. Rumelt } \\
\text { B. Wernerfelt } \\
\text { J. B. Barney } \\
\text { M. Peteraf }\end{array}$ & $\begin{array}{l}\text { R. Jacobson } \\
\text { R. D'Aveni }\end{array}$ & $\begin{array}{ll}\text { D. Teece, } & \text { G. } \\
\text { Pisano e A. } \\
\text { Shuen } \\
\text { C. K. Prahalad e } \\
\text { G. Hamel } \\
\text { I. Dierickx e } & \text { K. } \\
\text { Cool } & \\
\text { R. Amit e } & \text { P. } \\
\text { Shoemaker } & \\
\text { R. Sanchez, A. } \\
\text { Heene e } \\
\text { Thomas }\end{array}$ \\
\hline
\end{tabular}

*Lucros acima da média do mercado devido à inelasticidade da oferta de determinados recursos (VASCONCELOS e CYRINO, 2000)

Fonte: Vasconcelos e Cyrino (2000).

Os estudos de Porter $(1980,1985,1990)$ tem grande destaque na literatura de vantagem competitiva. O autor desenvolveu um modelo de "cinco forças" competitivas externas à organização (entrantes potenciais, fornecedores, concorrentes na indústria, substitutos e compradores) que devem ser analisadas em conjunto para o desenvolvimento da estratégia empresarial (SERRA, TORRES e TORRES, 2004).

Já a teoria da visão baseada em recursos, proposta por Barney (1991), analisa a organização de forma interna, explorando seus recursos-chaves e focando nas capacidades mais apropriadas para obtenção de vantagem competitiva.

Foss (1996) afirma que ambas as teorias tem complementaridades que podem ser tratadas em conjunto. Entretanto, por ser voltada à organização e não à indústria em que ela está inserida, esta pesquisa fundamenta-se na teoria da visão baseada em recursos. O correto gerenciamento dos recursos possibilita a criação de valor econômico, isto torna a abordagem sob a luz da RBV um importante fator para o desenvolvimento estratégico das organizações (GONÇALVES, COELHO, SOUZA, 2011)

\subsection{1}

\section{Teoria da visão baseada em recursos}

Esta pesquisa está fundamentada na teoria da visão baseada em recursos da empresa (resource based view, em inglês - RBV), proposta por Barney (1991) e Schoenherr (2012). De acordo com esta teoria as empresas devem identificar seus recursos-chaves com base em suas capacidades internas e focar nas mais 
apropriadas para obter vantagens competitivas. A RBV parte da premissa de que estes recursos são heterogêneos, quando as capacidades e habilidades diferem de outras empresas, e imóveis, quando não é possível simplesmente transferi-los de uma empresa para outra.

Segundo a RBV, a vantagem competitiva potencial que sustenta o crescimento econômico a longo prazo de uma empresa, é alcançada quando seus recursos são valiosos, raros, imperfeitamente imitáveis e não-substituíveis (VRIN), conforme exibido na Figura 2.

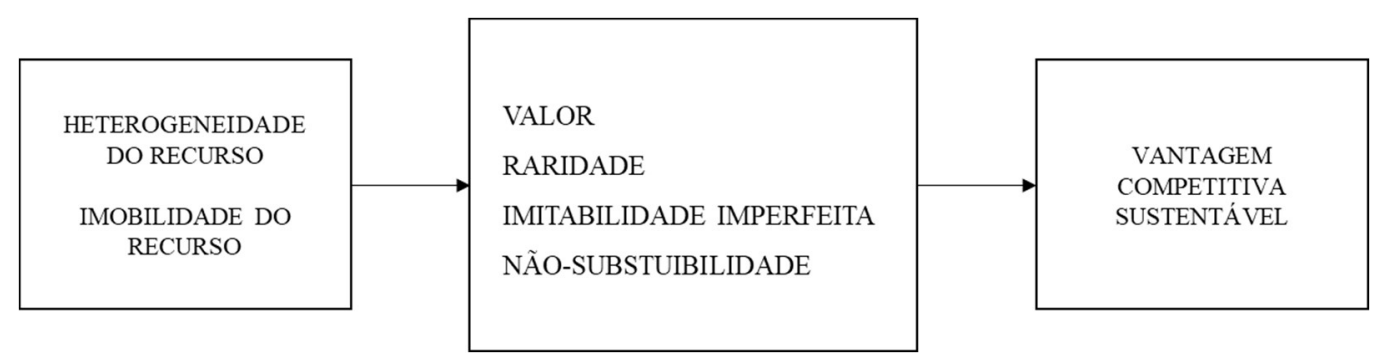

Figura 2 - A relação entre heterogeneidade e imobilidade de recursos, valor, raridade, imitabilidade imperfeita, não-substituibilidade, e vantagem competitiva sustentável

Fonte: Kirca, Jayachandran e Bearden (2005); Radas e Božić (2009) (Tradução livre).

Os recursos são valiosos quando exploram as oportunidades e/ou neutralizam as ameaças no meio em que a empresa se encontra, melhorando a eficiência e eficácia da organização, raros se proporcionam disparidade competitiva benéfica para a empresa, imperfeitamente imitáveis quando difíceis de replicar por outras empresas devido à sua singularidade ou complexidade, por exemplo, e não-substituíveis se não houverem recursos estrategicamente equivalentes (NARVER e SLATER, 1990). Estes atributos podem nortear os esforços voltados para inovação e uma cultura orientada ao mercado nas empresas.

\subsection{2}

\section{Desempenho operacional}

O desempenho operacional é comumente representado por cinco escalas: custo, entrega, flexibilidade, qualidade e inovação (RUSHTON e CARSON, 1985). Não há consenso na literatura sobre quais dimensões utilizar. A priorização de quais critérios serão utilizados para avaliar o desempenho, dever ser feito a partir de identificação prévia junto ao segmento de clientes que se deseja atender (WARD et al., 1998).

Em serviços, estas dimensões são mensuradas levando em consideração o fato do serviço ser uma experiência perecível, intangível desenvolvida para um 
consumidor que atua como coprodutor (FITZSIMMONS e FITZSIMMONS, 2000), sendo, portanto, avaliado por um número maior de escalas em virtude do contato mais intenso entre o sistema de operações e o cliente (GIANESI e CORRÊA, 1994).

Gianesi e Corrêa (1994) propuseram nove dimensões de desempenho em serviços: consistência, competência, velocidade de atendimento, atendimento/atmosfera, flexibilidade, credibilidade/segurança, acesso, tangíveis e custo. Fitzgerald et al. (1991) propuseram seis dimensões para o desempenho em serviços: financeiro, competitividade, qualidade do serviço, flexibilidade, utilização de recurso e inovação. Entre estas haverá interações e trade-offs que devem ser considerados na elaboração de um plano estratégico.

A partir dos conceitos da literatura considera-se nesta pesquisa que o desempenho operacional é composto por dimensões, tanto de manufatura quanto de serviços, que não se sobreponham. Quando alguma dimensão de serviço corresponde a outra já existente na manufatura, considera-se apenas uma delas. O desempenho operacional é composto, portanto, das dimensões de custo, entrega, flexibilidade, qualidade e inovação, pois o trade-off entre estas pode resultar em diferencial competitivo.

\section{Custo}

Um dos fatores de desempenho operacional mais relevantes para a maioria das empresas de manufatura é o custo de produção, que inclui custo (direto) de produção, produtividade, utilização da capacidade e redução de estoque (RUSHTON e CARSON, 1985).

Em serviços, esta dimensão é importante por ser a base da precificação do serviço, é o critério que avalia quanto o consumidor irá pagar, em moeda, por determinado serviço (GIANESI e CORRÊA,1994). Calcular o custo de uma unidade de serviço é complexo e impreciso devido à sua intangibilidade, o que resulta em métodos de precificação baseada em custos imprecisos (RUSHTON e CARSON, 1985). O preço é um dos critérios que pode levar a escolha de determinado serviço, e como a precificação do serviço é feita a partir do custo, o fator custo pode garantir vantagem competitiva e, portanto, deve ser medido (WARD et al., 1998).

Apesar de sua importância, a maioria das organizações não compete exclusivamente, ou sequer, principalmente nesta base, mas em conjunto com outras dimensões de desempenho (NOBLE, 1995). 


\section{Entrega}

$\mathrm{Na}$ literatura da estratégia de manufatura, a dimensão de entrega é geralmente definida em termos de capacidade de entregar o produto ao cliente no prazo prometido. A organização pode não ter o produto de menor custo ou de alta qualidade, mas pode ser capaz de competir com base em entrega confiável de produtos.

A garantia de que o produto certo (atendendo aos requisitos de qualidade, confiabilidade e manutenção) seja entregue na quantidade certa, no momento certo, no lugar certo, da fonte certa (um fornecedor confiável cumprirá compromissos em tempo hábil), com o serviço certo (antes e depois da venda) e ao preço certo, pode gerar vantagem competitiva para a organização e por isso deve ser incluída como dimensão de desempenho operacional.

\section{Flexibilidade}

Significa a capacidade de mudar e adaptar a operação, devido a mudanças nas necessidades dos clientes no processo ou no suprimento de recursos (GIANESI e CORREAA, 1994). A flexibilidade pode ser dividida em: flexibilidade de volume de serviço, capacidade de responder a diferentes níveis de demanda; da velocidade de entrega, adaptabilidade às diferentes necessidades do cliente em termos de velocidade de resposta ou processamento do cliente; e flexibilidade de especificação, nível de adaptabilidade que o processo pode ter às necessidades individuais do cliente (FITZGERALD et al., 1991).

Por ser uma potencial fonte de vantagem competitiva para muitas organizações, a flexibilidade precisa ser considerada na avaliação de desempenho (PARASURAMAN, ZEITHAML e BERRY, 1988).

\section{Qualidade}

As funções de uma organização tendem a tratar a definição de qualidade de maneiras diferentes, o que levou Garvin (1987) a sugerir um framework de oito dimensões (desempenho, características, confiabilidade, conformidade, durabilidade, manutenção, estética e qualidade percebida) explicando estes diferentes pontos de vista.

$\mathrm{Na}$ visão tradicional de manufatura, o controle de qualidade reflete o foco na dimensão de qualidade de conformidade. Cada uma das outras dimensões também representa possíveis bases para vantagem competitiva, mas exigem uma maior coordenação interfuncional entre produção, marketing e P\&D o que torna a 
obtenção de conformidade mais próxima da realidade da maioria das empresas (PARASURAMAN, ZEITHAML e BERRY, 1988).

Quanto à qualidade em serviços Parasuraman, Zeithaml e Berry (1988) definiriam cinco dimensões avaliadas através do modelo SERVQUAL: confiabilidade, competência, responsividade, empatia, segurança e tangibilidade. Estas dimensões e suas respectivas definições estão dispostas na Tabela 12.

Tabela 12 - Dimensões da qualidade em serviços

\begin{tabular}{ll}
\hline \multicolumn{1}{c}{ Dimensão } & \multicolumn{1}{c}{ Definição } \\
\hline Confiabilidade & Habilidade de desempenhar o serviço prometido de forma correta \\
\hline Responsividade & $\begin{array}{l}\text { Prontidão da empresa e de seus funcionários em ajudar o cliente } \\
\text { e prestar o serviço }\end{array}$ \\
\hline Empatia & A cortesia e atenção do funcionário para o cliente \\
\hline Segurança & $\begin{array}{l}\text { Competências e habilidades dos funcionários em inspirar } \\
\text { confiança }\end{array}$ \\
\hline Tangibilidade & Aparência de qualquer evidência física do serviço de operações
\end{tabular}

Fonte: Adaptado de Nijssen, Hillebrand e Vermeulen (2006) (Tradução livre).

A importância de cada dimensão para a qualidade pode variar de acordo com o tipo de atividade exercido pela organização (PARASURAMAN et al., 1988).

\section{Inovação}

A inovação foi definida no modelo cumulativo proposto em Nakane e Hall (1990) como a capacidade de introduzir novos produtos com sucesso. A Organização para Cooperação e Desenvolvimento Econômico (OECD, 2005) define quatro tipos de inovação: inovação de produtos, inovação de processos, inovação de marketing e inovação organizacional, os quais seguem definidos abaixo:

- Inovação de produto: um bem/serviço novo ou significativamente melhorado em especificações técnicas, componentes e materiais, software no produto, facilidade de uso ou outras características funcionais;

- Inovação de processos: um método de produção/entrega novo ou significativamente melhorado incluindo mudanças significativas nas técnicas, equipamentos e/ou softwares;

- Inovação de marketing: um novo método de marketing envolvendo mudanças significativas no design ou embalagem do produto, colocação de produtos, promoção de produtos ou preços; 
- Inovação organizacional: um novo método organizacional em práticas comerciais, organização no local de trabalho ou relações externas.

Como as necessidades do mercado evoluem, as empresas devem adotar inovações ao longo do tempo que permitam o alcance de algum tipo de vantagem competitiva.

Devido a sua potencial capacidade de gerar vantagem competitiva, a inovação é um fator que precisa ser medido ao se considerar o desempenho de uma organização (FITZGERALD et al., 1991).

A inovação de produto ou serviço pode ser tanto algo totalmente novo, algo nunca feito antes; quanto uma mudança incremental em um produto ou serviço existente.

Em serviços, isso também corresponde a novas aplicações, novas soluções na interface do cliente, nos métodos de distribuição ou operação, novas aplicações de tecnologia no processo de serviço ou até mesmo novas formas de gerenciamento de serviços (QUAGGIO e SILVA, 2015).

Fitzsimmons e Fitzsimmons (2000) dividem o desenvolvimento de novos serviços em diferentes níveis, conforme exposto na Tabela 13.

Tabela 13 - Níveis de inovação em serviços

\begin{tabular}{|c|c|}
\hline Nova categoria de serviços & Descrição \\
\hline \multicolumn{2}{|l|}{ Inovações radicais } \\
\hline Inovação importante & $\begin{array}{l}\text { Novos serviços para mercados que ainda } \\
\text { não estão definidos. Essas inovações são } \\
\text { normalmente orientadas por tecnologias } \\
\text { baseadas em computadores e informação. }\end{array}$ \\
\hline Negócio em fase inicial & $\begin{array}{l}\text { Novos serviços em um mercado que já é } \\
\text { servido por serviços existentes. }\end{array}$ \\
\hline Novos serviços para o mercado que já é servido & $\begin{array}{l}\text { Novas ofertas de serviços para clientes } \\
\text { existentes de uma organização (apesar de } \\
\text { os serviços poderem estar disponíveis por } \\
\text { outras empresas). }\end{array}$ \\
\hline \multicolumn{2}{|l|}{ Inovações incrementais } \\
\hline Extensões de uma linha de serviços & $\begin{array}{l}\text { Incrementos da linha de serviços existente, } \\
\text { tais como acrescentar novos itens ao menu, } \\
\text { novas rotas e novos cursos. }\end{array}$ \\
\hline Melhorias em serviços & $\begin{array}{l}\text { Mudanças nas características dos serviços } \\
\text { que estão sendo atualmente oferecidos. }\end{array}$ \\
\hline Mudança de estilo & $\begin{array}{l}\text { O mais comum de todos "novos serviços" } \\
\text { são formas modestas de mudança visíveis } \\
\text { que têm um impacto sobre as percepções, } \\
\text { emoções e atitudes do cliente. Mudanças de } \\
\text { estilo não mudam o serviço } \\
\text { fundamentalmente, apenas suas aparências. }\end{array}$ \\
\hline $\begin{array}{l}\text { Fonte: Fitzsimmons e } \\
\text { Em geral, as empresas que desenv }\end{array}$ & $\begin{array}{l}\text { zsimmons (2000). } \\
\text { vem novos produtos ou serviços bem- }\end{array}$ \\
\hline
\end{tabular}


alinhar sua cultura e sistemas às atividades de inovação, de modo a dar o máximo de apoio aos esforços de inovação (QUAGGIO e SILVA, 2015).

Alguns estudos fornecem evidências de que a orientação ao mercado está relacionada ao sucesso de novos produtos e serviço (QUAGGIO e SILVA, 2015). Quando uma empresa tende a comprometer-se com a inovação, ela pode impactar positivamente seu desempenho operacional (QUAGGIO e SILVA, 2015).

Há evidências de que essas escalas não são necessariamente mutuamente exclusivas, uma vez que algumas empresas, em comparação com seus concorrentes, têm melhor qualidade, respondem mais rápido às mudanças no mercado com soluções inovadoras e, apesar de tudo isso, conseguem custos mais baixos (KETOKIVI e SCHROEDER, 2004). Ketokivi e Schroeder (2004) propõem uma análise multidimensional de desempenho, pois defendem que o objetivo estratégico de cada organização deve ser levado em consideração separadamente, não de maneira unificada, como é feito em algumas pesquisas.

\subsection{3 \\ Recursos VRIN em desempenho operacional}

Foi realizada uma revisão preliminar na literatura a fim de verificar evidências de recursos VRIN no desempenho operacional. Identificou-se inovação (tanto os esforços para isso quanto o seu resultado) e orientação ao mercado como fatores frequentemente relacionados ao desempenho. Este levantamento preliminar não restringiu quanto ao tipo de atividade realizada, portanto quando o trabalho levantado tratava de prestação de serviços, os estudos também levaram em consideração as características do serviço (LIEVENS e MOENAERT, 2000; COWELL, 1988; QUAGGIO e SILVA, 2015; ZEITHAML, PARASURAMAN e BERRY, 1985; BRENTANI, 1995; STOREY e HULL, 2010; JAW, LO e LIN, 2010; AGARWAL, ERRAMILLI e DEV, 2003; HAN, KIM e SRIVASTAVA, 1998). Isto nos leva a elaboração de algumas hipóteses apresentadas na seção 3.2.

\section{Orientação ao mercado}

A orientação ao mercado é a disseminação e aplicação dos conceitos de marketing, que tem como objetivo a criação de valor ao cliente levando a um desempenho superior ao de seus concorrentes (NARVER e SLATER, 1990). A orientação ao mercado é composta por três componentes: orientação ao cliente, 
orientação ao concorrente e integração interfuncional, que contribuem para o construto de orientação ao mercado (NARVER e SLATER, 1990).

\section{Orientação ao cliente}

A orientação ao cliente é a compreensão das necessidades e desejos do consumidor a fim de criar valor para estes continuamente (NARVER e SLATER, 1990). Por serem focadas nas necessidades dos clientes, estas empresas são facilmente relacionadas a atividades de inovação bem sucedidas, já que as chances do cliente ficar insatisfeito com algo desenvolvido para o atendimento das suas necessidades são baixas (HAN, KIM e SRIVASTAVA, 1998).

\section{Orientação ao concorrente}

A orientação ao concorrente é a compreensão dos pontos fortes e fracos e das capacidades e estratégias tanto do concorrente atual quanto do concorrente em potencial (DAY e WENSLEY, 1988). Apoiar-se completamente na orientação ao cliente pode levar a uma estratégia de negócios incompleta, pois deixa a organização propensa a uma postura reativa, ao invés de uma proativa, ao lidar com as estratégias dos concorrentes (NARVER e SLATER, 1990). Por isso, o equilíbrio entre a orientação ao cliente e a orientação ao concorrente é prérequisito para manter a vantagem competitiva (HAN, KIM e SRIVASTAVA, 1998).

\section{Integração interfuncional}

A integração interfuncional é o uso coordenado dos recursos na criação de valor superior para os clientes-alvo (HAN, KIM e SRIVASTAVA, 1998). À medida que as funções de uma organização são integradas, a capacidade de resolução de problemas é aprimorada pelos funcionários que trabalham direcionados por um objetivo comum. Quando não há essa integração, os funcionários são mais propensos a se adequarem ao seu modo rotineiro de resolução de problemas e reduzem suas chances de serem mais criativos e de assumir riscos (HAN, KIM e SRIVASTAVA, 1998). Portanto, a integração interfuncional na criação de valor superior para os clientes está intimamente ligada à orientação ao cliente e ao concorrente.

Os efeitos da orientação do mercado sobre o desempenho tem sido objeto de diversos estudos, sendo identificados como fortes discriminantes no desempenho das empresas pois a orientação ao mercado oferece maior capacidade de detectar as variações do mercado e de se conectar a empresa ao cliente (KOHLI E JAWORSKI, 1990; NARVER E SLATER, 1990; CANO, 
CARRILLAT e JARAMILLO, 2004; KIRCA, JAYACHANDRAN e BEARDEN, 2005; TSE et al., 2003; TSIOTSOU, 2009).

\section{Esforços de inovação}

Jaw, Lo e Lin (2010) dividem os esforços realizados para se manter uma cultura de inovação na empresa em recursos de inovação e recompensa pela inovação.

\section{Recursos de inovação}

Recursos de inovação consistem em disponibilizar recursos voltados para atividades de inovação. Além da incerteza inerente ao processo de inovação, há evidências empíricas de que as empresas que concentram recursos em atividades de inovação aumentam o desenvolvimento bem-sucedido de um novo produto ou serviço, pois aumentam a capacidade de aprender com ele, através de feedbacks e continuam a desenvolver melhores inovações (JAW, LO e LIN, 2010). As empresas devem fornecer recursos adequados para atividades inovadoras, a fim de aumentar suas chances de ter novos produtos e serviços bem-sucedidos e, consequentemente, melhor desempenho em comparação com seus concorrentes.

\section{$\underline{\text { Recompensas por inovação }}$}

As recompensas por inovação consistem na gratificação pela realização de ações inovadoras na empresa. A motivação para continuar desenvolvendo novas ideias são uma forma importante de incentivar a melhoria do desempenho organizacional, entretanto, esta pode diminuir se não for reconhecida e recompensada devidamente (JAW, LO e LIN, 2010). Portanto, recompensar adequadamente os membros das empresas por atividades de inovação pode aumentar sua vontade de gerar novas ideias.

A relação entre a cultura de inovação e a melhoria no desempenho das empresas tem sido objeto de diversos estudos. (AGARWAL, ERRAMILLI e DEV, 2003; HAN, KIM e SRIVASTAVA, 1998; JAW, LO e LIN, 2010; LIEVENS e MOENAERT, 2000; RUSHTON e CARSON, 1985). Os esforços de inovação, considerando recursos de inovação e recompensas por inovação, devem ser considerados um elemento importante do desempenho (AGARWAL, ERRAMILLI e DEV, 2003; HAN, KIM e SRIVASTAVA, 1998; JAW, LO e LIN, 2010; LIEVENS e MOENAERT, 2000; RUSHTON e CARSON, 1985).

Estes esforços podem ainda ser determinados pela orientação de mercado, influenciando também o desempenho (AGARWAL, ERRAMILLI e DEV, 2003; 
HAN, KIM e SRIVASTAVA, 1998; JAW, LO e LIN, 2010; LIEVENS e MOENAERT, 2000; RUSHTON e CARSON, 1985). Os esforços de inovação são um dos principais recursos de criação de valor que impulsionam a relação entre orientação ao mercado e desempenho (BRENTANI, 1995; LIEVENS e MOENAERT, 2000).

As empresas orientadas ao mercado são mais propensas a investir no desenvolvimento da inovação (i.e., esforços de inovação), o que geralmente resulta em um aprimoramento de seu desempenho (LIEVENS e MOENAERT, 2000).

\section{Características do serviço}

O serviço é uma experiência perecível, intangível desenvolvida para um consumidor que atua como coprodutor (FITZSIMMONS e FITZSIMMONS, 2000). Com o cliente atuando como coprodutor, o sucesso na prestação desse serviço é parcialmente associado as ações deste cliente, que assume ou não o risco de participar dessa atividade (ZEITHAML, PARASURAMAN e BERRY, 1985). A natureza do serviço compreende parte dos desafios no desenvolvimento de atividades inovadoras bem-sucedidas, pois influencia a incerteza associada com essa inovação, isto levaria a um aumento nos esforços voltados para soluções inovadoras que reduzam a percepção desta incerteza para o consumidor (LIEVENS e MOENAERT, 2000).

\section{Intangibilidade}

Os serviços não são tangíveis, eles não podem ser tocados e sentidos como bens. Esta intangibilidade é um dos diferenciais mais reconhecidos entre serviços e produtos e é a origem das todas as outras três características (LIEVENS AND MOENAERT, 2000).

A intangibilidade presente nos serviços aumenta a complexidade no entendimento de quais mudanças estão sendo feitas, e induz a percepção de incerteza e de risco com o cliente (LIEVENS e MOENAERT, 2000). Os clientes, portanto, podem hesitar em assumir um risco que não é claro para eles, desistindo de experimentar serviços inovadores. A literatura sugere que, quanto maior o nível de intangibilidade de um serviço, maiores são os esforços para implementar a inovação (COWELL, 1988).

\section{$\underline{\text { Inseparabilidade }}$}

Atividades de prestação de serviços geralmente exigem a presença do consumidor ou um alto nível de interação com eles para serem realizadas 
(QUAGGIO e SILVA, 2015). Nestas atividades, produção e consumo ocorrem simultaneamente, e a inseparabilidade entre essas duas etapas inviabiliza a possibilidade de estocagem de serviços (JAW, LO e LIN, 2010).

A participação dos clientes neste processo de produção e consumo do serviço pode variar de empresa para empresa. Os clientes podem estar apenas presentes no momento participando apenas como consumidores de fato (ex.: cabeleireiro, teatro), ou podem atuar como co-criadores dessas atividades (ex.: fast foods, bancos) (COWELL, 1988; QUAGGIO e SILVA, 2015; ZEITHAML, PARASURAMAN e BERRY, 1985).

Esta participação do cliente no serviço pode afetar os processos de inovação, pois é necessário que este conheça o papel a ser desempenhado por ele na atividade. Isso, muitas vezes, exige orientação por parte da empresa até que aquele cliente se adapte ao que está sendo proposto. Um maior nível de inseparabilidade da produção e do consumo de um serviço pode exigir mais esforços, pela empresa, no processo de inovação (LIEVENS e MOENAERT, 2000).

\section{Heterogeneidade}

Por serem realizados essencialmente por seres humanos, os serviços são mais propensos a variar de acordo com horários, funcionários e percepções dos clientes, fatores críticos para as operações que exigem intensiva interação social (LIEVENS e MOENAERT, 2000). Para estas operações, a diferença entre as expectativas dos clientes e sua percepção da qualidade do serviço prestado pode variar em muitas ocasiões, o que também pode aumentar sua percepção de risco, resultando em incerteza ao experimentar algo novo (LIEVENS e MOENAERT, 2000).

A inovação pode ser usada para criação de pacotes de serviços visando a redução de heterogeneidade na sua realização (BRENTANI, 1995; JAW, LO e LIN, 2010). Quanto mais heterogênea for a prestação do serviço, maiores serão os esforços dedicados as atividades inovadoras para transformar isso em pacotes de serviços.

\section{$\underline{\text { Perecibilidade }}$}

Serviços não podem ser produzidos e então estocados para atender posteriormente as flutuações na demanda tais quais bens tangíveis. Por isso sua oportunidade de venda é perdida quando a capacidade de prestação do serviço não atende à demanda (BRENTANI, 1995; STOREY e HULL, 2010). 
Visto que esta perecibilidade do serviço também é um fator de variabilidade que aumenta a incerteza para o cliente, o desafio nesta escala é utilizar a inovação para o desenvolvimento de diferentes níveis de serviço que atendam os períodos de baixa e alta demanda, reduzindo a perecibilidade (ex.: serviços completos ou limitados) (BRENTANI, 1995).

As características dos serviços (intangibilidade, inseparabilidade, heterogeneidade e perecibilidade) podem influenciar os esforços de inovação (COWELL, 1988; JAW, LO e LIN, 2010; LIEVENS e MOENAERT, 2000; QUAGGIO e SILVA, 2015) que, por sua vez, podem estar relacionados ao desempenho desse serviço (AGARWAL, ERRAMILLI e DEV, 2003; BRENTANI, 1995; HAN, KIM e RIVASTAVA, 1998; JAW, LO e LIN, 2010; LIEVENS e MOENAERT, 2000). Isto leva a crer que a relação da orientação de mercado com os esforços de inovação pode ser influenciada pelas características do serviço, mesmo não havendo estudos anteriores que trabalhem esta abordagem. 


\section{3 \\ Procedimentos metodológicos}

Este capítulo detalha as duas metodologias que se complementaram no desenvolvimento da pesquisa para a elaboração da taxonomia e do framework, além de uma proposta inicial de survey.

\section{1}

\section{Revisão sistemática da literatura}

A revisão sistemática da literatura (RSL) é uma metodologia utilizada com sucesso há muitos anos nos ramos de medicina e em diversas áreas de pesquisa. Esta ferramenta de investigação responde a questões de pesquisa específicas em temas já conhecidos ou em temas emergentes através de processos rigorosos para identificar, analisar e sintetizar as informações na literatura de maneira sistemática, transparente e replicável (TORRACO, 2005).

Utiliza-se a RSL para diversos fins de pesquisa, cujos nove conhecidos são segundo Mulrow (1994) apud Thomé, Scavarda e Scavarda (2016):

- Contribuir para a redução de grande volume de informação;

- Integrar informações críticas para tomadas de decisão, pesquisa e política;

- Ser eficiente e menos custosa, principalmente, se for atualizada continuamente;

- Facilitar a generalização das descobertas reagrupando resultados similares de diferentes populações ou intervenções;

- Permitir uma avaliação sistemática das relações entre variáveis;

- Evidenciar e ajudar a explicar dados inconsistentes e contraditórios de descobertas em determinado campo;

- Aumentar o poder estatístico em sínteses quantitativas;

- Aumentar a precisão de estimação de riscos estatísticos;

- Aumentar a acurácia ou permitir sua verificação por reportar, sistematicamente, procedimentos e métodos.

Em quaisquer casos, a RSL deve oferecer uma nova perspectiva para o assunto, seja este já debatido ou ainda emergente (TORRACO, 2005). 
Por ser voltado para pesquisas em gerência de operações, este estudo baseou-se nos oito passos propostos por Thomé, Scavarda e Scavarda (2016) que serão descritos nas próximas subseções:

- Planejamento e formulação do problema;

- Busca na literatura;

- Coleta de dados;

- Avaliação da qualidade da coleta de dados;

- Análise e síntese de dados;

- Interpretação dos resultados;

- Apresentação dos resultados;

- Atualização da revisão.

\subsection{1}

\section{Planejamento e formulação do problema}

No primeiro passo, de planejamento e formulação do problema, foi realizada uma busca preliminar na literatura para se tomar conhecimento de pesquisas já existentes a respeito de desempenho operacional em pequenas empresas cujos resultados compõem o Capítulo 2 (Referencial teórico) e a elaboração das perguntas de pesquisa apresentadas no Capítulo 1 (Introdução).

A partir da revisão preliminar da literatura, foram identificadas divergências nos resultados dos estudos em desempenho operacional, o que justifica o desenvolvimento de uma RSL. Buscou-se reunir detalhadamente pesquisas empíricas realizadas em desempenho operacional em pequenas empresas de forma a integrar os diferentes resultados em um único estudo, além de contribuir para que pesquisadores e praticantes tenham uma melhor compreensão dos resultados já alcançados.

\subsection{2}

\section{Busca na literatura}

Thomé, Scavarda e Scavarda (2016) sugerem que pelo menos duas bases de dados sejam utilizadas na busca. Scopus e Web of Science foram as bases de dados escolhidas para a busca dos artigos visto que estas abrangem a maior parte dos trabalhos publicados na área de gerência de operações (MONGEON e PAULHUS, 2016).

Apesar da seleção das palavras-chave ter sido realizada de forma abrangente para evitar a limitação dos resultados, isso não comprometeu a 
especificidade ao coletar apenas estudos relacionados ao tema. As palavraschave utilizadas foram adaptadas para as ferramentas de busca de cada base utilizada sendo aplicadas a títulos, resumos e palavras-chave, resultando nas queries apresentadas na Tabela 14.

Tabela 14 - Queries de busca

\begin{tabular}{|c|c|}
\hline BASE & QUERY \\
\hline Scopus & $\begin{array}{l}\text { TITLE-ABS-KEY ("performance") AND TITLE-ABS-KEY ("structural } \\
\text { equation model" OR "regression" OR "path analysis") AND TITLE-ABS- } \\
\text { KEY ("small and medium enterprise*" OR "small and medium organization" } \\
\text { OR "small and medium organisation" OR "small and medium business" } \\
\text { OR "small and medium firm" OR "small and medium compan" OR "small } \\
\text { enterprise*" OR "small organization*" OR "small organisation*" OR "small } \\
\text { business*" OR "small firm*" OR "small compan*") AND (LIMIT-TO ( } \\
\text { LANGUAGE, "English")) }\end{array}$ \\
\hline Web Of Science & $\begin{array}{l}\text { (TS=("performance") AND TS=("structural equation model" OR "regression" } \\
\text { OR "path analysis") AND TS=("small and medium enterprise*" OR "small and } \\
\text { medium organization*" OR "small and medium organisation" OR "small and } \\
\text { medium business*" OR "small and medium firm*" OR "small and medium } \\
\text { compan*" OR "small enterprise*" OR "small organization*" OR "small } \\
\text { organisation*" OR "small business*" OR "small firm*" OR "small compan*")) } \\
\text { AND Idioma: (English) }\end{array}$ \\
\hline
\end{tabular}

Fonte: Autora (2018).

A busca foi finalizada em outubro de 2017 e retornou 333 artigos no Scopus e 311 no Web of Science, um total de 644 artigos. Excluíram-se 140 duplicados restando 504 artigos. Não houve limitação quanto à data de publicação dos artigos.

A inclusão dos artigos foi dividida em dois rounds de seleção para confirmar a inclusão de estudos que atendessem os critérios de pesquisa. $O$ critério de exclusão rejeitou os artigos que não atendiam as condições:

- Ser um estudo empírico que analisa modelos causais estatisticamente;

- A variável dependente do modelo é composta por pelo menos uma das cinco dimensões de desempenho operacional (custo, entrega, flexibilidade, qualidade ou inovação).

Os 504 artigos encontrados tiveram seus resumos revisados para confirmar a inclusão de estudos que atendam aos critérios de pesquisa. O primeiro round consistiu na leitura do título e resumo e ao final 109 artigos foram para o segundo round. O segundo round de seleção consistiu na leitura do artigo completo e ao final 87 artigos foram selecionados para a análise.

A Figura 3 apresenta um resumo dos passos adotados para a seleção dos estudos. 


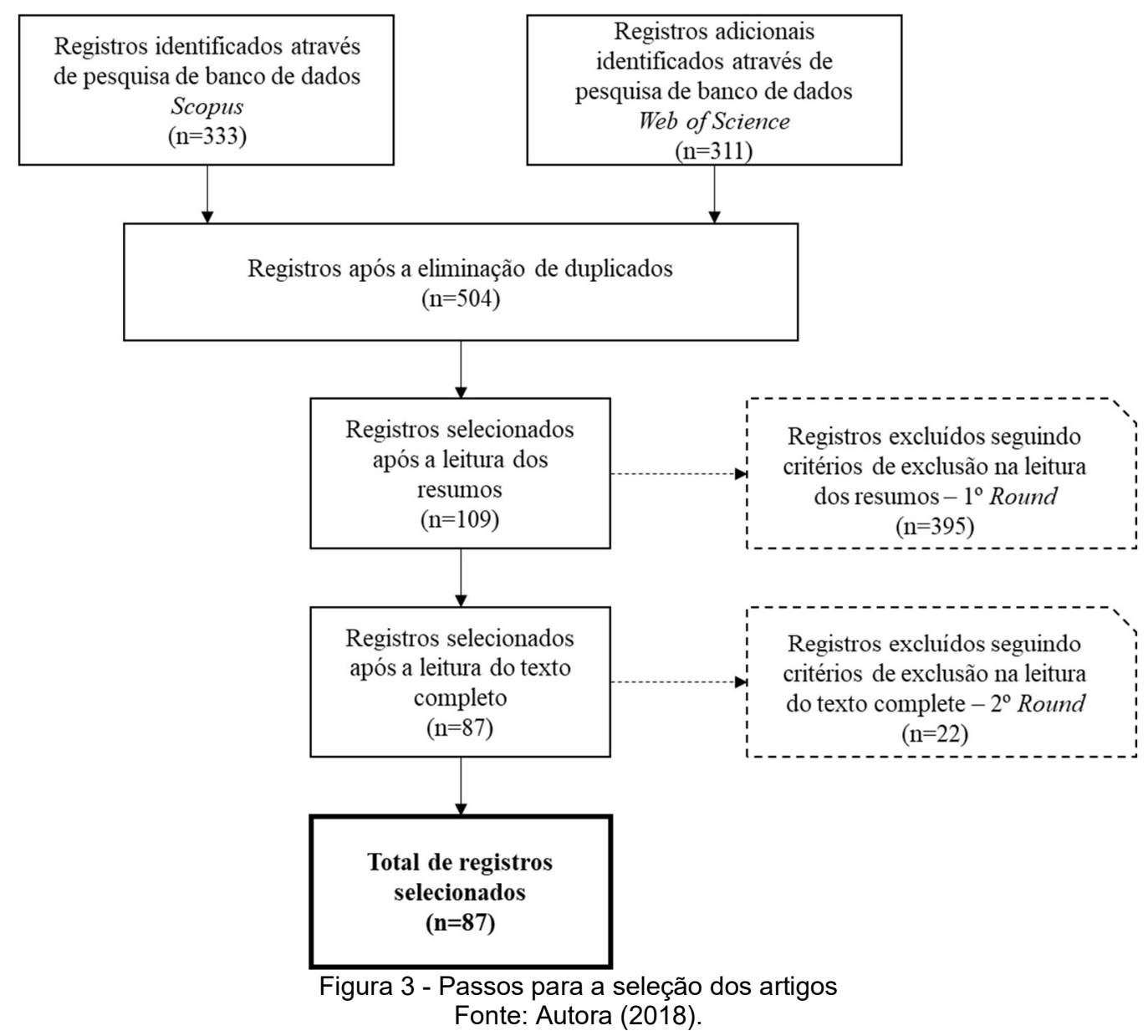

\subsection{3}

\section{Coleta de dados e avaliação da qualidade da coleta de dados}

Para uma coleta de dados que se adequasse e facilitasse a organização dos dados relevantes para futura interpretação, utilizaram-se as Tabelas 15 e 16. As tabelas foram testadas com algumas publicações para verificar se os campos a serem preenchidos correspondiam ao objetivo da pesquisa e para assegurar o entendimento comum sobre os conceitos e classificação dos artigos. A validação dos resultados foi feita a partir do alinhamento entre os objetivos e características de implementação da pesquisa e seus métodos aplicados que garantiam sua qualidade (VALENTINE, 2009).

Após as alterações necessárias, estas tabelas foram utilizadas para a extração dos dados relevantes de cada publicação categorizados em informações gerais e específicas. As Tabelas 15 e 16 apresentam o formato e definição dos campos utilizados para as tabelas principais a partir das quais foram montados gráficos e realizadas análises e sínteses. 
Tabela 15 - Parâmetros de informação geral

INFORMAÇÕES DE CLASSIFICAÇÃO GERAL

\begin{tabular}{ll}
\hline & INFORMAÇÕES DE CLASSIFICAÇÃO GERAL \\
\hline Título & Título da publicação no formato original \\
\hline Autores & Autores da publicação \\
\hline Palavras-chave & Listas de palavras-chave utilizadas na publicação \\
\hline Fonte & $\begin{array}{l}\text { Título do congresso ou periódico em que a publicação } \\
\text { foi realizada }\end{array}$ \\
\hline Tipo de documento & $\begin{array}{l}\text { Tipo de publicação (ex.: artigo, artigo de congresso, } \\
\text { revisão, etc.) }\end{array}$ \\
\hline Resumo & Resumo dos pontos principais da publicação \\
\hline Número de citaçães & Número de vezes que a publicação foi citada \\
\hline Ano de publicação & Ano em que a publicação foi realizada \\
\hline & Fonte: Autora (2018).
\end{tabular}

Tabela 16 - Parâmetros de informação específica

\begin{tabular}{ll}
\hline \multicolumn{1}{c}{ INFORMAÇÕES DE CLASSIFICAÇÃO ESPECÍFICA } \\
\hline Teoria & Teorias que embasam o estudo \\
\hline Variáveis & $\begin{array}{l}\text { Variáveis dependente e independentes do modelo } \\
\text { (desempenho; determinante; moderadora; mediadora; } \\
\text { controle) }\end{array}$ \\
\hline País & País de onde foram coletados os dados \\
\hline Ano da coleta de dados & Ano em que os dados foram coletados \\
\hline Setor & $\begin{array}{l}\text { Setor analisado (ex.: manufatura, serviços, construção, } \\
\text { etc.) }\end{array}$ \\
\hline Indústria & $\begin{array}{l}\text { Indústria em que o estudo foi aplicado (baseado no SIC } \\
\text { - Standard Industrial Classification) }\end{array}$ \\
\hline Tamanho da amostra & Tamanho da amostra analisada \\
\hline Unidade de análise & $\begin{array}{l}\text { Unidade analisada (ex.: companhia, planta, setor, } \\
\text { indivíduo, etc.) }\end{array}$ \\
\hline Método de análise & $\begin{array}{l}\text { Método/técnica utilizada para o desenvolvimento das } \\
\text { análises (ex.: regressão, equações estruturais, etc.) }\end{array}$ \\
\hline Software & Software utilizado para a realização das análises \\
\hline Resultados & Resumo dos principais resultados alcançados \\
\hline Estudos futuros & $\begin{array}{l}\text { Propostas de trabalhos a serem realizados daquele } \\
\text { ponto em diante }\end{array}$ \\
\hline
\end{tabular}

Fonte: Autora (2018).

\subsection{4}

\section{Análise, síntese e interpretação dos dados}

A análise crítica e síntese trabalham em conjunto utilizando a literatura (os dados) para geração de conhecimento sobre um determinado tópico (THOMÉ, SCAVARDA e SCAVARDA, 2016). Não existe um método universal para a realização da fase de análise, por isso deve-se elaborar a pergunta de pesquisa e só então definir o método mais adequado para respondê-la, não apenas revisitando a literatura, mas examinando-a de forma crítica.

A partir da análise crítica são criados novos conhecimentos sobre pesquisas anteriores. A síntese baseia-se nestes novos conhecimentos para criar novas perspectivas a respeito do tema como um todo (TORRACO, 2005).

O método de síntese em RSL pode se distinguir em agenda de pesquisa, taxonomias, frameworks e meta-teoria, resumidos na Tabela 17 (TORRACO, 2005). 
Tabela 17 - Métodos de síntese da literatura

\begin{tabular}{cl}
\hline MÉTODO & \multicolumn{1}{c}{ DEFINIÇÃo } \\
\hline $\begin{array}{c}\text { Agenda de } \\
\text { pesquisa }\end{array}$ & $\begin{array}{l}\text { Flui logicamente a partir da análise crítica da literatura apresentando questões } \\
\text { provocativas (ou proposições) que dão orientação para pesquisas futuras. }\end{array}$ \\
\hline Taxonomia & $\begin{array}{l}\text { Desenvolve um meio de classificação de pesquisas anteriores que, por sua vez, } \\
\text { serve de base para novas teorias. }\end{array}$ \\
\hline Framework & $\begin{array}{l}\text { Apresenta novas perspectivas sobre o tema abordado pela revisão integrativa e } \\
\text { deriva diretamente da análise crítica e síntese. }\end{array}$ \\
\hline Meta-teoria & $\begin{array}{l}\text { Deriva da integração e síntese de uma RSL que fornece a base para desenvolver } \\
\text { a meta-teoria em domínios teóricos através de pesquisas futuras. }\end{array}$ \\
\hline
\end{tabular}
Fonte: Adaptado de Torraco (2005) (Tradução livre).

Foi realizada uma análise crítica de conteúdo e, por ser pautada em formas de classificação de estudos anteriores, a taxonomia é o tipo de síntese que mais se adequa a esta pesquisa, o que gerou um framework com os resultados encontados.

\subsection{5}

\section{Apresentação dos resultados e atualização da revisão}

A apresentação dos resultados foi escrita no formato de dissertação de mestrado cumprindo as recomendações propostas por Thomé, Scavarda e Scavarda (2016). A dissertação é composta de introdução, referencial teórico, procedimentos metodológicos, elaboração e aplicação do instrumento de pesquisa, discussão de resultados e considerações finais. A partir dela, será feita a atualização da revisão, no formato de um artigo, tendo como objetivo a revisão da literatura das principais variáveis relacionadas às medidas de desempenho operacional.

\section{2}

\section{Surveys}

Em gerência de operações, diversos métodos têm sido desenvolvidos para estreitar a distância entre a teoria e a prática (Flynn et al., 1990). Pesquisas do tipo survey tem contribuído com sucesso para que diferentes teorias sejam testadas. Este sucesso é devido, principalmente, à flexibilidade deste tipo de pesquisa em alcançar diferentes objetivos de natureza exploratória, confirmatória ou descritiva (Forza, 2002). A partir do resultado preliminar na literatura, elaborou uma proposta inicial de survey para aplicações práticas. O processo utilizado segue os três primeiros passos (Relação com a teoria, Design, e Teste piloto) da metodologia apresentada por Forza (2002) na Figura 4. 


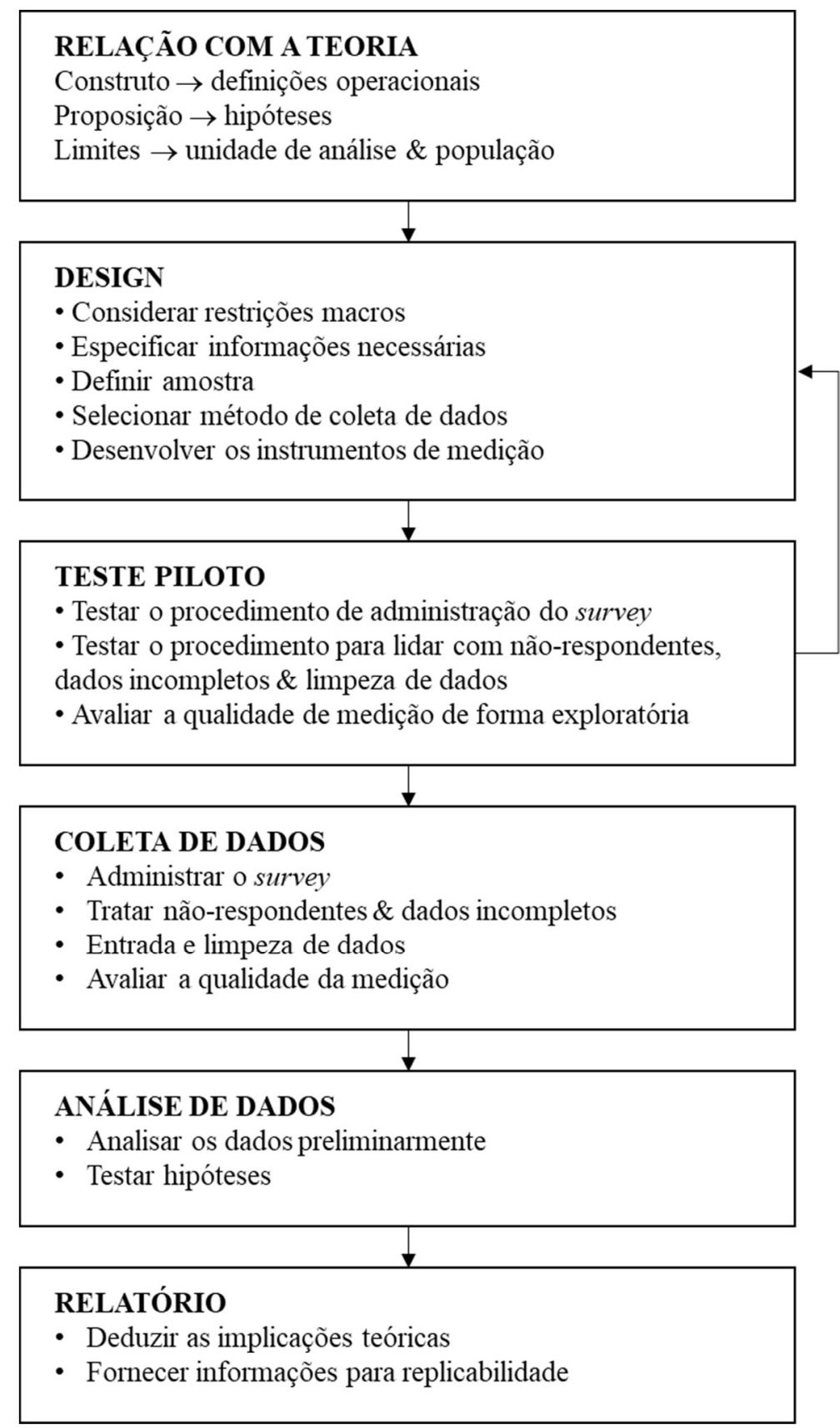

Figura 4 - Processo de teste de teoria através de survey Fonte: Forza (2002) (Tradução livre)

Os passos seguintes (Coleta de dados, Análise de dados, e Relatório) não correspondem ao escopo desta pesquisa.

\subsection{1}

\section{Relação com a teoria}

Como já mencionado no capítulo 2 de Referencial teórico, este trabalho foi desenvolvido sob a luz da teoria da visão baseada em recursos proposta por Barney (1991). O levantamento preliminar da literatura permitiu que as proposições fossem desenvolvidas nas seguintes hipóteses: 
H1: Quanto maior o nível de orientação ao mercado, maior o desempenho operacional, em termos de a) custo, b) flexibilidade, c) qualidade e d) inovação

H2: Quanto maior o nível de esforços de inovação, maior o desempenho operacional, em termos de a) custo, b) flexibilidade, c) qualidade e d) inovação

H3: Quanto maior o nível de orientação de mercado, maior o nível de esforços de inovação.

H4: Quanto maior o nível de intangibilidade, inseparabilidade, heterogeneidade e perecibilidade (características do serviço), maior será o efeito da orientação de mercado sobre o nível de esforços de inovação.

Estas hipóteses resultaram na elaboração do modelo estrutural disposto na Figura 5.

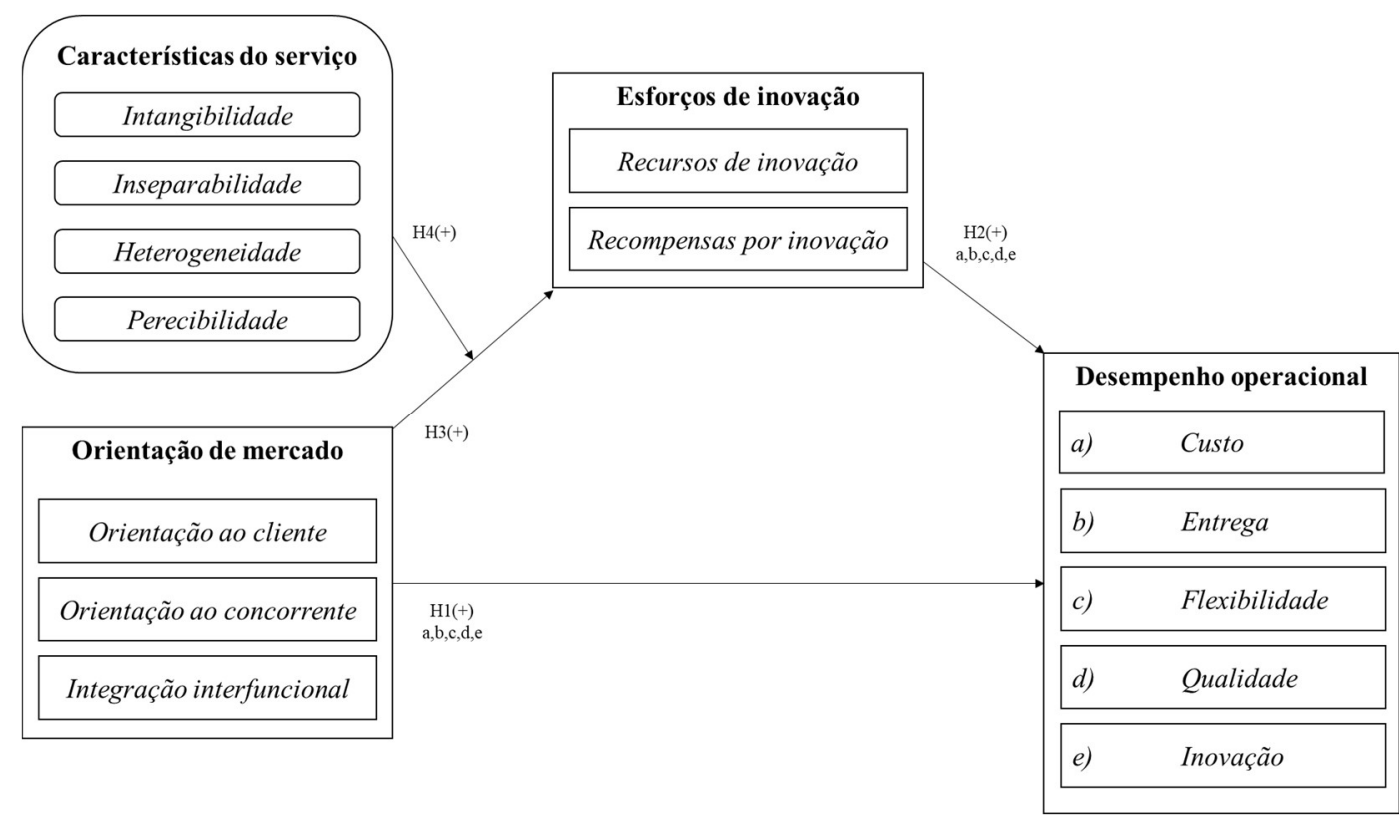

Figura 5 - Modelo estrutural Fonte: Autora (2018)

O desempenho operacional do serviço é influenciado pelas variáveis "esforços de inovação" e "orientação de mercado". A variável "esforços de inovação" age tanto como determinante do desempenho operacional, quanto como mediadora das características do serviço e da orientação de mercado da organização. O modelo conceitual na Figura 5 descreve como as características do serviço, a orientação de mercado e os esforços de inovação influenciam coletivamente o desempenho operacional.

Após a definição do modelo teórico, foram definidas as medidas operacionais dos construtos. Buscou-se identificar como os construtos de 
orientação de mercado, características do serviço, esforços de inovação e desempenho operacional das empresas são definidos e operacionalizados na literatura. Neste primeiro momento, as definições e operacionalizações dos construtos foram feitas individualmente, não havendo necessariamente uma relação direta entre as variáveis nas publicações em que estas foram identificadas. Isto só foi levado em consideração no momento da revisão sistemática da literatura.

As escalas foram adaptadas a partir de similares já existentes na literatura. Isto requer que sejam feitas posteriores análises teóricas e estatísticas para a seleção dos itens de cada escala.

As escalas propostas para cada dimensão, bem como as pesquisas anteriores nas quais estas foram baseadas, estão dispostas no Apêndice I

A população a ser estudada compreende o grupo de pequenas empresas prestadoras de serviço existente no estado do Rio de Janeiro devido à sua expressiva participação na economia nacional (SEBRAE, 2015). Incluem-se as atividades de comércio em atividades de prestação de serviço.

\section{2 .2 \\ Design}

A coleta de informações em pesquisas do tipo survey deve respeitar as restrições de recursos financeiros, humanos e do tempo disponibilizados. Por isso, esta pesquisa é direcionada apenas a pequenas prestadoras de serviço, registradas na base de dados do SEBRAE, cujas atividades possuem maior participação percentual no estado do Rio de Janeiro. Propõe-se que os dados sejam coletados através de um questionário aplicado pelo software de pesquisa on-line, Survey Monkey.

O questionário foi dividido em cinco partes, iniciando com a identificação do perfil do entrevistado, seguido pela caracterização da empresa, pela classificação dos determinantes (características do serviço, orientação de mercado e esforços de inovação), ordenamento dos objetivos de desempenho (custo, entrega, flexibilidade, qualidade e inovação) e pela avaliação do desempenho operacional (custo, entrega, flexibilidade, qualidade e inovação).

A primeira e a segunda etapa possuem tanto questões abertas, quanto fechadas. Já os construtos da terceira etapa (determinantes) são medidos por uma escala de Likert de cinco pontos avaliando o grau em que o entrevistado concordou ou discordou desses itens ( 1 - discordo totalmente, até 5 - concordo 
totalmente). A quarta etapa será o ordenamento dos critérios de desempenho numa escala de importância ( $1^{\circ}$ - mais importante, $4^{\circ}$ - menos importante). E a quinta etapa será a avaliação do desempenho em escala de Likert de cinco pontos comparando a situação atual da empresa a sua situação nos últimos anos (1 reduziu, 5 - cresceu fortemente) e comparando ao concorrente (1 - muito inferior, 5 - muito superior).

A escala de Likert de cinco pontos foi escolhida por existirem evidências de que o número de opções no formato de resposta da escala Likert pode interferir nos resultados da pesquisa quando há mais de 20 perguntas no questionário da pesquisa (DALMORO e VIEIRA, 2013). Isto é, um número menor de opções de resposta é preferível quando o questionário é grande, sendo aconselhável utilizar mais opções de resposta em cada escala apenas quando existem poucas perguntas a serem respondidas. Isso ajuda a reduzir a quantidade de itens a serem analisados, reduzindo também o processamento mental pelos respondentes.

De acordo com Dalmoro e Vieira (2013), a escala Likert de três pontos é menos confiável ao expressar a opinião do entrevistado, não havendo diferença significativa entre as escalas de cinco e sete pontos. No entanto, a escala de cinco pontos é mais fácil e mais rápida de responder, motivo pelo qual está sendo utilizada nesta pesquisa. Swait e Adamowicz (2001) e Weathers et al. (2005) mostram que, à medida que o tamanho das escalas aumenta, há uma chance de produzir o chamado efeito status quo, que é o viés introduzido por um respondente ao escolher a mesma resposta para sucessivos itens de escala.

Em casos onde há apenas um respondente, algumas precauções devem ser tomadas para evitar o viés de método único ou de variância única (PODSAKOFF et al., 2003). Tais precauções são: formular questões claras e concisas, garantir anonimato e confidencialidade do entrevistado e separar claramente medidas de desempenho e outras características no questionário. Essas medidas durante a construção do questionário contribuem para redução de respostas aleatórias e variância nas respostas (PODSAKOFF et al., 2003).

\subsection{3}

\section{Teste piloto}

Um teste piloto preliminar foi aplicado a três entrevistados em empresas de comércio/serviço:

- A dona de uma loja de biquínis no bairro da Rocinha (Rio de Janeiro/RJ) 
- O dono de uma mercearia no bairro do Parque da Cidade (Rio de Janeiro/RJ)

- Antiga gerente de um pub no bairro Prado (Bucaramanga/Colômbia)

As respostas deste teste preliminar não foram salvas. O teste foi conduzido na presença do pesquisador, que observou as dificuldades em responder o questionário, o tempo para completá-lo e como este pode ser melhorado para facilitar a compreensão das questões e reduzir o viés de método comum (PODSAKOFF et al., 2003).

Não foram testados nesta etapa os procedimentos para lidar com nãorespondentes, dados incompletos e limpeza de dados, o que constitui uma das limitações desta pesquisa. 


\section{4 \\ Resultados e discussões}

Após a aplicação dos procedimentos metodológicos da RSL foi possível analisar o comportamento das 87 publicações selecionadas de forma geral e específica. Com as informações de classificação geral, foi realizada a análise descritiva, verificando-se a quantidade de artigos publicados por ano, autores mais frequentes, fontes de publicação, palavras-chave. No contexto específico, abordaram-se as principais contribuições de cada modelo proposto nas publicações, avaliando e classificando de acordo com as dimensões de desempenho operacional.

Com o retorno do teste piloto, o modelo estrutural inicial pôde ser analisado novamente e redesenhado, bem como os módulos de pergunta do questionário inicial.

Os resultados da revisão da literatura serão apresentados sob forma de taxonomia e framework, seguido da análise dos resultados do teste piloto do questionário do survey.

\section{1}

\section{Análise descritiva da RSL}

De forma a caracterizar como os estudos acerca de desempenho operacional em pequenas empresas se mostraram ao longo do período avaliado na RSL (desde o início dos registros até 19 de outubro de 2017), tem-se, num primeiro momento, a distribuição de publicações no decorrer dos anos. Com base na Figura 6, é possível analisar o comportamento da quantidade total de publicações por ano, que atingiu o pico no ano de 2013, com 16 publicações, seguida do ano de 2016, com 12 publicações. 


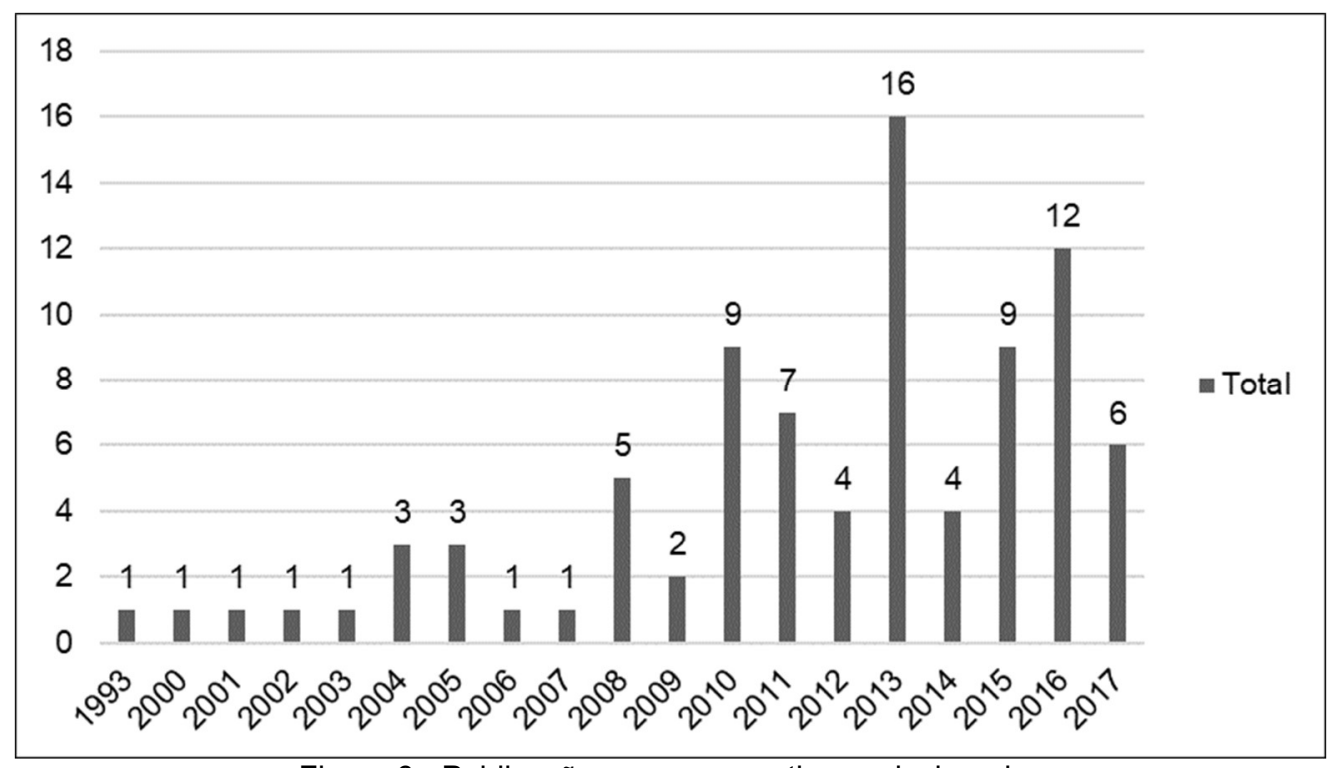

Figura 6 - Publicações por ano - artigos selecionados Fonte: Autora (2017).

Quanto ao tipo de publicação, 77 são artigos de periódicos (75 Articles; 1 Article in Press; 1 Review) contra 10 artigos de congressos (1 Article/Proceedings Paper; 5 Conference Papers; 4 Proceedings Paper).

Os locais de publicação com maiores acervos conferem o Technovation e o Service Industries Journal, ambos com 3 publicações, no período correspondente à RSL. O periódico Technovation publicou o quinto e o sétimo trabalho com maior número de citações desta revisão. E o Service Industries Journal publicou o décimo mais citado.

$\mathrm{Na}$ Figura 7, podem ser verificados os principais acervos, correspondentes aqueles que possuem mais de uma publicação no tema.

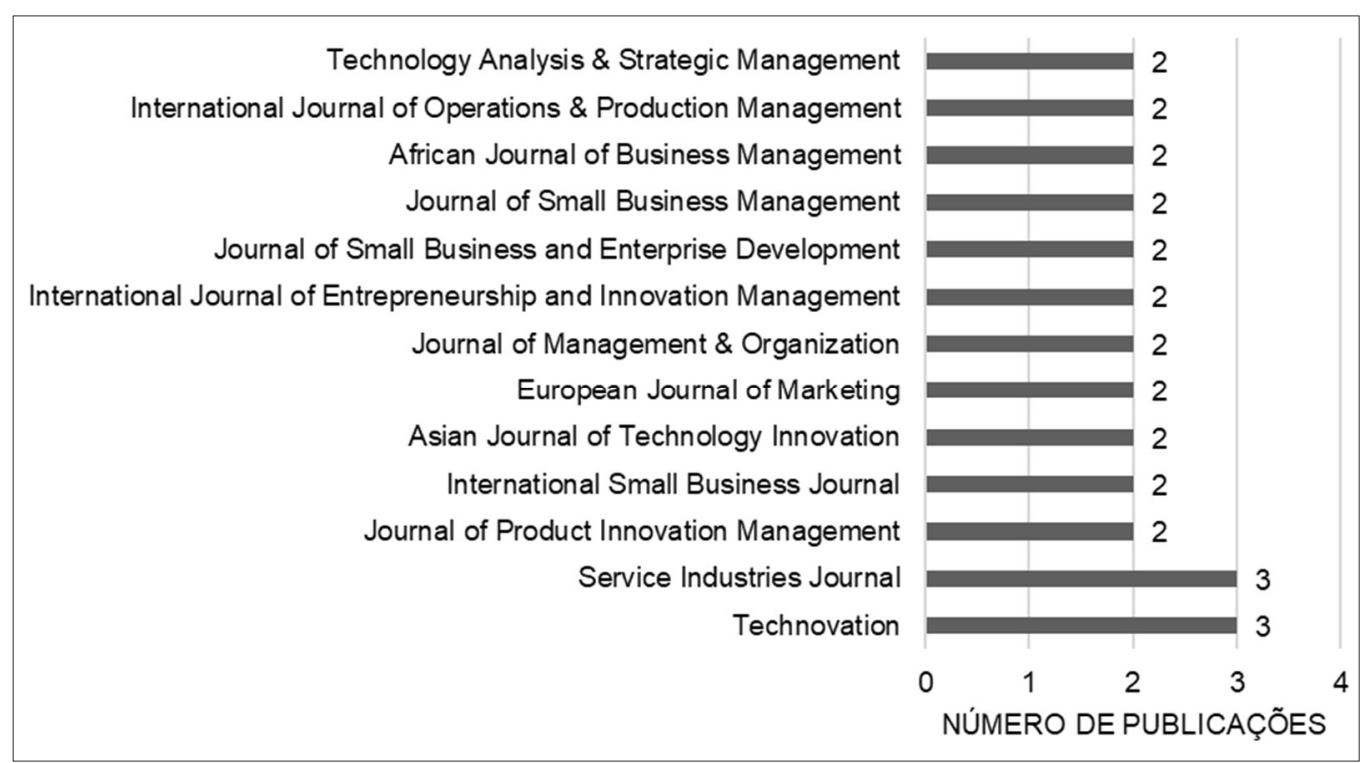

Figura 7 - Maiores acervos Fonte: Autora (2018). 
É possível verificar que há uma dispersão de publicações nos periódicos. Devido a busca ter utilizado palavras-chaves abrangentes, diversos journals contem publicações nos assuntos pesquisados o que pode justificar tal dispersão. Entretanto, por tratar de pequenas empresas, há uma concentração maior em journals de inovação, gestão e pequenas empresas.

As palavras-chave utilizadas nas publicações também foram analisadas e identificou-se que as principais estavam relacionadas a inovação, desempenho, e pequenos e médios empreendimentos, conforme apresentado na Tabela 18. As palavras-chave relacionadas a inovação foram comuns a 6 dos 10 artigos mais citados desta pesquisa, as relacionadas a desempenho apareceram em 2 destes e as relacionadas a pequenos e médios empreendimentos também apareceram em 2. Palavras utilizadas nos títulos dos artigos analisados não foram evitadas nas palavras-chaves, portanto a análise não excluiu as palavras-chaves importantes para a pesquisa.

Tabela 18 - Palavras-chave mais utilizadas

\begin{tabular}{lc}
\hline Palavras-chave & Tabela 18 - Palavras-chave mais utilizadas publicações \\
em que aparecem
\end{tabular}

\section{INOVAÇÃO}

Innovation; product innovation; innovation performance; process innovation; employee innovation behavior; non-technological innovations; behavioral innovativeness; degree of novelty of innovation; inbound open innovation; organisational innovation; innovation activity; technology innovation performance; innovation audit; micro-innovation; innovation implementation; open innovation; innovation networks; predictors of innovative efforts; product innovativeness; determinants of innovation; service innovation; technological innovation capability; strategic innovativeness; innovation planning policy; technological innovation influencers (tiis); innovation policy; technology innovation strategy; innovations; marketing innovation

\section{DESEMPENHO}

Performance; firm performance; innovation performance; organisational performance; organizational performance; performance management; business performance; sme performance; manufacturing firm performance (mfp); financial performance; nonfinancial performance; quality performance; company performance; technology innovation performance; ict-performance; new product performance

\section{PEQUENOS E MÉDIOS EMPREENDIMENTOS}

Small and medium enterprises; small business; small to medium-sized enterprises; small and medium enterprise (sme); small enterprises; micro and small enterprises; small firms; small and medium-sized enterprises (smes); micro and small companies; small businesses; small and medium enterprises (smes); small firm; small to medium sized enterprises; small and large wholesalers; small- to medium-sized enterprises; small and medium-sized enterprises; small- and medium-sized enterprises

Fonte: Autora (2018).

$\mathrm{Na}$ Tabela 19 estão expressas as 10 publicações mais citadas, a fim de servir como fonte de consulta para futuras pesquisas que necessitem de embasamento teórico já consolidado acerca do tema. 
Tabela 19 - 10 publicações mais citadas

\begin{tabular}{|c|c|c|}
\hline Autores & 10 publicações mais citadas & $\begin{array}{l}\text { Número } \\
\text { de } \\
\text { citações }\end{array}$ \\
\hline Yam et al. (2004) & $\begin{array}{l}\text { An audit of technological innovation capabilities in Chinese } \\
\text { firms: Some empirical findings in Beijing, China }\end{array}$ & 181 \\
\hline $\begin{array}{l}\text { Richey, Genchev e } \\
\text { Daugherty (2005) }\end{array}$ & $\begin{array}{l}\text { The role of resource commitment and innovation in reverse } \\
\text { logistics performance }\end{array}$ & 106 \\
\hline $\begin{array}{l}\text { Badri, Davis e Davis } \\
(2000)\end{array}$ & $\begin{array}{l}\text { Operations strategy, environmental uncertainty and } \\
\text { performance: A path analytic model of industries in developing } \\
\text { countries }\end{array}$ & 92 \\
\hline $\begin{array}{l}\text { Droge, Calantone e } \\
\text { Harmancioglu } \\
(2008)\end{array}$ & $\begin{array}{l}\text { New product success: Is it really controllable by managers in } \\
\text { highly turbulent environments? }\end{array}$ & 81 \\
\hline $\begin{array}{l}\text { Keizer, Dijkstra e } \\
\text { Halman (2002) }\end{array}$ & $\begin{array}{l}\text { Explaining innovative efforts of SMEs. An exploratory survey } \\
\text { among SMEs in the mechanical and electrical engineering } \\
\text { sector in The Netherlands }\end{array}$ & 80 \\
\hline $\begin{array}{l}\text { Mahmood e Mitchell } \\
(2004)\end{array}$ & $\begin{array}{l}\text { Two faces: Effects of business groups on innovation in } \\
\text { emerging economies }\end{array}$ & 77 \\
\hline Amara et al. (2008) & $\begin{array}{l}\text { Learning and novelty of innovation in established manufacturing } \\
\text { SMEs }\end{array}$ & 69 \\
\hline Guan et al. (2006) & $\begin{array}{l}\text { Technology transfer and innovation performance: Evidence } \\
\text { from Chinese firms }\end{array}$ & 60 \\
\hline $\begin{array}{l}\text { Rahman, } \\
\text { Laosirihongthong e } \\
\text { Sohal (2010) }\end{array}$ & $\begin{array}{l}\text { Impact of lean strategy on operational performance: A study of } \\
\text { Thai manufacturing companies }\end{array}$ & 53 \\
\hline $\begin{array}{l}\text { Johns, Avcí e } \\
\text { Karatepe (2004) }\end{array}$ & $\begin{array}{l}\text { Measuring service quality of travel agents: Evidence from } \\
\text { northern Cyprus }\end{array}$ & 52 \\
\hline
\end{tabular}

\section{2}

\section{Taxonomia}

Após a análise descritiva das publicações, realizou-se uma análise específica a partir da leitura completa das mesmas a fim de responder às perguntas de pesquisa. Esta análise inclui a classificação de indicadores de desempenho, determinantes (variáveis que influenciam positiva ou negativamente o desempenho operacional), mediadores (variáveis que bloqueiam parcialmente ou completam a relação entre os determinantes e o desempenho operacional), moderadores (variáveis que afetam a direção e/ou a força da relação entre os determinantes e o desempenho operacional) e variáveis de controle.

A primeira pergunta "Pergunta 1 - Como é mensurado o desempenho operacional em pequenas empresas?" pode ser respondida através da análise de como as dimensões de custo, entrega, flexibilidade, qualidade e inovação, correspondentes ao desempenho operacional, são utilizadas para o indicador de desempenho analisada. A Tabela 20 resume os principais indicadores de desempenho nas pesquisas empíricas de desempenho operacional em pequenas empresas. Os outros indicadores possuíam apenas quatro publicações ou menos 
e por isso não foram agrupados nesta tabela. Estes indicadores podem ser visualizados de forma mais detalhada no Apêndice II.

Tabela 20 - Principais indicadores de desempenho que apresentam dimensões de desempenho operacional em pequenas empresas

\begin{tabular}{ll}
\hline $\begin{array}{l}\text { Indicador de } \\
\text { desempenho }\end{array}$ & Referências \\
\hline Inovação & Alam et al. (2016); Amara et al. (2008); Bala Subrahmanya (2013);
\end{tabular}

(28 publicações) Ebersberger e Herstad (2013); Guan et al. (2006); Heimonen (2012); Hu e Mathews (2009); Huang, Lai e Huang (2015); Jha e Bose (2016); Jo, Park e Kang (2016); Reade e Lee (2016); Rodríguez e Guzmán (2013); Keizer, Dijkstra e Halman (2002); Laforet (2009); Markič et al. (2011); McAdam et al. (2010); Medrano e Olarte-Pascual (2016); Minguela-Rata, FernándezMenéndez e Fossas-Olalla (2014); Papula, Volná e Hul'vej (2013); Parida e Örtqvist (2015); Soni, Lilien e Wilson (1993); Tejada e Moreno (2013); Tomlinson e Fai (2013); Urban e Greyling (2015); Verbano e Crema (2016); Yam et al. (2004); Yun et al. (2016); Zhou et al. (2017)

Desempenho Ali e Shabir (2017); Augusto, Lisboa e Yasin (2014); Biju e Bhasi (2014); Yu e organizacional Duan (2016); Gholami et al. (2013); Hilmi et al. (2010); Jing (2017); Khalique e (20 publicações) Pablos (2015); Kongmanila e Takahashi (2010); Mahmood e Rosli (2013); Mahmood et al. (2017); Malmström e Wincent (2012); O'Dwyer e Ledwith (2010); Rojas-Méndez, Kara e Spillan (2006); Rosli e Sidek (2007); Sheehan e Cooper (2011); Singh, Khamba e Nanda (2017); Sinha, Garg e Dhall (2016); Subramaniam, Shamsudin e Ibrahim (2011); Theriou e Chatzoudes (2015)

Desempenho Adawiyah et al. (2015); Agyapong, Agyapong e Poku (2017); Badri, Davis e operacional Davis (2000); Richey, Genchev e Daugherty (2005); Jones et al. (2013); (8 publicações) Rahman, Laosirihongthong e Sohal (2010); Rawwas e Lyer (2013); Sorooshian et al. (2011)

Fonte: Autora (2018).

Inovação aparece como um mediador, indicador de desempenho e como determinante. Inovação em processos, solução em inovação e tipos de inovação são algumas das escalas utilizadas para compor a dimensão de Inovação como mediadora do desempenho.

Quanto indicador de desempenho, a dimensão de Inovação aparece composta por escalas como nível de inovação, desempenho de inovação, vendas relativas a inovação, taxa de inovação, sucesso da inovação, patentes concedidas, licenciamento de tecnologia, empresas encubadas, processos de inovação, desenvolvimento de novos produtos/serviços. A Inovação é uma das dimensões que compõem o desempenho operacional e em pequenas empresas ela demonstrou ser uma importante medida de desempenho visto que, dos 87 estudos, 28 assumiram a inovação como um indicador do desempenho da empresa.

Diversas publicações consideram algumas das medidas de desempenho operacional dentro do Desempenho organizacional (também definido como Desempenho da firma ou Desempenho do negócio). Medidas como satisfação do consumidor (pertinente à qualidade em serviços), produtividade (pertinente a custo), desenvolvimento de novos produtos (pertinente à inovação) são algumas 
das que compõem as cinco medidas tradicionais de desempenho operacional conforme discutido na seção 2.2.2 Desempenho operacional.

O Desempenho operacional é classicamente mensurado a partir de cinco dimensões: custo, entrega, flexibilidade, qualidade e inovação. As publicações analisadas consideram algumas das medidas que compõem estas dimensões como produtividade (pertinente a custo), velocidade de atendimento ao consumidor (pertinente à entrega) ou extensão da falha no produto ou serviço (pertinente à qualidade), ou as dimensões em si.

A partir da análise, observa-se que o desempenho operacional em pequenas empresas é mensurado através de uma ou mais de suas cinco dimensões como escala do Desempenho Operacional, como escala de outros indicadores (Qualidade como escala de Desempenho organizacional), ou ainda sendo as próprias dimensões os indicadores de Desempenho (Inovação).

Na Tabela 21 estão expostas as 20 publicações encontradas após a análise que consideram pelo menos um dos fatores de desempenho operacional dentro de desempenho organizacional, além da identificação destes fatores. No Apêndice II, encontra-se o detalhamento completo de todos os indicadores de desempenho que ilustram como o desempenho operacional é mensurado em pequenas empresas.

Tabela 21 - Dimensões do desempenho operacional em desempenho organizacional

\begin{tabular}{|c|c|c|}
\hline Referência & $\begin{array}{l}\text { - Indicador de desempenho } \\
\text {-Dimensão }\end{array}$ & $\begin{array}{l}\text { Dimensão de } \\
\text { desempenho } \\
\text { operacional } \\
\text { identificada }\end{array}$ \\
\hline Ali e Shabir (2017) & $\begin{array}{l}\text { - Características do empreendimento } \\
\text {-Localização; } \\
\text {-Tamanho; } \\
\text {-Tipo; } \\
\text {-Idade } \\
\text { - Desempenho do negócio } \\
\text {-Crescimento anual de vendas; } \\
\text {-Crescimento de emprego; } \\
\text {-Produtividade laboral'; } \\
\text {-Utilização da capacidade } \\
\text { - Obstáculos do negócio } \\
\text {-Acesso a recursos; } \\
\text {-Políticas e regulações; } \\
\text {-Externalidades do negócio }\end{array}$ & 1-Custo \\
\hline
\end{tabular}




\begin{tabular}{|c|c|c|}
\hline Referência & $\begin{array}{l}\text { - Indicador de desempenho } \\
\text {-Dimensão }\end{array}$ & $\begin{array}{l}\text { Dimensão de } \\
\text { desempenho } \\
\text { operacional } \\
\text { identificada } \\
\text { 1-Custo } \\
\text { 2-Entrega } \\
\text { 3-Flexibilidade } \\
\text { 4-Qualidade } \\
\text { 5-Inovação }\end{array}$ \\
\hline $\begin{array}{l}\text { Augusto, Lisboa } \\
\text { eYasin (2014) }\end{array}$ & $\begin{array}{l}\text { - Desempenho organizacional } \\
\text {-Crescimento de fatia de mercado; } \\
\text {-Produtividade laboral }{ }^{1 ;} \\
\text {-Satisfação do consumidor; } \\
\text {-Retenção de clientes; } \\
\text {-Lucro econômico médio; } \\
\text {-Lucro de vendas médio }\end{array}$ & $\begin{array}{l}\text { 1-Custo } \\
\text { 4-Qualidade }\end{array}$ \\
\hline Biju e Bhasi (2014) & $\begin{array}{l}\text { - Desempenho da firma } \\
\text {-Desempenho de vendas; } \\
\text {-Plano de crescimento pela firma; } \\
\text {-Metas de conquista; } \\
\text {-Níveis de lucro alcançados; } \\
\text {-Prontidão de entrega2; } \\
\text {-Redução de leadtime } \\
\end{array}$ & 2-Entrega \\
\hline Gholami et al. (2013) & $\begin{array}{l}\text { - Desempenho organizacional } \\
\text {-Produtividade }{ }^{1 ;} \\
\text {-Desempenho financeiro; } \\
\text {-Desempenho do pessoal; } \\
\text {-Inovação }{ }^{5} \text {; } \\
\text {-Relações laborais; } \\
\text {-Satisfação do consumidor }{ }^{4}\end{array}$ & $\begin{array}{l}\text { 1-Custo } \\
\text { 4-Qualidade } \\
\text { 5-Inovação }\end{array}$ \\
\hline Hilmi et al. (2010) & $\begin{array}{l}\text { - Desempenho da firma } \\
\text {-Número de reclamações; } \\
\text {-ROI; } \\
\text {-Desempenho financeiro; } \\
\text {-Crescimento de vendas; } \\
\text {-Produtividade }{ }^{1 ;} \\
\text {-Satisfação do consumidor } \\
\text {-Satisfação do empregado }\end{array}$ & $\begin{array}{l}\text { 1-Custo } \\
\text { 4-Qualidade }\end{array}$ \\
\hline Jing (2017) & $\begin{array}{l}\text { - Desempenho organizacional } \\
\text {-Satisfação do pessoal; } \\
\text {-Satisfação do consumidor; } \\
\text {-Desempenho financeiro; } \\
\text {-Produtividade }{ }^{1 ;} \\
\text {-Ternura do pessoal/gerente }\end{array}$ & $\begin{array}{l}\text { 1-Custo } \\
\text { 4-Qualidade }\end{array}$ \\
\hline $\begin{array}{l}\text { Khalique e Pablos } \\
\text { (2015) }\end{array}$ & $\begin{array}{l}\text { - Desempenho organizacional } \\
\text {-Perspectiva financeira; } \\
\text {-Perspectiva do consumidor4; } \\
\text {-Perspectiva de processo interno do negócio; } \\
\text {-Perspectiva de crescimento e aprendizado }\end{array}$ & 4-Qualidade \\
\hline $\begin{array}{l}\text { Kongmanila e } \\
\text { Takahashi (2010) }\end{array}$ & $\begin{array}{l}\text { - Comportamento do subcontratado } \\
\text { - Desempenho da firma } \\
\text {-Eficiência do capital; } \\
\text {-Eficiência do trabalho }{ }^{1}\end{array}$ & 1-Custo \\
\hline $\begin{array}{l}\text { Mahmood e Rosli } \\
(2013)\end{array}$ & $\begin{array}{l}\text { - Desempenho do negócio } \\
\text {-Receita de vendas; } \\
\text {-Lucro; } \\
\text {-Estabilidade do negócio; } \\
\text {-Crescimento de emprego; } \\
\text {-Redução nos custos de produção }{ }^{1} ; \\
\text {-Satisfação do consumidor; } \\
\text {-Alcance do mercado; } \\
\text {-Valor dos ativos do negócio; } \\
\text {-Networks do negócio }\end{array}$ & $\begin{array}{l}\text { 1-Custo } \\
\text { 4-Qualidade }\end{array}$ \\
\hline
\end{tabular}




\begin{tabular}{|c|c|c|}
\hline Referência & $\begin{array}{l}\text { - Indicador de desempenho } \\
\text {-Dimensão }\end{array}$ & $\begin{array}{l}\text { Dimensão de } \\
\text { desempenho } \\
\text { operacional } \\
\text { identificada } \\
\text { 1-Custo } \\
\text { 2-Entrega } \\
\text { 3-Flexibilidade } \\
\text { 4-Qualidade } \\
\text { 5-Inovação }\end{array}$ \\
\hline $\begin{array}{l}\text { Mahmood et al. } \\
\text { (2017) }\end{array}$ & $\begin{array}{l}\text { - Desempenho da firma } \\
\text {-Receita de vendas; } \\
\text {-Lucro; } \\
\text {-Geração de emprego; } \\
\text {-Estabilidade do negócio; } \\
\text {-Crescimento do negócio; } \\
\text {-Contribuição para o desenvolvimento da } \\
\text { comunidade; } \\
\text {-Satisfação do consumidor } \\
\text {-Networking }\end{array}$ & 4-Qualidade \\
\hline $\begin{array}{l}\text { Malmström e Wincent } \\
(2012)\end{array}$ & $\begin{array}{l}\text { - Desempenho da firma } \\
\text {-Qualidade de produtos e serviços desenvolvidos } \\
\text { pela firma } \\
\text {-Eficiência no desenvolvimento de produtos e } \\
\text { serviços }^{5} \text {; } \\
\text {-Eficiência na manufatura de produtos e/ou prestação } \\
\text { de serviços }{ }^{1} \text {; } \\
\text {-Habilidade de descobrimento dos desejos do cliente; } \\
\text {-Eficiência em marketing e vendas }\end{array}$ & $\begin{array}{l}\text { 1-Custo } \\
\text { 4-Qualidade } \\
\text { 5-Inovação }\end{array}$ \\
\hline $\begin{array}{l}\text { O'Dwyer e Ledwith } \\
(2010)\end{array}$ & $\begin{array}{l}\text { - Desempenho organizacional } \\
\text {-Crescimento de vendas; } \\
\text {-Lucro; } \\
\text {-Sucesso de novos produtos }{ }^{5} \\
\text {-Fatia de vendas de novos produtos; } \\
\text {-Fatia de mercado; } \\
\text {-ROI ou IRR }\end{array}$ & 5-Inovação \\
\hline $\begin{array}{l}\text { Rojas-Méndez, Kara } \\
\text { e Spillan (2005) }\end{array}$ & $\begin{array}{l}\text { - Desempenho organizacional } \\
\text {-Sucesso do produto } 5 \\
\text {-Retenção do consumidor; } \\
\text {-Qualidade do preço-produto } 4\end{array}$ & $\begin{array}{l}\text { 4-Qualidade } \\
\text { 5-Inovação }\end{array}$ \\
\hline Rosli e Sidek (2007) & $\begin{array}{l}\text { - Desempenho da firma } \\
\text {-Retorno das vendas; } \\
\text {-Retorno nos ativos; } \\
\text {-Lucratividade; } \\
\text {-Fatia de mercado; } \\
\text {-Receita de vendas; } \\
\text {-Produtividade laboral; } \\
\text {-Empregabilidade }\end{array}$ & 1-Custo \\
\hline $\begin{array}{l}\text { Sheehan e Cooper } \\
(2011)\end{array}$ & $\begin{array}{l}\text { - Terceirização de recursos humanos; } \\
\text {-Treinamento e desenvolvimento; } \\
\text {-Recrutamento e seleção; } \\
\text {-Avaliação de desempenho; } \\
\text {-Remuneração por desempenho; } \\
\text {-Relações entre empregados; } \\
\text {-Remuneração administrativa; } \\
\text {-Sistema de informação de gerência de recursos } \\
\text { humanos; } \\
\text {-Gestão de mudanças } \\
\text { - Eficiência da organização } \\
\text {-Eficiência do desempenho organizacional total; } \\
\text {-Perspectiva de futuro; } \\
\text {-Qualidade de produtos e serviços } \\
\text {-Liderança na indústria }\end{array}$ & 4-Qualidade \\
\hline
\end{tabular}




\begin{tabular}{|c|c|c|}
\hline Referência & $\begin{array}{l}\text { - Indicador de desempenho } \\
\text {-Dimensão }\end{array}$ & $\begin{array}{l}\text { Dimensão de } \\
\text { desempenho } \\
\text { operacional } \\
\text { identificada } \\
\text { 1-Custo } \\
\text { 2-Entrega } \\
\text { 3-Flexibilidade } \\
\text { 4-Qualidade } \\
\text { 5-Inovação }\end{array}$ \\
\hline & $\begin{array}{l}\text { - Desempenho financeiro percebido } \\
\text {-Lucratividade organizacional; } \\
\text {-ROI; } \\
\text {-Metas financeiras internas } \\
\end{array}$ & \\
\hline $\begin{array}{l}\text { Singh, Khamba e } \\
\text { Nanda (2017) }\end{array}$ & $\begin{array}{l}\text { - Desempenho industrial da firma } \\
\text {-Desempenho do produto; } \\
\text {-Desempenho de vendas; } \\
\text {-Desempenho de inovação } 5\end{array}$ & 5-Inovação \\
\hline $\begin{array}{l}\text { Sinha, Garg e Dhall } \\
(2016)\end{array}$ & $\begin{array}{l}\text { - Desempenho organizacional } \\
\text {-Resultados de consumidor } \\
\text {-Resultados de processo; } \\
\text {-Resultados de empregado }\end{array}$ & 4-Qualidade \\
\hline $\begin{array}{l}\text { Subramaniam, } \\
\text { Shamsudin e Ibrahim } \\
(2011)\end{array}$ & $\begin{array}{l}\text { - Específicos da organização } \\
\text {-Qualidade percebida do produto } \\
\text {-Custo percebido de produção }{ }^{1} \\
\text { - Relativos ao mercado } \\
\text {-Fatia de mercado percebida; } \\
\text {-Vendas percebidas } \\
\text { - Desempenho organizacional total }\end{array}$ & $\begin{array}{l}\text { 1-Custo } \\
\text { 4-Qualidade }\end{array}$ \\
\hline $\begin{array}{l}\text { Theriou e Chatzoudes } \\
\text { (2015) }\end{array}$ & $\begin{array}{l}\text { - Desempenho da firma } \\
\text {-Crescimento de vendas; } \\
\text {-Crescimento da receita; } \\
\text {-Crescimento do número de empregados; } \\
\text {-Margem de lucro líquido; } \\
\text {-Crescimento da inovação de produtos e serviços } \\
\text {-Qualidade e variedade de produtos e serviços } \\
\text {-Adoção de novas tecnologias } \\
\text {-Satisfação do consumidor }\end{array}$ & $\begin{array}{l}\text { 4-Qualidade } \\
\text { 5-Inovação }\end{array}$ \\
\hline Yu e Duan (2016) & $\begin{array}{l}\text { - Desempenho da firma } \\
\text {-Crescimento de vendas; } \\
\text {-Crescimento da receita; } \\
\text {-Crescimento do lucro; } \\
\text {-ROI; } \\
\text {-Crescimento no número de empregados; } \\
\text {-Desenvolvimento de novos produtos; } \\
\text {-Desenvolvimento de mercado; } \\
\text {-Satisfação do consumidor } \\
\text {-Imagem social; } \\
\text {-Qualidade dos funcionários }\end{array}$ & 4-Qualidade \\
\hline
\end{tabular}

A partir da análise da Tabela 21, é possível perceber que, além do desempenho organizacional receber outras nomenclaturas como "Desempenho do negócio" ou "Desempenho da firma", alguns indicadores se repetem, como a Receita. Em variados contextos, ela é considerada como uma potencial medida para monitorar o desempenho de uma organização. 
Outra importância da Tabela 21 é apresentar as dimensões que compuseram o desempenho organizacional em cada publicação analisada. Isto disponibiliza uma fonte de consulta rápida para pequenas empresas que necessitam criar indicadores de desempenho organizacional através de indicadores já consolidados pela literatura. No Apêndice IV, encontra-se uma tabela resumo de como cada fator de desempenho operacional foi medido nos estudos levantados.

A segunda pergunta de pesquisa "Pergunta 2 - Quais os determinantes, mediadores, moderadores e variáveis de controle do desempenho operacional em pequenas empresas?" foi respondida através da classificação dos determinantes, mediadores, moderadores e variáveis de controle do desempenho operacional em pequenas empresas. Alguns fatores se repetem em algumas categorias dessas variáveis como Inovação, Conhecimento e Tamanho.

Os principais determinantes identificados foram reagrupados em Inovação, Fatores empreendedores, Conhecimento, Tamanho, Pesquisa \& Desenvolvimento (P\&D), Orientação ao mercado, Treinamento e Tecnologia. $\mathrm{Na}$ Tabela 22 estão identificados os principais determinantes encontrados e os respectivos autores que trabalham com cada tema.

Tabela 22 - Principais determinantes encontrados e os autores que abordam o tema

\begin{tabular}{ll}
\hline Determinantes & Referências \\
\hline Inovação & Agyapong, Agyapong e Poku (2017); Alam et al. (2016); Augusto, Lisboa e \\
(23 publicações) & Yasin (2014); Bala Subrahmanya (2013); Droge, Calantone e Harmancioglu \\
& (2008); Hilmi et al. (2010); Hu e Mathews (2009); Keizer, Dijkstra e Halman \\
& (2002);Liu e Chen (2015); Mahmood et al. (2017); Markič et al. (2011); \\
& McAdam et al. (2010); Medrano e Olarte-Pascual (2016); Ndubisi e Iftikhar \\
& (2012); Richey, Genchev e Daugherty (2005); Rosli e Sidek (2007); Singh, \\
& Khamba e Nanda (2017); Soni, Lilien e Wilson 1993; Tomlinson e Fai (2013); \\
& Verbano e Crema (2016); Yam et al. (2004); Yun et al. (2016); Zhou et al. \\
& (2017) \\
\hline Tecnologia & Aragon-Correa e Cordon-Pozo (2005); Bae e Chung (2002); Bala \\
(21 publicações) & Subrahmanya (2013); Chung, Bae e Kim (2003); Yu e Duan (2016); Richey, \\
& Genchev e Daugherty (2005); Guan et al. (2006); Hu e Mathews (2009); \\
& Huang, Lai e Huang (2015); Jha e Bose (2016); Jo, Park e Kang (2016); \\
& Keizer, Dijkstra e Halman (2002); Khalique e Pablos (2015); Kongmanila e \\
& Takahashi (2010); Liu e Chen (2015); Mendes e Ganga (2013); Minguela- \\
& Rata, Fernández-Menéndez e Fossas-Olalla (2014); Papastathopoulos e \\
& Beneki (2010); Singh, Khamba e Nanda (2017); Verbano e Crema (2016); \\
\hline & Yam et al. (2004) \\
\hline Fatores & Amir, Auzair e Amiruddin (2016); Aragon-Correa e Cordon-Pozo (2005); \\
empreendedores & Hosseini e Eskandari (2013); Mahmood e Rosli (2013); Mahmood et al. \\
(14 publicações) & (2017); Malmström e Wincent (2012); Markič et al. (2011); Papastathopoulos \\
& e Beneki (2010); Prajapati e Biswas (2011); Rodríguez e Guzmán (2013); \\
& Singh, Khamba e Nanda (2017); Sorooshian et al. (2011); Theriou e \\
& Chatzoudes (2015); Yun et al. (2016) \\
\hline &
\end{tabular}




\begin{tabular}{ll}
\hline Determinantes & Referências \\
\hline Tamanho & Augusto, Lisboa e Yasin (2014); Bala Subrahmanya (2013); Correia e Petiz \\
(14 publicações) & (2006); Djupdal e Westhead (2015); Heimonen (2012); Hu e Mathews \\
& (2009); Kongmanila e Takahashi (2010); Laforet (2009); Mahmood e Rosli \\
& (2013); Minguela-Rata, Fernández-Menéndez e Fossas-Olalla (2014); \\
& Prajapati e Biswas (2011); Sheehan e Cooper (2011); Soni, Lilien e Wilson \\
& (1993); Tomlinson e Fai (2013) \\
\hline Conhecimento & Amara et al. (2008); Gholami et al. (2013); Gui-Lin, Xiao-Hong e Guo-Qun \\
(10 publicações) & (2008); Huang, Lai e Huang (2015); Keizer, Dijkstra e Halman (2002); \\
& Markham e Lee (2014); McAdam et al. (2010); Papastathopoulos e Beneki \\
& (2010); Papula, Volná e Hul'vej (2013); Ukenna et al. (2010) \\
\hline P\&D & Ebersberger e Herstad (2013); Guan et al. (2006); Gui-Lin, Xiao-Hong e Guo- \\
(9 publicações) & Qun (2008); Heimonen (2012); Jha e Bose (2016); Keizer, Dijkstra e Halman \\
& (2002); Sheng e Song (2013); Tomlinson e Fai (2013); Yam et al. (2004) \\
\hline Treinamento & Amara et al. (2008); Guan et al. (2006); Jones et al. (2013); Mahmood et al. \\
(7 publicações) & (2017); Mahmood e Rosli (2013); Subramaniam, Shamsudin e Ibrahim \\
\hline Orientação ao & (2011); Ukenna et al. (2010) \\
mercado & Gaur, Vasudevan e Gaur (2011); Laforet (2009); Liu e Chen (2015); O’Dwyer \\
(5 publicações) & e Ledwith (2010); Rojas-Méndez, Kara e Spillan (2006) \\
\hline
\end{tabular}

Fonte: Autora (2018).

Ao analisar a Tabela 22, pode-se perceber que o determinante mais abordado é a Inovação, seguido pela Tecnologia e por último a Orientação ao Mercado. Isto identifica os pontos mais relevantes e de maiores áreas de estudos quando o assunto é desempenho operacional em pequenas empresas.

Os principais mediadores identificados foram reagrupados na Tabela $23 \mathrm{em}$ Inovação, Conhecimento, Capital humano e Fatores empreendedores, a fim de facilitar a compreensão e proporcionar uma classificação mais abrangente.

Tabela 23 - Principais mediadores encontrados e os autores que abordam o tema

\begin{tabular}{ll}
\hline Mediadores & Referências \\
\hline $\begin{array}{l}\text { Inovação } \\
\text { (5 publicações) }\end{array}$ & $\begin{array}{l}\text { Agyapong, Agyapong e Poku (2017); Hu e Mathews (2009); Liu e Chen } \\
\text { (2015); Ndubisi e Iftikhar (2012); Soni, Lilien e Wilson (1993) }\end{array}$ \\
\hline $\begin{array}{l}\text { Conhecimento } \\
\text { (3 publicações) }\end{array}$ & $\begin{array}{l}\text { Gui-Lin, Xiao-Hong e Guo-Qun (2008); Markham e Lee (2014); McAdam et } \\
\text { al. (2010) }\end{array}$ \\
\hline $\begin{array}{l}\text { Capital humano } \\
\text { (2 publicações) }\end{array}$ & Ukenna et al. (2010); Verbano e Crema (2016) \\
\hline $\begin{array}{l}\text { Fatores } \\
\text { empreendedores } \\
\text { (2 publicações) }\end{array}$ & Amir, Auzair e Amiruddin (2016); Sorooshian et al. (2011) \\
\hline
\end{tabular}

Fonte: Autora (2018).

Os principais moderadores identificados foram reagrupados na Tabela 24 em Fatores ambientais, Fatores tecnológicos, Fatores comportamentais e Tamanho da empresa.

Tabela 24 - Principais moderadores encontrados e os autores que abordam o tema 


\begin{tabular}{|c|c|}
\hline Moderadores & Referências \\
\hline $\begin{array}{l}\text { Fatores ambientais } \\
\text { (7 publicações) }\end{array}$ & $\begin{array}{l}\text { Bae e Chung (2002); Droge, Calantone e Harmancioglu (2008); Gaur, } \\
\text { Vasudevan e Gaur (2011); Hosseini e Eskandari (2013); Malmström and } \\
\text { Wincent (2012); Theriou e Chatzoudes (2015); Zhou et al. (2017) }\end{array}$ \\
\hline $\begin{array}{l}\text { Fatores tecnológicos } \\
\text { (5 publicações) }\end{array}$ & $\begin{array}{l}\text { Bae e Chung (2002); Chung, Bae e Kim (2003); Gaur, Vasudevan e Gaur } \\
\text { (2011); Jo, Park e Kang (2016); Malmström e Wincent (2012) }\end{array}$ \\
\hline \multicolumn{2}{|c|}{$\begin{array}{l}\text { Fatores comportamentais Fan et al. (2013); Pantouvakis e Patsiouras (2016); Reade e Lee (2016); } \\
\text { - tipo de cultura; estilo de Yun et al. (2016) } \\
\text { liderança; estilo de gestão } \\
\text { de conflitos; } \\
\text { empreendedorismo } \\
\text { (4 publicações) }\end{array}$} \\
\hline $\begin{array}{l}\text { Tamanho da empresa } \\
\text { (3 publicações) }\end{array}$ & Fan et al. (2013); Ndubisi e Iftikhar (2012); Sheehan e Cooper (2011) \\
\hline
\end{tabular}
Fonte: Autora (2018).

As principais variáveis de controle identificadas foram reagrupadas na Tabela 25 em Tamanho da empresa, Idade da empresa, Indústria/setor, Propriedade, Pesquisa e Desenvolvimento (P\&D), Fatores tecnológicos, Gênero, Formação e Localização.

Tabela 25 - Principais indicadores de controle encontrados e os autores que abordam o tema

\section{Controle Referências}

Tamanho da empresa

(31 publicações)

Idade da empresa

(17 publicações)

Indústria/setor
(10 publicações)

Propriedade

(6 publicações)

Agyapong, Agyapong e Poku (2017); Amara et al. (2008); Aragon-Correa e Cordon-Pozo (2005); Bae e Chung (2002); Chung, Bae e Kim (2003); Da Silveira e Sousa (2010); Ebersberger e Herstad (2013); Gaur, Vasudevan e Gaur (2011); Richey, Genchev e Daugherty (2005); Hosseini e Eskandari (2013); Huang, Lai e Huang (2015); Kongmanila e Takahashi (2010); Laforet (2009); Liu e Chen (2015); Mahmood et al. (2017); Martínez-Caro e CegarraNavarro (2010); McAdam et al. (2010); O'Dwyer e Ledwith (2010); Odoom (2016); Parida e Örtqvist (2015); Rahman, Laosirihongthong e Sohal (2010); Rawwas e lyer (2013); Reade e Lee (2016); Rosli e Sidek (2007); Sheng e Song (2013); Siqueira e Cosh (2008); Tejada e Moreno (2013); Tomlinson e Fai (2013); Verbano e Crema (2016); Yam et al. (2004); Yun et al. (2016)

Agyapong, Agyapong e Poku (2017); Amara et al. (2008); Bae e Chung (2002); Yu e Duan (2016); Gaur, Vasudevan e Gaur (2011); Hosseini e Eskandari (2013); Huang, Lai e Huang (2015); Jha e Bose (2016); Johns, Avcí e Karatepe (2004); Liu e Chen (2015); Mahmood et al. (2017); Minguela-Rata, FernándezMenéndez e Fossas-Olalla (2014); Odoom (2016); Reade e Lee (2016); Rosli e Sidek (2007); Siqueira e Cosh (2008); Urban e Greyling (2015)

Agyapong, Agyapong e Poku (2017); Fening, Pesakovic e Amaria (2008); Bala Subrahmanya (2013); Hosseini e Eskandari (2013); Huang, Lai e Huang (2015); Laforet (2009); Liu e Chen (2015); Odoom (2016); Siqueira e Cosh (2008); Urban e Greyling (2015) (2007); Sheng e Song (2013)

P\&D

(6 publicações)

Huang, Lai e Huang (2015); Jha e Bose (2016); Jo, Park e Kang (2016);

Fatores tecnológicos Amara et al. (2008); Bae e Chung (2002); Huang, Lai e Huang (2015); (5 publicações) Minguela-Rata, Fernández-Menéndez e Fossas-Olalla (2014); Verbano e Crema (2016)

Gênero $\quad$ Fening, Pesakovic e Amaria (2008); Yu e Duan (2016); Johns, Avcí e Karatepe (4 publicações) (2004); Reade e Lee (2016)

\begin{tabular}{ll}
\hline $\begin{array}{l}\text { Formação } \\
\text { (4 publicações) }\end{array}$ & $\begin{array}{l}\text { Fening, Pesakovic e Amaria (2008); Yu e Duan (2016); Johns, Avcí e Karatepe } \\
\text { (2004); Rosli e Sidek (2007) }\end{array}$ \\
\hline Localização & Guan et al. (2006); Hosseini e Eskandari (2013); Sheng e Song (2013) \\
\hline
\end{tabular}




\section{Controle Referências}

(3 publicações)

Fonte: Autora (2018).

Após a elaboração das Tabelas 22, 23, 24 e 25 encontraram-se os principais indicadores determinantes, moderadores, mediadores e de controle, além dos autores que abordam cada um desses indicadores. Dessa forma, é possível realizar uma conexão entre esses indicadores e perceber de que forma eles são abordados nas diferentes situações estudadas.

\section{3}

\section{Framework}

Após a RSL, identificaram-se algumas das variáveis encontradas na revisão preliminar que nortearam a elaboração do modelo de survey. As variáveis encontradas na RSL viabilizam a elaboração de outras hipóteses relacionadas conforme apresentado na Figura 8 , e do teste via survey das hipóteses já desenvolvidas.

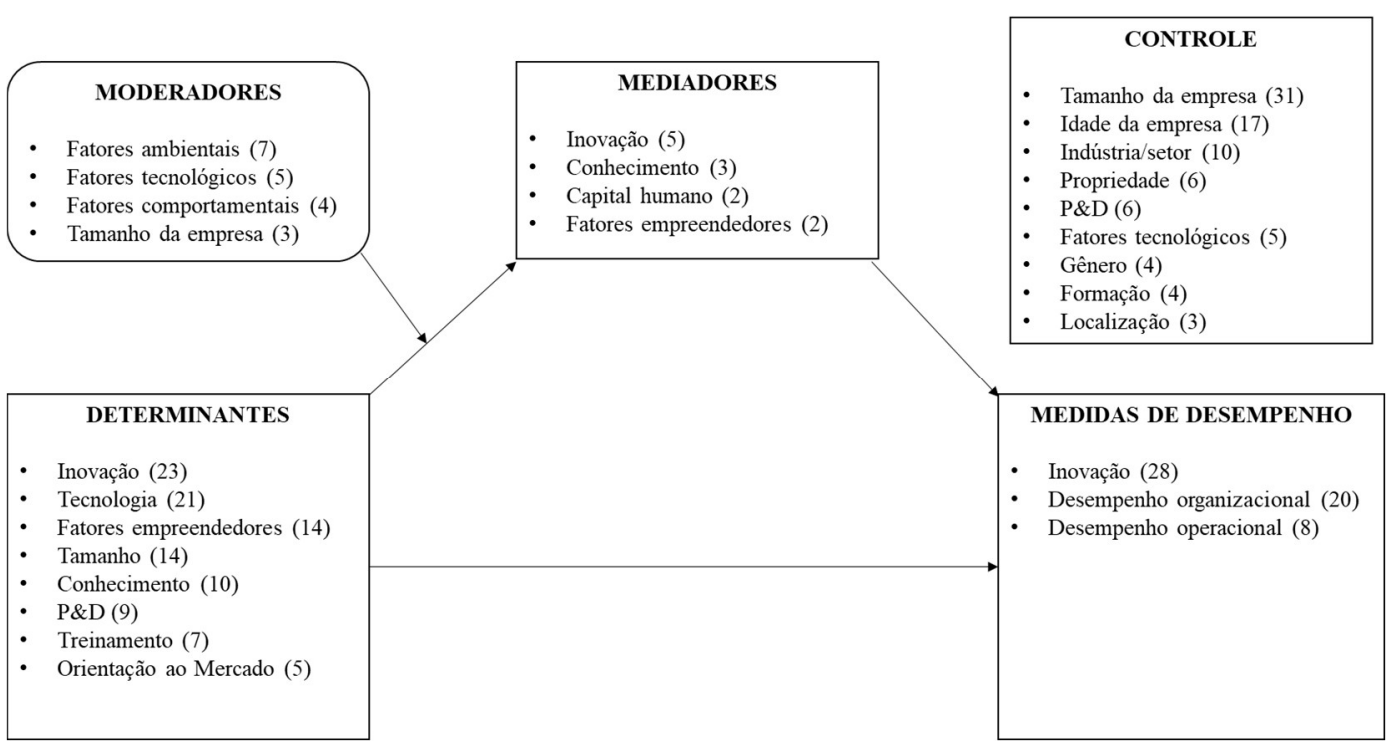

Figura 8 - Resumo das variáveis encontradas na RSL

Fonte: Autora (2018).

\section{4}

\section{Novo modelo estrutural}

Durante o teste piloto preliminar, identificou-se que os tempos de preenchimento do survey eram muito elevados, o que poderia levar a um abandono por parte do respondente. 
Optou-se então, além da modificação de algumas palavras para melhor entendimento, pela redução do questionário através da retirada do módulo de características do serviço, resultando no modelo estrutural da Figura 9.

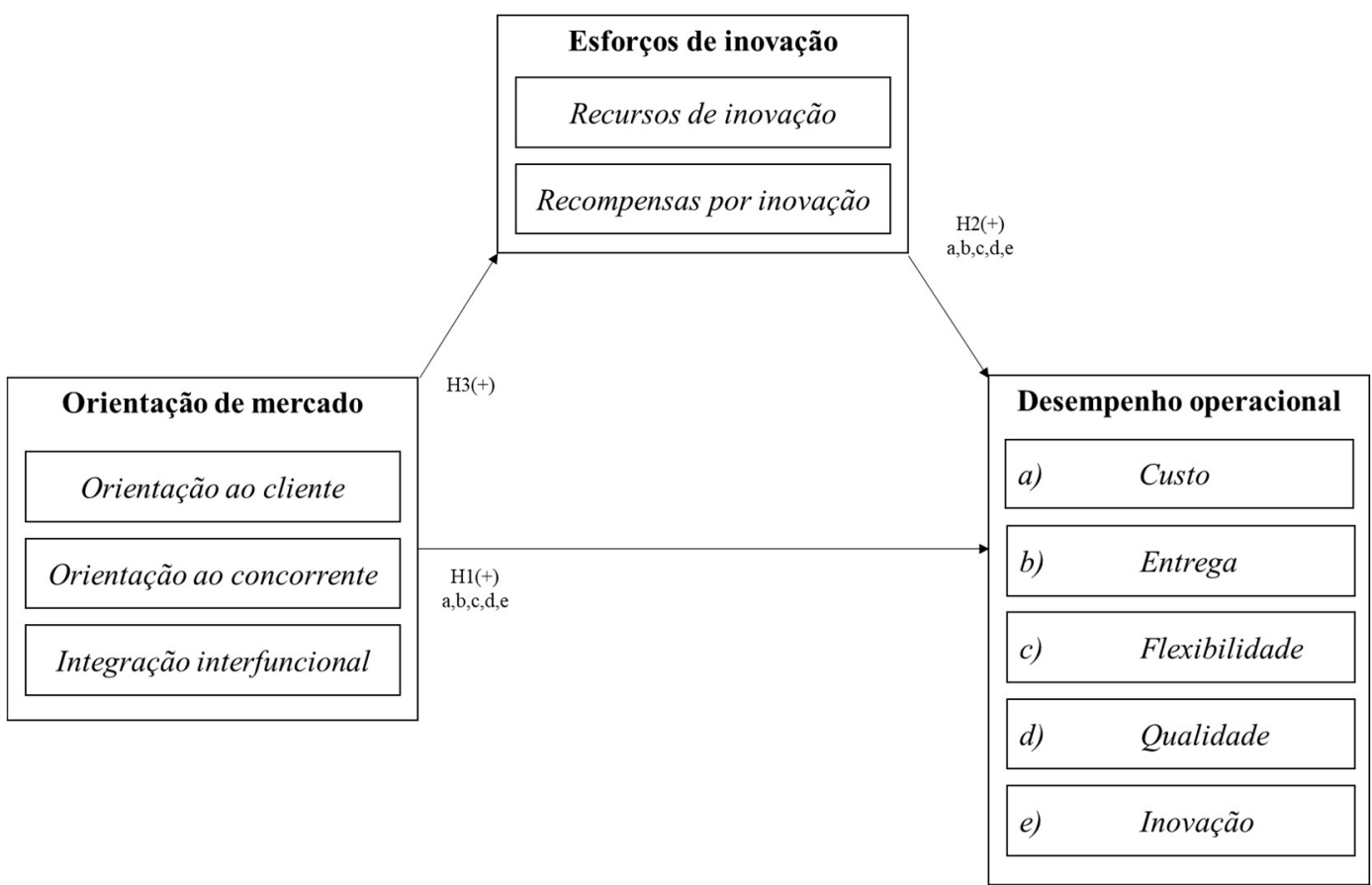

Figura 9 - Novo modelo estrutural Fonte: Autora (2018).

A hipótese "H4: Quanto maior o nível de intangibilidade, inseparabilidade, heterogeneidade e perecibilidade (características do serviço), maior será o efeito da orientação de mercado sobre o nível de esforços de inovação" foi eliminada do modelo.

Restaram para teste as seguintes hipóteses:

H1: Quanto maior o nível de orientação ao mercado, maior o desempenho operacional, em termos de a) custo, b) entrega, c) flexibilidade, d) qualidade e e) inovação

H2: Quanto maior o nível de esforços de inovação, maior o desempenho operacional, em termos de a) custo, b) entrega, c) flexibilidade, d) qualidade e e) inovação

H3: Quanto maior o nível de orientação de mercado, maior o nível de esforços de inovação.

O novo questionário já com as modificações está disposto no Apêndice III para que as etapas de Coleta de dados, Análise de dados, e Relatório sejam concluídas, além do teste piloto com um maior número de respondentes. 


\section{Conclusão}

Neste capítulo são apresentadas as considerações obtidas com a realização da pesquisa, além das principais limitações encontradas no desenvolvimento do estudo.

\section{1}

\section{Considerações sobre os resultados obtidos}

Esta dissertação abordou o tema de medição do desempenho operacional em pequenas empresas através de uma revisão sistemática da literatura que resultou numa taxonomia e um framework, além da proposta de um survey para aplicações práticas. O presente estudo tem extrema importância, pois os pequenos negócios são fundamentais para a economia dos países, especialmente em tempos de crise, e pesquisas neste contexto ainda são escassas.

O objetivo geral do trabalho foi alcançado e discutido na seção 4.2 do capítulo 4 , onde foi proposta uma taxonomia e agenda de pesquisa. Isto permitiu a identificação das principais variáveis de controle (Tamanho da empresa; Idade da empresa; Indústria/setor; Propriedade; P\&D; Fatores tecnológicos; Gênero; Formação; e Localização.), determinantes (Inovação; Tecnologia; Fatores empreendedores; Tamanho; Conhecimento; P\&D; Treinamento; e Orientação ao mercado), moderadores (Fatores ambientais; Fatores tecnológicos; Fatores comportamentais; e Tamanho da empresa), mediadores (Inovação; Conhecimento; Capital humano; e Fatores empreendedores), e medidas de desempenho em pequenas empresas, que são mensuradas através de uma ou mais dimensões do desempenho operacional dentro de outros indicadores (como nível de inovação dentro de Inovação e satisfação do consumidor dentro de Desempenho organizacional) ou a partir das próprias dimensões de desempenho operacional dentro de Desempenho operacional. Com esta classificação, foi possível criar um framework para elaboração de pesquisa mais ampla com diferentes variantes causais relacionando as variáveis encontradas. A partir do framework, um modelo causal relacionando determinantes, mediadores, 
moderadores e desempenho são propostos, respectivamente, para teste de survey aplicada a serviços em pequenas e médias empresas.

O cumprimento dos objetivos permitiu que as duas perguntas de pesquisa que nortearam essa dissertação fossem respondidas por meio da elaboração de tabelas que condensaram os principais indicadores encontrados e literatura e de que forma eles são abordados, além das diferentes nomenclaturas existentes.

Este trabalho contribui com a construção de conhecimento acerca de desempenho operacional em pequenas empresas, servindo como fonte de consulta para o desenvolvimento de teorias futuras e aplicações práticas.

\section{2}

\section{Limitações da pesquisa e propostas de trabalhos futuros}

Em relação às limitações da pesquisa, deve-se destacar o período de publicações considerados, que abrangeu até outubro de 2017. Por considerar um período específico e o possível aumento no publicações, a revisão precisa ser atualizada após um determinado tempo, considerando que a maneira de medir o desempenho em pequenas empresas, bem como as variáveis que podem influencia-lo podem mudar.

As palavras-chave utilizadas também são consideradas como limitações, pois conforme já foi citado anteriormente, os termos possuem muitos sinônimos, logo, existe a possibilidade de algum trabalho não ter sido incluído na pesquisa. Todavia, optou-se pelos termos mais abrangentes justamente para adquirir uma perspectiva geral do assunto permitindo a continuação e expansão desse trabalho. Além disso, esse trabalho abordou somente o desempenho operacional de pequenas empresas de uma maneira geral, portanto, se tivessem sido escolhidas outras categorias de empreendimento ou um setor de atuação específico, os resultados poderiam ser diferentes dos encontrados nesta dissertação. Sugere-se, para trabalhos futuros, a utilização de técnicas como o snowball para otimizar a seleção de artigos.

Sugere-re ainda a elaboração de uma revisão de literatura que aborde somente trabalhos nacionais, a fim de analisar e comparar os indicadores encontrados na pesquisa nacional aos da presente pesquisa. O contexto em que uma empresa está inserida pode influenciar a maneira como o desempenho operacional desta empresa é mensurado, assim como as variáveis relacionadas a este desempenho. 
Proposições e testes de modelos estruturais sobre as relações causais entre determinantes, mediadores, moderadores e desempenho operacional de pequenas empresas em contexto local também são incentivados. O resumo das principais variáveis dispostas da Figura 9 pode nortear a elaboração de diferentes modelos estruturais.

O questionário desenvolvido focou em empresas prestadoras de serviços e leva em consideração apenas algumas das variáveis encontradas na RSL. O teste piloto foi aplicado de forma preliminar e não testou os procedimentos para lidar com não-respondentes, dados incompletos e limpeza de dados. Os passos restantes para se completar o survey (Coleta de dados, Análise de dados, e Relatório) não foram realizados por não estarem previstos no escopo da pesquisa. O desenvolvimento de um teste piloto mais extenso com análise das escalas mediante análise fatorial exploratória para validação dos construtos seria o recomendado para continuação da pesquisa. 


\section{Referências bibliográficas}

ADAWIYAH, W. R.; PRAMUKA, B. A.; NAJMUDIN; JATI, D. P. Green Supply Chain Management and Its Impact on Construction Sector Small and Medium Enterprises (SMEs) Performance: A Case of Indonesia. International Business Management 9(6): 1018-24, 2015.

AGARWAL, S.; ERRAMILLI, M. K.; DEV, C. S. Market orientation and performance in service firms: role of innovation. Journal Of Services Marketing, v. 17, n. 1, p.68-82, 2003.

AGYAPONG, F. O.; AGYAPONG, A.; POKU, K. Nexus between social capital and performance of micro and small firms in an emerging economy: The mediating role of innovation. Cogent Business \& Management, v. 4, n. 1, p.1-20, 2017.

AIRAKSINEN, A.; LUOMARANTA, H.; ALAJÄÄSKÖ, P.; ROODHUIJZEN, $A$. Statistics on small and medium-sized enterprises: Dependent and independent SMEs and large enterprises. 2015. Disponível em: $<$ http://ec.europa.eu/eurostat/statistics-

explained/index.php/Statistics_on_small_and_mediumsized_enterprises>. Acesso em: 22 jun. 2017.

ALAM, S. S.; BHUIYAN, A. B.; JANI, F. M.; WEL, C. A. C. The impact of innovation on growth and performance of processed food SMEs in Malaysia. International Journal Of Entrepreneurship And Innovation Management, v. 20, n. 1/2, p.61-79, 2016.

ALI, J.; SHABIR, S. Does gender make a difference in business performance? Gender In Management: An International Journal, v. 32, n. 3, p.218-233, 2017.

AMARA, N.; LANDRY, R.; BECHEIKH, N.; OUIMET, M. Learning and novelty of innovation in established manufacturing SMEs. Technovation, $v$. 28, n. 7, p.450-463, 2008.

AMIR, A.; AUZAIR, S. M.; AMIRUDDIN, R. Cost Management, Entrepreneurship and Competitiveness of Strategic Priorities for Small and Medium Enterprises. Procedia - Social And Behavioral Sciences, v. 219, p.84-90, 2016.

ANDREWS, K. R. The concept of corporate strategy. New York: Richard D. Irwin, 1980. 
ARAGON-CORREA, J. A.; CORDON-POZO, E. The influence of strategic dimensions and the environment on the introduction of internet as innovation into small and medium-sized enterprises. Technology Analysis \& Strategic Management, v. 17, n. 2, p.205-218, 2005.

AUGUSTO, M. G.; LISBOA, J. V.; YASIN, M. M. Organisational performance and innovation in the context of a total quality management philosophy: an empirical investigation. Total Quality Management \& Business Excellence, v. 25, n. 9-10, p.1141-1155, 262014.

BADRI, M. A.; DAVIS, D.; DAVIS, D. Operations strategy, environmental uncertainty and performance: a path analytic model of industries in developing countries. Omega, v. 28, n. 2, p.155-173, 2000.

BAE, Z.-T.; CHUNG, J.-W. The impact of external environment and technological learning system on the relationship between technological alliance and performance of Korean small telecom firms. Picmet '01. Portland International Conference On Management Of Engineering And Technology. Proceedings Vol.1: Book of Summaries (IEEE Cat. No.01CH37199), p.741-751, 2002.

BAIN, J. S. Barriers to new competition. Cambridge: Harvard University Press, 1956.

Banco Nacional do Desenvolvimento (BNDES). Apoio às micro, pequenas e médias empresas. Gabinete da Presidência, 2015.

BARNEY, J. Firm Resources and Sustained Competitive Advantage. Journal Of Management, v. 17, n. 1, p.99-120, 1991.

BELL, S. Small and Medium Enterprises (SMEs) Finance. 2017. Disponível em: <http://www.worldbank.org/en/topic/financialsector/brief/smes-finance>. Acesso em: 22 jun. 2017.

BERISHA, G.; PULA, J. S. Defining Small and Medium Enterprises: A Critical Review. Academic Journal Of Business, Administration, Law And Social Sciences, v. 1, n. 1, p.17-28, 2015.

BIJU, P. A.; BHASI, M. A structural equation model linking forecasting, planning and controlling with SME performance. 2014 leee International Conference On Industrial Engineering And Engineering Management, p.86-105, 2014.

Boyer, K. K. Longitudinal linkages between intended and realized operations strategies. International Journal of Operations \& Production Management, v. 18, n. 4, p.356-373, 1998.

BRENTANI, U. New industrial service development: Scenarios for success and failure. Journal Of Business Research, v. 32, n. 2, p.93-103, 1995. 
CANO, C. R.; CARRILLAT, F. A.; JARAMILLO, F. A meta-analysis of the relationship between market orientation and business performance: evidence from five continents. International Journal Of Research In Marketing, v. 21, n. 2, p.179-200, 2004.

CARBONELL, P.; RODRÍGUEZ-ESCUDERO, A. I.; PUJARI, D. Customer Involvement in New Service Development: An Examination of Antecedents and Outcomes. Journal Of Product Innovation Management, v. 26, n. 5, p.536-550, 2009.

CHUNG, J.-W.; BAE, Z.-T.; KIM, J. S. Changing patterns of technological cooperation activities of innovative small firms along technological development stages in the Korean telecommunication sector. Technovation, v. 23, n. 2, p.163-173, 2003.

CORNELL UNIVERSITY; INSEAD; WIPO. The Global Innovation Index 2016: Winning with Global Innovation. 2016. Disponível em: <http://www.wipo.int/edocs/pubdocs/en/wipo_pub_gii_2016.pdf>. Acesso em: 22 jun. 2017.

CORREIA, I. M.; PETIZ, O. Firms and universities-do spillovers enhance firm's performance? International Entrepreneurship And Management Journal, v. 3, n. 2, p.145-157, 2006.

COWELL, D. W. New service development. Journal Of Marketing Management, v. 3, n. 3, p.296-312, 1988.

CRISCUOLO, C.; GAL, P. N.; MENON, C. The Dynamics of Employment Growth. Oecd Science, Technology And Industry Policy Papers, 2014.

DALMORO, M.; VIEIRA, K. M. Dilemas na Construção de Escalas Tipo Likert: o Número de Itens e a Disposição Influenciam nos Resultados? Revista Gestão Organizacional, v. 6, p.161-174, 2013.

DAY, George S.; WENSLEY, Robin. Assessing Advantage: A Framework for Diagnosing Competitive Superiority. Journal Of Marketing, v. 52, n. 2, p.1-20, 1988.

DJUPDAL, K.; WESTHEAD, P. Environmental certification as a buffer against the liabilities of newness and smallness: Firm performance benefits. International Small Business Journal, v. 33, n. 2, p.148-168, 2015.

DOSI, G.. Sources, Procedures, and Microeconomic Effects of Innovation. Journal Of Economic Literature, v. 26, n. 3, p.1120-1171, 1988.

DOUGHERTY, D.; HARDY, C. Sustained product innovation in large, mature organizations: overcoming innovation-to-organization problems. Academy of Management Journal, v. 39, n. 5, p.1120-1153, 1996. 
DROGE, C.; CALANTONE, R.; HARMANCIOGLU, N. New Product Success: Is It Really Controllable by Managers in Highly Turbulent Environments? Journal Of Product Innovation Management, v. 25, n. 3 , p.272-286, 2008.

EBERSBERGER, B.; HERSTAD, S. J. The relationship between international innovation collaboration, intramural R\&D and SMEs' innovation performance: a quantile regression approach. Applied Economics Letters, v. 20, n. 7, p.626-630, 2013.

FAN, P.; LIANG, Q.; LIU, H.; HOU, M. The moderating role of context in managerial ties-firm performance link: a meta-analytic review of mainly Chinese-based studies. Asia Pacific Business Review, v. 19, n. 4, p.461489, 2013.

FENING, F. A.; PESAKOVIC, G.; AMARIA, P. Relationship between quality management practices and the performance of small and medium size enterprises (SMEs) in Ghana. International Journal Of Quality \& Reliability Management, v. 25, n. 7, p.694-708, 2008.

FERDOWS, K.; DE MEYER, A. Lasting improvements in manufacturing performance: In search of a new theory. Journal of Operations Management, v. 9, n. 2, p.168-184, 1990.

FERNANDES, A. M.; FREUND, C.; PIEROLA, M. D. Exporter behavior, country size and stage of development: Evidence from the exporter dynamics database. Journal Of Development Economics, v. 119, p.121137, 2016.

FITZGERALD, L. ; JOHNSTON, R. ; BRIGNALL, T. J. ; SILVESTRO, R. ; VOSS, C. Performance measurement in service businesses. London: CIMA, 1991.

FORZA, C. Survey research in operations management: a process-based perspective. International Journal of Operations \& Production Management, v. 22, n. 2, p. 152-194, 2002.

FOSS, N. J. Research in strategy, economics, and Michael Porter. Journal of Management Studies, v. 33, n. 1, p.1-24, 1996.

GARVIN, D. A. Competing on the Eight Dimensions of Quality. 1987. Disponível em: <https://hbr.org/1987/11/competing-on-the-eightdimensions-of-quality>. Acesso em: 22 jun 2017.

GAUR, S. S.; VASUDEVAN, H.; GAUR, A. S. Market orientation and manufacturing performance of Indian SMEs. European Journal Of Marketing, v. 45, n. 7/8, p.1172-1193, 2011.

GHOLAMI, M. H.; ASLI, M. N.; NAZARI-SHIRKOUHI, S.; NORUZY, A. Investigating the Influence of Knowledge Management Practices on Organizational Performance: An Empirical Study. Acta Polytechnica Hungarica, v. 10, n. 2, p.205-216, 2013. 
GONÇALVES. C. A.; COELHO, M. F.; SOUZA. E. M. Vantagem competitiva sustentável pela organização. Rev. Cienc. Adm., Fortaleza, v. 17, n. 3, pp.819-855, 2011.

GONZALEZ, A. Entrepreneurs and Small Businesses Spur Economic Growth and Create Jobs. 2016. Disponível em: <http://www.worldbank.org/en/news/feature/2016/06/20/entrepreneursand-small-businesses-spur-economic-growth-and-create-jobs>. Acesso em: 22 jun. 2017.

GUAN, J. C.; MOK, C. K. ; YAM, R. C. M.; CHIN, K. S.; PUN, K. F. Technology transfer and innovation performance: Evidence from Chinese firms. Technological Forecasting And Social Change,v. 73, n. 6, p.666678, 2006.

GUI-LIN, G; XIAO-HONG, Z.; GUO-QUN, H. An empirical research on R\&D project management standardization and corresponding countermeasures. 2007 leee International Engineering Management Conference, p.124-129, 2008.

HALLGREN, M. ; OLHAGER, J. Lean and agile manufacturing: external and internal drivers and performance outcomes. International Journal of Operations \& Production Management, v. 29, n. 10, p.976-999, 2009.

HAN, J. K.; KIM, N.; SRIVASTAVA, R. K. Market Orientation and Organizational Performance: Is Innovation a Missing Link? Journal Of Marketing, v. 62, n. 4, p.30-45, 1998.

HAYEK, F.A. Economics and Knowledge. Economica, 4, p. 33-54, 1937.

HEIMONEN, T. What are the factors that affect innovation in growing SMEs? European Journal Of Innovation Management, v. 15, n. 1, p.122144, 2012.

HENARD, D. H.; SZYMANSKI, D. M. Why some new products are more successful than others. Journal of Marketing Research, v. 38, n. 3, p. 362-375, 2001.

HILMI, M. F.; RAMAYAH, T.; MUSTAPHA, Y.; PAWANCHIK, S.; AYUB, M. A. Strategic and Behavioral Innovativeness of Malaysian SMEs: Preliminary Results from a First Wave Data Collection. The International Journal Of Interdisciplinary Social Sciences, v. 5, n. 8, 2010.

HOSSEINI, M.; ESKANDARI, F. Investigating Entrepreneurial Orientation and Firm Performance in the Iranian Agricultural Context. Journal Of Agricultural Science And Technology, v. 15, n. 2, p.203-214, 2013.

HSIEH, C.-T.; OLKEN, B. The Missing "Missing Middle". Journal Of Economic Perspectives, v. 28, n. 3, p.89-108, 2014. 
HU, M.-C.; MATHEWS, J. A. Estimating the innovation effects of universityindustry-government linkages: The case of Taiwan. Journal of Management \& Organization, v. 15, n. 02, p.138-154, 2009.

HUANG, H-C; LAI, M-C; HUANG, W-W. Resource complementarity, transformative capacity, and inbound open innovation. Journal Of Business \& Industrial Marketing, v. 30, n. 7, p.842-854, 2015.

JAW, C; LO, J-Y; LIN, Y.-H. The determinants of new service development: Service characteristics, market orientation, and actualizing innovation effort. Technovation, v. 30, n. 4, p.265-277, 2010.

JHA, A. K.; BOSE, I. Innovation in IT firms: An investigation of intramural and extramural R\&D activities and their impact. Information \& Management, v. 53, n. 4, p.409-421, 2016.

JING, F. F. Leadership paradigms and performance in small service firms. Journal Of Management \& Organization, v. 24, n. 03, p.339-358, 2017.

JO, G. S.; PARK, G.; KANG, J. Unravelling the link between technological $M \& A$ and innovation performance using the concept of relative absorptive capacity. Asian Journal Of Technology Innovation, v. 24, n. 1, p.55-76, 2016.

JOHNS, N.; AVCÍ, T.; KARATEPE, O. M. Measuring service quality of travel agents: evidence from Northern Cyprus. The Service Industries Journal, v. 24, n. 3, p.82-100, 2004.

JONES, P.; BEYNON, M. J.; PICKERNELL, D.; PACKHAM, G. Evaluating the impact of different training methods on SME business performance. Environment And Planning C: Government and Policy, v. 31, n. 1, p.56-81, 2013.

KEIZER, J. A.; DIJKSTRA, L.; HALMAN, Johannes I. M. Explaining innovative efforts of SMEs. Technovation, v. 22, n. 1, p.1-13, 2002.

KELLY, D. ; STOREY, C. New service development: initiation strategies International Journal of Service Industry Management, v. 11, n. 1, p.4562, 2000.

KETOKIVI, M.; SCHROEDER, R. Manufacturing practices, strategic fit and performance. International Journal Of Operations \& Production Management, v. 24, n. 2, p.171-191, 2004.

KHALIQUE, M.; PABLOS, P. O. Intellectual capital and performance of electrical and electronics SMEs in Malaysia. International Journal of Learning And Intellectual Capital, v. 12, n. 3, p.251-269, 2015.

KIM, J. S.; ARNOLD, P. Manufacturing competence and business performance: a framework and empirical analysis. International Journal of Operations \& Production Management, v. 13, n. 10, p.4-25, 1992. 
KIRCA, A. H.; JAYACHANDRAN, S.; BEARDEN, W. O. Market Orientation: A Meta-Analytic Review and Assessment of Its Antecedents and Impact on Performance. Journal Of Marketing, v. 69, n. 2, p.24-41, 2005.

KNIGHT, G. A.; CAVUSGIL, S. T. Innovation, organizational capabilities, and the born-global firm. Journal Of International Business Studies, v. 35, n. 4, p.334-334, 2004.

KOHLI, A. K.; JAWORSKI, B. J. Market Orientation: The Construct, Research Propositions, and Managerial Implications. Journal Of Marketing, v. 54, n. 2, p.1-18, 1990.

KONGMANILA, X.; TAKAHASHI, Y. Determinants of Subcontracting and Firm Performance in Lao PDR: Evidence from a Garment Industry Cluster. Asia Pacific Management Review, v. 15, n. 1, p.97-112, 2010.

KUSHNIR, K.; MIRMULSTEIN, M. L.; RAMALHO, R. Micro, Small, and Medium Enterprises Around the World: How Many Are There, and What Affects the Count?, 2010. Disponivel em: <https://www.ifc.org/wps/wcm/connect/9ae1dd80495860d6a482b519583b 6d16/MSME-Cl-AnalysisNote.pdf?MOD=AJPERES>. Acesso em: 22 jun. 2017.

LAFORET, S. Effects of size, market and strategic orientation on innovation in non-high-tech manufacturing SMEs. European Journal Of Marketing, v. 43, n. 1/2, p.188-212, 2009.

LIEVENS, A.; MOENAERT, R. K. Project Team Communication in Financial Service Innovation. Journal Of Management Studies, v. 37, n. 5, p.733766, 2000.

LIU, T.-C.; CHEN, Y.-J. Strategy orientation, product innovativeness, and new product performance. Journal Of Management \& Organization, $v$. 21, n. 01, p.2-16, 2015.

MAHMOOD, I. P.; MITCHELL, W. Two faces: effects of business groups on innovation in emerging economies. Management Science. v. 50, n. 10, p.1348-1365, 2004.

MAHMOOD, R.; ROSLI, M. M. Microcredit position in micro and small enterprise performance: the Malaysian case. Management Research Review, v. 36, n. 5, p.436-453, 2013.

MAHMOOD, R., ZAHARI, A. S. M.; YAACOB, N. M.; ZIN, S. M. Small firm performance: an empirical analysis in Malaysian housing construction industry. International Journal Of Housing Markets And Analysis, v. 10, n. 1, p.50-65, 2017.

MALMSTRÖM, M.; WINCENT, Joakim. Modelling competence acquisition in small firms. International Journal Of Entrepreneurship And Innovation Management, v. 15, n. 1/2, p.131, 2012. 
MARKHAM, S. K.; LEE, H. Marriage and Family Therapy in NPD Teams: Effects of We-ness on Knowledge Sharing and Product Performance. Journal Of Product Innovation Management, v. 31, n. 6 , p.1291-1311, 2014.

MARKIČ, M.; LIKAR, B.; MEŠKO, M.; RAŠIČ, K.; ŽIVKOVIĆ, S. Innovation policy and successfulness of micro and small companies in the Republic of Slovenia. African Journal Of Business Management, v. 5, n. 22, p.95599567, 2011.

MARTÍNEZ-CARO, Eva; CEGARRA-NAVARRO, Juan Gabriel. The impact of e-business on capital productivity. International Journal Of Operations \& Production Management, v. 30, n. 5, p.488-507, 2010.

MASON, E. Price and production policies of large-scale enterprise. American Economic Review, v. 1, n. 29, p. 61-74, 1939.

MCADAM, R.; MOFFETT, S.; HAZLETT, S. A.; SHEVLIN, M. Developing a model of innovation implementation for UK SMEs: A path analysis and explanatory case analysis. International Small Business Journal, v. 28, n. 3, p.195-214, 2010.

MEDRANO, N.; OLARTE-PASCUAL, C. An empirical approach to marketing innovation in small and medium retailers: an application to the Spanish sector. Contemporary Economics, v. 10, n. 3, p.205-216, 30 2016.

MEGICKS, P.; MISHRA, A.; LEAN, J. Enhancing microfinance outreach through market-oriented new service development in Indian regional rural banks. International Journal Of Bank Marketing, v. 23, n. 1, p.107-125, 2005.

MENDES, G. H. S.; GANGA, G. M. D. Predicting Success in Product Development: The Application of Principal Component Analysis to Categorical Data and Binomial Logistic Regression. Journal Of Technology Management \& Innovation, v. 8, n. 3, p.15-16, 2013.

MINGUELA-RATA, B.; FERNÁNDEZ-MENÉNDEZ, J.; FOSSAS-OLALLA, $M$. Cooperation with suppliers, firm size and product innovation. Industrial Management \& Data Systems, v. 114, n. 3, p.438-455, 2014.

MISES, L. V. Economic calculation in a socialist commonwealth. In : Hayek, F. A. (ed.), Collectivist Economic Planning. Londres: Routledge, 1920.

MONGEON, P.; PAUL-HUS, A. The journal coverage of Web of Science and Scopus: a comparative analysis. Scientometrics, v. 106, n. 1, p.213228, 2015.

MULROW, C. D. Systematic reviews - Rationale for systematic reviews. British Medical Journal, v. 309, n. 6954, p. 597-599, 1994. 
NAKANE, Jinichiro; HALL, Robert W. Holonic manufacturing: flexibility-the competitive battle in the 1990s. Production Planning \& Control, v. 2, n. 1 , p.2-13, 1991.

NARVER, John C.; SLATER, Stanley F. The Effect of a Market Orientation on Business Profitability. Journal Of Marketing, v. 54, n. 4, p.20-35, 1990.

NDUBISI, N. O.; IFTIKHAR, K. Relationship between entrepreneurship, innovation and performance. Journal Of Research In Marketing And Entrepreneurship, v. 14, n. 2, p.214-236, 2012.

NELSON, R. R. Why do firms differ, and how does it matter. Strategic Management Journal, v. 12, p. 61-74, 1991.

NIJSSEN, E. J.; HILLEBRAND, B.; VERMEULEN, P. A. M.; KEMP, R. G. $M$. Exploring product and service innovation similarities and differences. International Journal Of Research In Marketing, v. 23, n. 3, p.241-251, 2006.

NOBLE, M. A. Manufacturing Strategy: Testing the Cumulative Model in a Multiple Country Context. Decision Sciences, v. 26, n. 5, p.693-721, 1995.

O'DWYER, M.; LEDWITH, A. Size matters: market orientation and NPD in small and large firms. International Journal Of Product Development, v. 12, n. 2, p.107, 2010.

ODOOM, R. Brand-building efforts in high and low performing small and medium-sized enterprises (SMEs). Journal Of Small Business And Enterprise Development, v. 23, n. 4, p.1229-1246, 2016.

OECD. Small and Medium-sized Enterprises: Local Strength, Global Reach. $2000 . \quad$ Disponível em: <http://www.oecd.org/regional/leed/1918307.pdf>. Acesso em: 22 jun. 2017.

OECD. Oslo Manual: Guidelines for Collecting and Interpreting Innovation Data. 2005. Disponivel em: <https://www.oecdilibrary.org/science-and-technology/oslo-manual_9789264013100-en>. Acesso em: 22 jun. 2017.

OTTENBACHER, M.; GNOTH, J. How to Develop Successful Hospitality Innovation. Cornell Hotel And Restaurant Administration Quarterly, v. 46, n. 2, p.205-222, 2005.

PANTOUVAKIS, A.; PATSIOURAS, C. Exploring the role of leadership style on the service quality-customer satisfaction link. International Journal Of Quality And Service Sciences, v. 8, n. 1, p.88-101, 2016.

PAPASTATHOPOULOS, A.; BENEKI, C. Does Entrepreneurial Experience and Strategy Really Matter for ICT Performance? A Greek Cross-Border Empirical Study. The Electronic Journal Information Systems Evaluation, v. 13, n. 2, p.177-186, 2010. 
PAPULA, J.; VOLNÁ, J.; HUI'VEJ, J. Knowledge Networks as a Source of Knowledge Initiatives and Innovation Activity in Small and Medium Enterprises: Regression Analysis for EU 27 Countries. Proceedings Of International Conference Kdir 2013 And Kmis 2013, Algarve, p.389-396, 2013.

PARASURAMAN, A.; ZEITHAML, Valarie A.; BERRY, Leonard L. SERVQUAL: A multiple-itemscale for measuring consumer perceptions of service quality. Journal Of Retailing, v. 64, n. 1, p.12-40, 1988.

PARIDA, V.; ÖRTQVIST, D. Interactive Effects of Network Capability, ICT Capability, and Financial Slack on Technology-Based Small Firm Innovation Performance. Journal Of Small Business Management, v. 53, p.278-298, 2015.

PENROSE, E. T. Facteurs, conditions et mécanismes de la croissance de l'entreprise. Neuilly-sur-Seine: Editions Hommes et Techniques, 1959/1963.

PODSAKOFF, P. M. ; MACKENZIE, S. B. ; LEE, J. Y. ; PODSAKOFF, N. P. Common method biases in behavioral research: A critical review of the literature and recommended remedies. Journal of Applied Psychology, v. 88, n. 5, p.879-903, 2003.

PORTER, M. E. Competitive strategy: techniques for analysing industries and competitors. New York : Free Press, 1980.

PORTER, M. E. Competitive advantage: creating and sustaining competitive performance. New York: Free Press, 1985.

PORTER, M. E. The competitive advantage of nations. New York : Free Press, 1990.

POWER, D.; SCHOENHERR, T.; SAMSON, D. The cultural characteristic of individualism/collectivism: A comparative study of implications for investment in operations between emerging Asian and industrialized Western countries. Journal of Operations Management, v. 28, n. 3, p.206222, 2010.

PRAJAPATI, K.; BISWAS, S. N. Effect of Entrepreneur Network and Entrepreneur Self-efficacy on Subjective Performance. The Journal Of Entrepreneurship, v. 20, n. 2, p.227-247, 2011.

QUAGGIO, F. M.; SILVA, M. T. Professional services redesign: a challenge to new service development models. Brazilian Journal Of Operations \& Production Management, v. 12, n. 1, p.40-47, 2015.

RADAS, S.; BOžlć, L. The antecedents of SME innovativeness in an emerging transition economy. Technovation, v. 29, n. 6-7, p.438-450, 2009. 
RAHMAN, S.; LAOSIRIHONGTHONG, T.; SOHAL, A. S. Impact of lean strategy on operational performance: a study of Thai manufacturing companies. Journal Of Manufacturing Technology Management, v. 21, n. 7, p.839-852, 2010.

RAWWAS, M. Y. A.; IYER, K. N. S. How do small firms possibly survive? A comparison study of marketing skills and logistics infrastructure of small and large wholesalers. International Business Review, v. 22, n. 4, p.687-698, 2013.

READE, C.; LEE, H.-J. Does ethnic conflict impede or enable employee innovation behavior? International Journal Of Conflict Management, v. 27, n. 2, p.199-224, 2016.

RIBEIRO NETO, A. B. Fatores que impactam o desempenho de pequenas empresas. 2008. 379 f. Tese (Doutorado) - Curso de Engenharia de Produção, Universidade Federal do Rio de Janeiro, Rio de Janeiro, 2008.

RICHEY, R. G.; GENCHEV, S. E.; DAUGHERTY, P. J. The role of resource commitment and innovation in reverse logistics performance. International Journal Of Physical Distribution \& Logistics Management, v. 35, n. 4, p.233-257, 2005.

RODRÍGUEZ, M. J.; GUZMÁN, C. Innovation in social economy firms. Management Decision, v. 51, n. 5, p.986-998, 2013.

ROJAS-MÉNDEZ, J. I.; KARA, A.; SPILLAN, J. E. Market Orientation in the Chilean Small Business Context. Journal Of Global Marketing, v. 19, n. 34, p.93-132, 2006.

ROSLI, M. M.; SIDEK, S. Innovation and Firm Performance: Evidence from Malaysian Small and Medium Enterprises. Entrepreneurship Vision 2020: Innovation, Development Sustainability, And Economic Growth, p.794809, 2007.

RUSHTON, A. M.; CARSON, D. J. The Marketing of Services: Managing the Intangibles. European Journal Of Marketing, v. 19, n. 3, p.19-40, 1985.

SCHOENHERR, T. The role of environmental management in sustainable business development: A multi-country investigation. International Journal Of Production Economics, v. 140, n. 1, p.116-128, 2012.

SCHUMPETER, J. A. The Theory of Economic Development: an inquiry into profits, capital, credit, interest and the business cycle. Cambridge, MA: Harvard University Press, 1934/1955.

SEBRAE. Participação das Micro e Pequenas Empresas na Economia Brasileira: RELATÓRIO EXECUTIVO. Brasília: Sebrae, 52 p., 2015. 
SEBRAE. Pequenos negócios em números. Disponível em: $<$ http://www.sebrae.com.br/sites/PortalSebrae/ufs/sp/sebraeaz/pequenosnegocios-em-

numeros,12e8794363447510VgnVCM1000004c00210aRCRD> Acesso em: 14 set. 2018.

SEBRAE. Lei geral das micro e pequenas empresas. 2018. Disponível

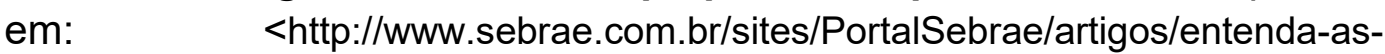
diferencas-entre-microempresa-pequena-empresa-e-

mei,03f5438af1c92410VgnVCM100000b272010aRCRD>. Acesso em: 14 set. 2018.

SELZNICK, P. Leadership and administration. New York: Harper \& Row, 1957.

SERRA, F. A. R.; TORRES, A. P.; TORRES, M. C. S. Administração estratégica: conceito, roteiros práticos e casos. Rio de Janeiro: Reichmann \& Affonso Editores, 2004.

SHEEHAN, C.; COOPER, B. K. HRM outsourcing: the impact of organisational size and HRM strategic involvement. Personnel Review, v. 40, n. 6, p.742-760, 2011.

SHENG, Y.; SONG, L. Re-estimation of firms' total factor productivity in China's iron and steel industry. China Economic Review, v. 24, p.177-188, 2013.

SILVEIRA, G. J. C.; SOUSA, R. S. Paradigms of choice in manufacturing strategy. International Journal Of Operations \& Production Management, v. 30, n. 12, p.1219-1245, 2010.

SINGH, D.; KHAMBA, J. S.; NANDA, T.. Influence of technological innovation on performance of small manufacturing companies. International Journal Of Productivity And Performance Management, v. 66, n. 7, p.838-856, 2017.

SINHA, N.; GARG, A. K.; DHALL, N. Effect of TQM principles on performance of Indian SMEs: the case of automotive supply chain. The Tqm Journal, v. 28, n. 3, p.338-359, 2016.

SIQUEIRA, A. C. O.; COSH, A. D. Effects of product innovation and organisational capabilities on competitive advantage: evidence from UK small and medium manufacturing enterprises. International Journal Of Innovation Management, v. 12, n. 02, p.113-137, 2008.

SITKIN, S. B. Learning Through Failure: the strategy of small losses. Research In Organizational Behavior, v. 14, p.231 - 266, 1992.

SMITH, A. M.; FISCHBACHER, M.; WILSON, F. A. New Service Development: From Panoramas to Precision. European Management Journal, v. 25, n. 5, p.370-383, 2007. 
SONI, P. K.; LILIEN, G. L.; WILSON, D. T. Industrial innovation and firm performance: A re-conceptualization and exploratory structural equation analysis. International Journal Of Research In Marketing, v. 10, n. 4, p.365-380, 1993.

SOROOSHIAN, S.; ZULKIFLI, N.; ISMAIL, M. Y.; MOHD, R. Y. Novel performance modelling in small and medium-sized enterprises in the pistachio industry. African Journal Of Business Management, v. 5, n. 10, p.3828-3833, 2011.

STOREY, C.; HULL, F. M. Service development success: a contingent approach by knowledge strategy. Journal Of Service Management, v. 21, n. 2, p.140-161, 2010.

SUBRAHMANYA, M. H. B. Why do only some SMEs achieve external support for better innovation performance: empirical evidence from Bangalore, India. Asian Journal Of Technology Innovation, v. 21, n. 1, p.21-33, 2013.

SUBRAMANIAM, C.; SHAMSUDIN, F. M.; IBRAHIM, H. Linking Human Resource Practices and Organisational Performance: Evidence from Small and Medium Organisations in Malaysia. Jurnal Pengurusan, v. 32, p.2737, 2011.

SWAIT, J.; ADAMOWICZ, W. The influence of task complexity on consumer choice: a latent class model of decision strategy switching. Journal of Consumer Research, v. 28, n. 1, p. 135-148, 2001.

TEJADA, P.; MORENO, P. Patterns of innovation in tourism 'Small and Medium-size Enterprises'. The Service Industries Journal, v. 33, n. 7-8, p.749-758, 2013.

TEECE, D. J. Economic analysis and strategic management. California Management Review, v. 26, n. 3, p. 87-110, 1984.

THERIOU, G.; CHATZOUDES, D. Exploring the entrepreneurshipperformance relationship: evidence from Greek SMEs. Journal Of Small Business And Enterprise Development, v. 22, n. 2, p.352-375, 2015.

THOMÉ, A. M. T.; SCAVARDA, L. F.; SCAVARDA, A. J. Conducting systematic literature review in operations management. Production Planning \& Control, v. 27, n. 5, p.408-420, 2016.

TOMLINSON, P. R.; FAI, F. M. The nature of SME co-operation and innovation: A multi-scalar and multi-dimensional analysis. International Journal Of Production Economics, v. 141, n. 1, p.316-326, 2013.

TORRACO, R. J. Writing integrative literature reviews: guidelines and examples. Human Resource Development Review, v. 4, n. 3, p.356-367, 2005. 
TSE, A. C. B.; SIN, L. Y. M.; YAU, O. H. M.; LEE, J. S. Y.; CHOW, R. Market orientation and business performance in a Chinese business environment. Journal Of Business Research, v. 56, n. 3, p.227-239, 2003.

TSIOTSOU, R. H. Delineating the effect of market orientation on services performance: a component-wise approach. The Service Industries Journal, v. 30, n. 3, p.375-403, 2009.

UKENNA, S.; IJEOMA, N.; ANIONWU, C.; OLISE, M. C. Effect of Investment in Human Capital Development on Organisational Performance: Empirical Examination of the Perception of Small Business Owners in Nigeria. European Journal Of Economics, Finance And Administrative Sciences, v. 26, p.93-107, 2010.

URBAN, B.; GREYLING, B. C. Open source software adoption and links to innovation performance. International Journal Of Technological Learning, Innovation And Development, v. 7, n. 3, p.261, 2015.

VALENTINE, J. C. Judging the quality of primary research. In: COOPER, H.; HEDGES, L. V.; VALENTINE, J. C. The handbook of research synthesis and meta-analysis. Nova York: Russell Sage Foundation, $p$. 129-146, 2009.

VASCONCELOS, F. C.; CYRINO, A. B. Vantagem competitiva: os modelos teóricos atuais e a convergência entre estratégia e teoria organizacional. Revista de Administração de Empresas, v. 40, n. 4, p.2037, 2000.

VERBANO, C.; CREMA, M. Linking technology innovation strategy, intellectual capital and technology innovation performance in manufacturing SMEs. Technology Analysis \& Strategic Management, v. 28, n. 5, p.524540, 2015.

WARD, P. T.; MCCREERY, J. K.; RITZMAN, L. P.; SHARMA, D. Competitive Priorities in Operations Management. Decision Sciences, $v$. 29, n. 4, p.1035-1046, 1998.

WEATHERS, D.; SHARMA, S.; NIEDRICH, R. W. The impact of the number of scale points, dispositional factors, and the status quo decision heuristic on scale reliability and response accuracy. Journal of Business Research, v. 58, n. 11 SPEC. ISS., p.1516-1524, 2005.

WINTER, S. On Coase, competence, and the corporation. Journal of Law, Economics, and Organization, v. 4, p. 163-180, 1988.

WOO, Y. Y.; HSU, S.-L.; WU, S. An integrated inventory model for a single vendor and multiple buyers with ordering cost reduction. International Journal of Production Economics, v. 73, p.203-215, 2001.

World Trade Organization (WTO). Annual Report. Genebra: WTO. 188 p., 2016. 
YAM, R. C. M.; GUAN, J. C.; PUN, K. F.; TANG, E. P. Y. An audit of technological innovation capabilities in chinese firms: some empirical findings in Beijing, China. Research Policy, v. 33, n. 8, p.1123-1140, 2004.

YU, D.; DUAN, Y. The Impact of Regional Soft Environment on SME Performance in China: Considering the Moderating Effect of Firm Life Cycle. Proceedings Of The 2016 International Symposium On Business Cooperation And Development, p.9-17, 2016.

YUN, J. J.; PARK, K.; KIM, J.; YANG, J. Open Innovation Effort, Entrepreneurship Orientation and their Synergies onto Innovation Performance in SMEs of Korea. Science, Technology And Society, v. 21, n. 3, p.366-390, 2016.

ZEITHAML, V. A.; PARASURAMAN, A.; BERRY, L. L. Problems and Strategies in Services Marketing. Journal Of Marketing, v. 49, n. 2, p.3346, 1985.

ZHOU, Q.; FANG, G.; YANG, W.; WU, Y.; REN, L. The performance effect of micro-innovation in SMEs: evidence from China. Chinese Management Studies, v. 11, n. 1, p.123-138, 2017. 


\section{APÊNDICE I - Operacionalização dos construtos a partir da literatura}

Tabela 26 - Dimensões do desempenho operacional em pequenas empresas

\begin{tabular}{|c|c|}
\hline DIMENSÃO & CONSTRUTO/VARIÁVEL \\
\hline \multirow{12}{*}{$\begin{array}{l}\text { Característica } \\
\text { do serviço }\end{array}$} & Intangibilidade \\
\hline & $\begin{array}{l}\text { O conceito deste serviço é de difícil } \\
\text { entendimento para os clientes. }\end{array}$ \\
\hline & $\begin{array}{l}\text { É difícil ilustrar o conteúdo exato ou o } \\
\text { significado desse serviço para o cliente. }\end{array}$ \\
\hline & $\begin{array}{l}\text { É difícil comunicar as vantagens exatas } \\
\text { deste serviço ao cliente. }\end{array}$ \\
\hline & $\begin{array}{l}\text { O cliente tem poucas evidências tangíveis } \\
\text { durante a entrega do serviço } \\
\text { (equipamentos, pessoal, tecnologias da } \\
\text { informação). }\end{array}$ \\
\hline & Inseparabilidade \\
\hline & $\begin{array}{l}\text { A produção e o consumo desse serviço } \\
\text { ocorrem simultaneamente. }\end{array}$ \\
\hline & $\begin{array}{l}\text { O processo de produção do serviço é } \\
\text { visível para o cliente. }\end{array}$ \\
\hline & $\begin{array}{l}\text { Este serviço é prestado em contato direto } \\
\text { com o cliente. }\end{array}$ \\
\hline & Heterogeneidade \\
\hline & $\begin{array}{l}\text { A realização dos serviços é personalizada: } \\
\text { dependendo do cliente, o serviço é } \\
\text { realizado de maneira diferente }\end{array}$ \\
\hline & $\begin{array}{l}\text { Não há uma maneira única de se realizar } \\
\text { este serviço, depende do contato com o } \\
\text { cliente. } \\
\text { A qualidade da prestação do serviço pode } \\
\text { variar de um cliente para o outro. }\end{array}$ \\
\hline
\end{tabular}

\begin{tabular}{ll}
\hline Perecibilidade & Jaw, Lo e Lin (2010); Kelly e \\
& Storey (2000); Lievens e \\
& Moenaert (2000); Rushton e \\
& Carson (1985)
\end{tabular}

Este serviço pode gerar problemas de Brentani (1995); Jaw, Lo e Lin (2010); Lievens e Moenaert (2000); Zeithaml, Parasuraman e Berry (1985)

Lievens e Moenaert (2000)

Cowell (1988); Jaw, Lo e Lin (2010); Lievens e Moenaert (2000); Zeithaml, Parasuraman e Berry (1985) capacidade: não podemos armazenar este serviço.

A demanda por este serviço excede a capacidade do pessoal para realizar o serviço.

A demanda por este serviço não está alinhada com a capacidade de realização deste serviço.

\begin{tabular}{ll}
\hline $\begin{array}{l}\text { Orientação ao } \\
\text { mercado }\end{array}$ & Orientação para o cliente \\
& $\begin{array}{l}\text { A satisfação do cliente é o objetivo do } \\
\text { nosso negócio. }\end{array}$
\end{tabular}




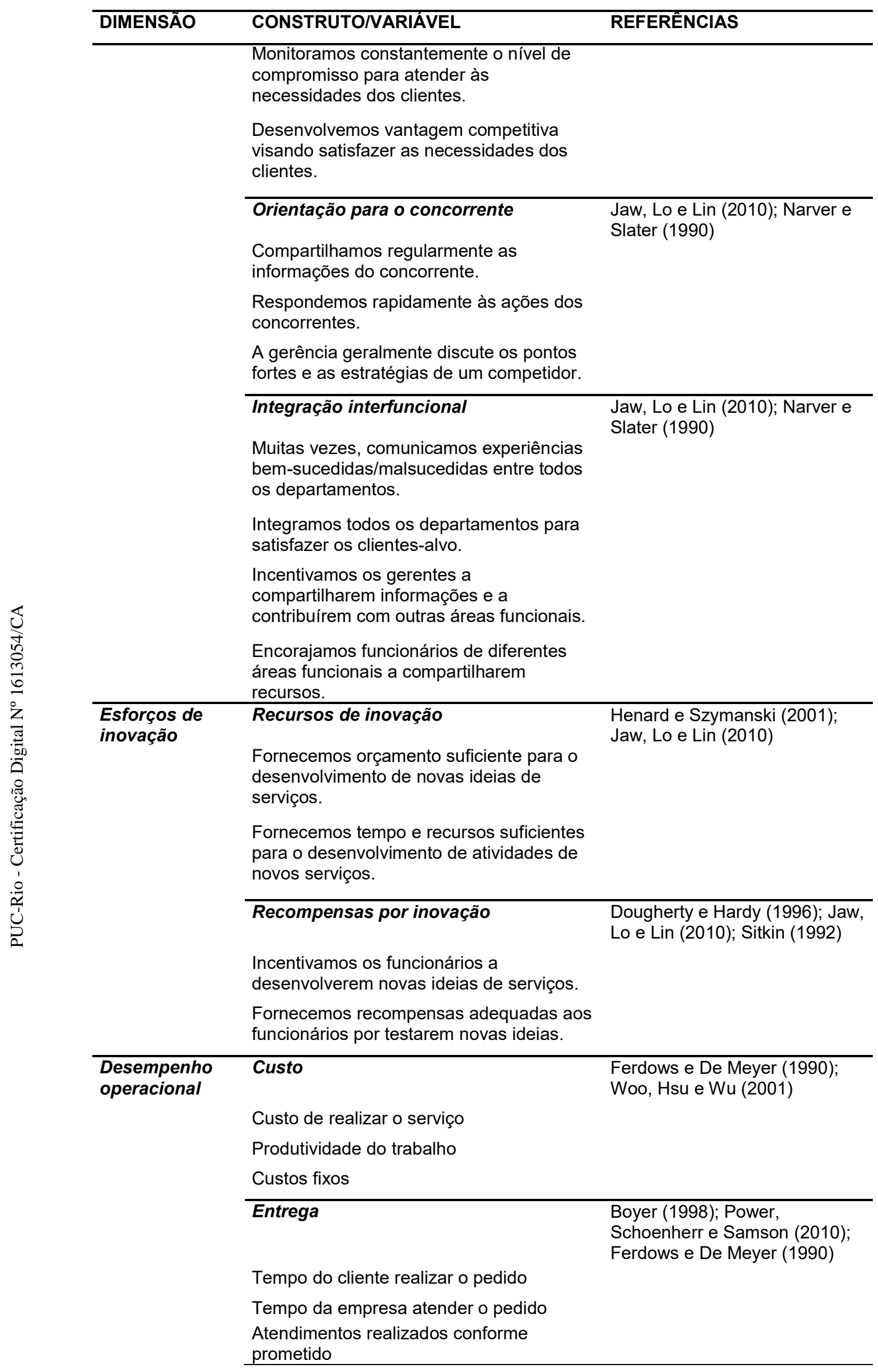




\begin{tabular}{lll}
\hline DIMENSÃO & CONSTRUTO/VARIÁVEL & REFERÉNCIAS \\
\hline & Flexibilidade & $\begin{array}{l}\text { Hallgren e Olhager (2009); Kim } \\
\text { e Arnold (1992); Fitzgerald et } \\
\text { al. (1991) }\end{array}$ \\
& $\begin{array}{l}\text { Contratação temporária } \\
\text { Personalização no atendimento }\end{array}$ & \\
& Uso de estratégias de promoção & \\
\cline { 2 - 2 } & Qualidade- & Parasuraman et al. (1988); \\
& $\begin{array}{l}\text { Conformidade do serviço (o que foi } \\
\text { prometido, foi entregue como acordado e }\end{array}$ & \\
no tempo acordado) & (1991) \\
& $\begin{array}{l}\text { Satisfação do cliente com as instalações } \\
\text { (móveis, prédio, banheiro) }\end{array}$ & \\
& $\begin{array}{l}\text { Satisfação do cliente com o atendimento } \\
\text { (velocidade, competência e cortesia dos } \\
\text { funcionários) }\end{array}$ & \\
& $\begin{array}{l}\text { Inovação } \\
\text { Capacidade de personalização do serviço }\end{array}$ & \\
& $\begin{array}{l}\text { Capacidade de introdução de novos } \\
\text { serviços }\end{array}$ & \\
\hline
\end{tabular}

Fonte: Autora (2018). 


\section{APÊNDICE II - Taxonomia}

Tabela 27 - Dimensões do desempenho operacional em pequenas empresas

\begin{tabular}{|c|c|c|}
\hline Referência & $\begin{array}{l}\text { - Indicador de desempenho } \\
\text {-Dimensão }\end{array}$ & $\begin{array}{l}\text { Dimensão de } \\
\text { desempenho } \\
\text { operacional } \\
\text { identificada } \\
\text { 1-Custo } \\
\text { 2-Entrega } \\
\text { 3-Flexibilidade } \\
\text { 4-Qualidade } \\
\text { 5-Inovação }\end{array}$ \\
\hline $\begin{array}{l}\text { Adawiyah et al. } \\
(2015)\end{array}$ & $\begin{array}{l}\text { - Desempenho organizacional relacionado ao SCM } \\
\text {-Vendas aumentadas; } \\
\text {-Financiamento mais preciso; } \\
\text {-Aumento da coordenação entre os fornecedores; } \\
\text {-Aumento da coordenação com os clientes } \\
\text { - Desempenho operacional } \\
\text {-Flexibilidade;; } \\
\text {-Leadtime reduzido na produção; } \\
\text {-Previsão; } \\
\text {-Planejamento de recursos; } \\
\text {-Poupança de custo'; } \\
\text {-Redução nos níveis de inventário } \\
\end{array}$ & $\begin{array}{l}\text { 1-Custo } \\
\text { 2-Entrega } \\
\text { 3-Flexibilidade }\end{array}$ \\
\hline $\begin{array}{l}\text { Agyapong, } \\
\text { Agyapong e Poku } \\
(2017)\end{array}$ & $\begin{array}{l}\text { - Desempenho operacional } \\
\text {-Extensão da flexibilidade no processo de entrega de } \\
\text { produto / serviço3; } \\
\text {-Quão consistentemente as necessidades do cliente são } \\
\text { atendidas }{ }^{4} ; \\
\text {-Extensão da falha no produto / serviço }{ }^{4} ; \\
\text {-Capacidade para } \\
\text { gerenciar variadas necessidades de clientes/mercado3; } \\
\text {-Produção/custo de operação }{ }^{1} ; \\
\text {-Velocidade de servir os clientes } \\
\text {-Taxa de introdução de novos produtos/serviços no } \\
\text { mercado } \\
\text { - Desempenho financeiro } \\
\text {-Visualiza os volumes; } \\
\text {-Crescimento nas vendas; } \\
\text {-Retorno sobre venda; } \\
\text {-Retorno sobre investimento; } \\
\text {-Crescimento da rentabilidade }\end{array}$ & $\begin{array}{l}\text { 1-Custo } \\
\text { 2-Entrega } \\
\text { 3-Flexibilidade } \\
\text { 4-Qualidade } \\
\text { 5-Inovação }\end{array}$ \\
\hline Alam et al. (2016) & $\begin{array}{l}\text { - Vendas anuais; } \\
\text { - Inovação }\end{array}$ & 5-Inovação \\
\hline Ali e Shabir (2017) & $\begin{array}{l}\text { - Características do empreendimento } \\
\text {-Localização; } \\
\text {-Tamanho; } \\
\text {-Tipo; } \\
\text {-Idade } \\
\text { - Desempenho do negócio } \\
\text {-Crescimento anual de vendas; } \\
\text {-Crescimento de emprego; } \\
\text {-Produtividade laboral'; } \\
\text {-Utilização da capacidade } \\
\text { - Obstáculos do negócio } \\
\text {-Acesso a recursos; } \\
\text {-Políticas e regulações; } \\
\text {-Externalidades do negócio }\end{array}$ & 1-Custo \\
\hline Amara et al. (2008) & - Inovação & 5-Inovação \\
\hline
\end{tabular}




\begin{tabular}{|c|c|c|}
\hline Referência & $\begin{array}{l}\text { - Indicador de desempenho } \\
\text {-Dimensão }\end{array}$ & $\begin{array}{l}\text { Dimensão de } \\
\text { desempenho } \\
\text { operacional } \\
\text { identificada } \\
\text { 1-Custo } \\
\text { 2-Entrega } \\
\text { 3-Flexibilidade } \\
\text { 4-Qualidade } \\
\text { 5-Inovação }\end{array}$ \\
\hline & - Grau de novidade da inovação ${ }^{5}$ & \\
\hline $\begin{array}{l}\text { Amir, Auzair e } \\
\text { Amiruddin (2016) }\end{array}$ & - Competitividade das estratégias competitivas ${ }^{12345}$ & $\begin{array}{l}\text { 1-Custo } \\
\text { 2-Entrega } \\
\text { 3-Flexibilidade } \\
\text { 4-Qualidade } \\
\text { 5-Inovação }\end{array}$ \\
\hline $\begin{array}{l}\text { Aragon-Correa e } \\
\text { Cordon-Pozo (2005) }\end{array}$ & - Introdução da internet ${ }^{5}$ & 5-Inovação \\
\hline $\begin{array}{l}\text { Augusto, Lisboa } \\
\text { eYasin (2014) }\end{array}$ & $\begin{array}{l}\text { - Desempenho organizacional } \\
\text {-Crescimento de fatia de mercado; } \\
\text {-Produtividade laboral }{ }^{1} ; \\
\text {-Satisfação do consumidor; } \\
\text {-Retenção de clientes; } \\
\text {-Lucro econômico médio; } \\
\text {-Lucro de vendas médio }\end{array}$ & $\begin{array}{l}\text { 1-Custo } \\
\text { 4-Qualidade }\end{array}$ \\
\hline $\begin{array}{l}\text { Badri, Davis e Davis } \\
(2000)\end{array}$ & $\begin{array}{l}\text { - Qualidade } \\
\text { - Flexibilidade } \\
\text { - Entrega } \\
\text { - Baixo custo }\end{array}$ & $\begin{array}{l}\text { 1-Custo } \\
\text { 2-Entrega } \\
\text { 3-Flexibilidade } \\
\text { 4-Qualidade }\end{array}$ \\
\hline Bae e Chung (2001) & - Desenvolvimento de novos produtos ${ }^{5}$ & 5-Inovação \\
\hline Subrahmanya (2013) & $\begin{array}{l}\text { - Desempenho da inovação (porcentagem da receita } \\
\text { gerada através da venda de produtos inovados no } \\
\text { volume total de vendas) }\end{array}$ & 5-Inovação \\
\hline Biju e Bhasi (2014) & $\begin{array}{l}\text { - Desempenho da firma } \\
\text {-Desempenho de vendas; } \\
\text {-Plano de crescimento pela firma; } \\
\text {-Metas de conquista; } \\
\text {-Níveis de lucro alcançados; } \\
\text {-Prontidão de entrega'; } \\
\text {-Redução de leadtime } \\
\end{array}$ & 2-Entrega \\
\hline $\begin{array}{l}\text { Chung, Bae e Kim } \\
\text { (2003) }\end{array}$ & $\begin{array}{l}\text { - Desempenho tecnológico } \\
\text {-Número total de desenvolvimento de novos produtos; } \\
\text {-Número de desenvolvimento radical de novos produtos } \\
\text { em cada estágio }\end{array}$ & 5-Inovação \\
\hline $\begin{array}{l}\text { Correia e Petiz } \\
(2006)\end{array}$ & - Produtividade do trabalho ${ }^{1}$ & 1-Custo \\
\hline $\begin{array}{l}\text { da Silveira e Sousa } \\
(2010)\end{array}$ & $\begin{array}{l}\text { - Desempenho da produção } \\
\text {-Custo } \\
\text {-Qualidade } \\
\text {-Entrega } \\
\text {-Entribidade } \\
\text {-Flexibilida }^{3}\end{array}$ & $\begin{array}{l}\text { 1-Custo } \\
\text { 2-Entrega } \\
\text { 3-Flexibilidade } \\
\text { 4-Qualidade } \\
\text { 5-Inovação } \\
\end{array}$ \\
\hline $\begin{array}{l}\text { Mendes e Ganga } \\
(2013)\end{array}$ & $\begin{array}{l}\text { - Sucesso percebido de novos produtos } \\
\text {-Aspectos financeiros; } \\
\text {-Fatia de mercado; } \\
\text {-Fortalecimento da marca; } \\
\text {-Desenvolvimento de novas competências }\end{array}$ & 5-Inovação \\
\hline $\begin{array}{l}\text { Djupdal e Westhead } \\
\text { (2015) }\end{array}$ & $\begin{array}{l}\text { - Eficiência (receita de operação total); } \\
\text { - Ineficiência (custo de produtos vendidos por } \\
\text { colaborador) }{ }^{1} \text {; } \\
\text { - Lucro }\end{array}$ & 1-Custo \\
\hline
\end{tabular}




\begin{tabular}{|c|c|c|}
\hline Referência & $\begin{array}{l}\text { - Indicador de desempenho } \\
\text {-Dimensão }\end{array}$ & $\begin{array}{l}\text { Dimensão de } \\
\text { desempenho } \\
\text { operacional } \\
\text { identificada } \\
\text { 1-Custo } \\
\text { 2-Entrega } \\
\text { 3-Flexibilidade } \\
\text { 4-Qualidade } \\
\text { 5-Inovação }\end{array}$ \\
\hline $\begin{array}{l}\text { Droge, Calantone e } \\
\text { Harmancioglu (2008) }\end{array}$ & - Sucesso de novos produtos ${ }^{5}$ & 5-Inovação \\
\hline $\begin{array}{l}\text { Ebersberger e } \\
\text { Herstad (2013) }\end{array}$ & - Inovação (vendas inovadoras relativas) ${ }^{5}$ & 5-Inovação \\
\hline Fan et al. (2013) & $\begin{array}{l}\text { - Financeiro } \\
\text {-Retorno sobre ativos; } \\
\text {-Lucro líquido; } \\
\text {-Retorno sobre vendas } \\
\text { - Estratégico } \\
\text {-Fatia de mercado; } \\
\text {-Comprometimento de mercado; } \\
\text {-Qualidade do produto }\end{array}$ & 4-Qualidade \\
\hline $\begin{array}{l}\text { Fening, Pesakovic e } \\
\text { Amaria (2008) }\end{array}$ & $\begin{array}{l}\text { - Lucratividade; } \\
\text { - Crescimento de vendas; } \\
\text { - Satisfação do consumidor } \\
\text { - Moral dos colaboradores; } \\
\text { - Fatia de mercado }\end{array}$ & 4-Qualidade \\
\hline $\begin{array}{l}\text { Gaur, Vasudevan e } \\
\text { Gaur (2011) }\end{array}$ & $\begin{array}{l}\text { - Desempenho da produção } \\
\text {-Custo }{ }^{1} ; \\
\text {-Qualidade }{ }^{4} ; \\
\text {-Entrega } \\
\text {-Flexibilidade } \\
\end{array}$ & $\begin{array}{l}\text { 1-Custo } \\
\text { 2-Entrega } \\
\text { 3-Flexibilidade } \\
\text { 4-Qualidade }\end{array}$ \\
\hline Gholami et al. (2013) & $\begin{array}{l}\text { - Desempenho organizacional } \\
\text {-Produtividade }{ }^{1 ;} \\
\text {-Desempenho financeiro; } \\
\text {-Desempenho do pessoal; } \\
\text {-Inovação }{ }^{5} \text {; } \\
\text {-Relações laborais; } \\
\text {-Satisfação do consumidor }{ }^{4}\end{array}$ & $\begin{array}{l}\text { 1-Custo } \\
\text { 4-Qualidade } \\
\text { 5-Inovação }\end{array}$ \\
\hline Guan et al. (2006) & - Proporção de inovação ${ }^{5}$ & 5-Inovação \\
\hline $\begin{array}{l}\text { Gui-Lin, Xiao-Hong e } \\
\text { Guo-Qun (2008) }\end{array}$ & $\begin{array}{l}\text { - Desempenho do projeto } \\
\text {-Tempo } \\
\text {-Custo } \\
\text {-Qualidade } \\
\text {-Inovação } \\
\text {-Satisfação } \\
\text {-Sa }\end{array}$ & $\begin{array}{l}\text { 1-Custo } \\
\text { 2-Entrega } \\
\text { 4-Qualidade } \\
\text { 5-Inovação }\end{array}$ \\
\hline Heimonen (2012) & - Atividade de inovação 5 & 5-Inovação \\
\hline Hilmi et al. (2010) & $\begin{array}{l}\text { - Desempenho da firma } \\
\text {-Número de reclamações; } \\
\text {-ROI; } \\
\text {-Desempenho financeiro; } \\
\text {-Crescimento de vendas; } \\
\text {-Produtividade }{ }^{1 ;} \\
\text {-Satisfação do consumidor } \\
\text {-Satisfação do empregado }\end{array}$ & $\begin{array}{l}\text { 1-Custo } \\
\text { 4-Qualidade }\end{array}$ \\
\hline $\begin{array}{l}\text { Hosseini e Eskandari } \\
(2013)\end{array}$ & $\begin{array}{l}\text { - Desempenho empreendedor } \\
\text {-Desempenho financeiro; } \\
\text {-Criação de empregos; } \\
\text {-Crescimento; } \\
\text {-Inovação }{ }^{5} \text {; } \\
\text {-Fatia de mercado; } \\
\text {-Satisfação }{ }^{4}\end{array}$ & $\begin{array}{l}\text { 4-Qualidade } \\
\text { 5-Inovação }\end{array}$ \\
\hline
\end{tabular}




\begin{tabular}{|c|c|c|}
\hline Referência & $\begin{array}{l}\text { - Indicador de desempenho } \\
\text {-Dimensão }\end{array}$ & $\begin{array}{l}\text { Dimensão de } \\
\text { desempenho } \\
\text { operacional } \\
\text { identificada } \\
\\
\text { 1-Custo } \\
\text { 2-Entrega } \\
\text { 3-Flexibilidade } \\
\text { 4-Qualidade } \\
\text { 5-Inovação }\end{array}$ \\
\hline $\begin{array}{l}\text { Hu e Mathews } \\
\text { (2009) }\end{array}$ & $\begin{array}{l}\text { - Desempenho da inovação }{ }^{5} \\
\text {-Transferência de tecnologia; } \\
\text {-Licença de tecnologia; } \\
\text {-Empresas incubadas; } \\
\text {-Patentes concedidas }\end{array}$ & 5-Inovação \\
\hline $\begin{array}{l}\text { Huang, Lai e Huang } \\
\text { (2015) }\end{array}$ & $\begin{array}{l}\text { - Capacidade transformadora; } \\
\text { - Inovação de entrada aberta }\end{array}$ & 5-Inovação \\
\hline Jha e Bosel (2016) & $\begin{array}{l}\text { - Inovação do produto } \\
\text { - Inovação do processo }\end{array}$ & 5-Inovação \\
\hline Jing (2017) & $\begin{array}{l}\text { - Desempenho organizacional } \\
\text {-Satisfação do pessoal; } \\
\text {-Satisfação do consumidor }{ }^{4} ; \\
\text {-Desempenho financeiro; } \\
\text {-Produtividade }{ }^{1} \text {; } \\
\text {-Ternura do pessoal/gerente }\end{array}$ & $\begin{array}{l}\text { 1-Custo } \\
\text { 4-Qualidade }\end{array}$ \\
\hline $\begin{array}{l}\text { Jo, Park e Kang } \\
(2016)\end{array}$ & - Desempenho da inovação ${ }^{5}$ & 5-Inovação \\
\hline $\begin{array}{l}\text { Johns, Avcí e } \\
\text { Karatepe (2004) }\end{array}$ & - Satisfação do consumidor ${ }^{4}$ & 4-Qualidade \\
\hline Jones et al. (2013) & $\begin{array}{l}\text { - Desempenho operacional } \\
\text {-Produtividade }{ }^{1 ;} \\
\text {-Rentabilidade }\end{array}$ & 1-Custo \\
\hline $\begin{array}{l}\text { Keizer, Dijkstra e } \\
\text { Halman (2002) }\end{array}$ & - Inovação5 & 5-Inovação \\
\hline $\begin{array}{l}\text { Khalique e Pablos } \\
\text { (2015) }\end{array}$ & $\begin{array}{l}\text { - Desempenho organizacional } \\
\text {-Perspectiva financeira; } \\
\text {-Perspectiva do consumidor4; } \\
\text {-Perspectiva de processo interno do negócio; } \\
\text {-Perspectiva de crescimento e aprendizado }\end{array}$ & 4-Qualidade \\
\hline $\begin{array}{l}\text { Kongmanila e } \\
\text { Takahashi }(2010)\end{array}$ & $\begin{array}{l}\text { - Comportamento do subcontratado } \\
\text { - Desempenho da firma } \\
\text {-Eficiência do capital; } \\
\text {-Eficiência do trabalho }{ }^{1}\end{array}$ & 1-Custo \\
\hline Laforet (2009) & $\begin{array}{l}\text { - Inovação } \\
\text {-Desenvolvimento de novos produtos } \\
\text {-Inovação do processo; } \\
\text {-Melhoria contínua; } \\
\text {-Cultura de empoderamento } \\
\text {-Estratégia de inovação } \\
\text { (separadamente) }\end{array}$ & 5-Inovação \\
\hline Liu e Chen (2015) & - Desenvolvimento de novos produtos ${ }^{5}$ & 5-Inovação \\
\hline $\begin{array}{l}\text { Mahmood e Mohd } \\
\text { Rosli (2013) }\end{array}$ & $\begin{array}{l}\text { - Desempenho do negócio } \\
\text {-Receita de vendas; } \\
\text {-Lucro; } \\
\text {-Estabilidade do negócio; } \\
\text {-Crescimento de emprego; } \\
\text {-Redução nos custos de produção }{ }^{1 ;} \\
\text {-Satisfação do consumidor } \\
\end{array}$ & $\begin{array}{l}\text { 1-Custo } \\
\text { 4-Qualidade }\end{array}$ \\
\hline
\end{tabular}




\begin{tabular}{|c|c|c|}
\hline Referência & $\begin{array}{l}\text { - Indicador de desempenho } \\
\text {-Dimensão }\end{array}$ & $\begin{array}{l}\text { Dimensão de } \\
\text { desempenho } \\
\text { operacional } \\
\text { identificada } \\
\text { 1-Custo } \\
\text { 2-Entrega } \\
\text { 3-Flexibilidade } \\
\text { 4-Qualidade } \\
\text { 5-Inovação }\end{array}$ \\
\hline & $\begin{array}{l}\text {-Alcance do mercado; } \\
\text {-Valor dos ativos do negócio; } \\
\text {-Networks do negócio }\end{array}$ & \\
\hline $\begin{array}{l}\text { Mahmood et al. } \\
(2017)\end{array}$ & $\begin{array}{l}\text { - Desempenho da firma } \\
\text {-Receita de vendas; } \\
\text {-Lucro; } \\
\text {-Geração de emprego; } \\
\text {-Estabilidade do negócio; } \\
\text {-Crescimento do negócio; } \\
\text {-Contribuição para o desenvolvimento da comunidade; } \\
\text {-Satisfação do consumidor } \\
\text {-Networking }\end{array}$ & 4-Qualidade \\
\hline $\begin{array}{l}\text { Mahmood e Mitchell } \\
\text { (2004) }\end{array}$ & - Vantagem comparativa relevada pela tecnologia ${ }^{5}$ & 5-Inovação \\
\hline $\begin{array}{l}\text { Malmström e } \\
\text { Wincent (2012) }\end{array}$ & $\begin{array}{l}\text { - Desempenho da firma } \\
\text {-Qualidade de produtos e serviços desenvolvidos pela } \\
\text { firma } \\
\text {-Eficiência no desenvolvimento de produtos e serviços }{ }^{5} ; \\
\text {-Eficiência na manufatura de produtos e/ou prestação de } \\
\text { serviços }^{1} ; \\
\text {-Habilidade de descobrimento dos desejos do cliente; } \\
\text {-Eficiência em marketing e vendas }\end{array}$ & $\begin{array}{l}\text { 1-Custo } \\
\text { 4-Qualidade } \\
\text { 5-Inovação }\end{array}$ \\
\hline $\begin{array}{l}\text { Markham e Lee } \\
\text { (2014) }\end{array}$ & $\begin{array}{l}\text { - Desempenho do produto } \\
\text {-Grau em que o programa de desenvolvimento de novos } \\
\text { produtos atingiu seu objetivo; } \\
\text {-Sucesso total do programa; } \\
\text {-Sucesso da unidade de negócio de desenvolvimento de } \\
\text { novos produtos } \\
\text {-Tempo de desenvolvimento; } \\
\text {-Sucesso de mercado; } \\
\text {-Sucesso financeiro }\end{array}$ & 5-Inovação \\
\hline Markic et al. (2011) & - Política de sucesso e inovação ${ }^{5}$ & 5-Inovação \\
\hline
\end{tabular}

\begin{tabular}{|c|c|c|}
\hline $\begin{array}{l}\text { Martinez-Caro e } \\
\text { Cegarra-Navarro } \\
(2010)\end{array}$ & - Produtividade de capital ${ }^{1}$ & 1-Custo \\
\hline $\begin{array}{l}\text { Massaro, Dumay e } \\
\text { Bagnoli (2015) }\end{array}$ & - Diversificação de produto e serviço ${ }^{35}$ & $\begin{array}{l}\text { 3-Flexibilidade } \\
\text { 5-Inovação }\end{array}$ \\
\hline $\begin{array}{l}\text { McAdam et al. } \\
(2010)\end{array}$ & - Implementação da inovação 5 & 5-Inovação \\
\hline $\begin{array}{l}\text { Medrano e Olarte- } \\
\text { Pascual (2016) }\end{array}$ & $\begin{array}{l}\text { - Inovação do mercado } \\
\text {-Design; } \\
\text {-Preço; } \\
\text {-Promoção; } \\
\text {-Praça }\end{array}$ & 5-Inovação \\
\hline
\end{tabular}




\begin{tabular}{|c|c|c|}
\hline Referência & $\begin{array}{l}\text { - Indicador de desempenho } \\
\text {-Dimensão }\end{array}$ & $\begin{array}{l}\text { Dimensão de } \\
\text { desempenho } \\
\text { operacional } \\
\text { identificada } \\
\text { 1-Custo } \\
\text { 2-Entrega } \\
\text { 3-Flexibilidade } \\
\text { 4-Qualidade } \\
\text { 5-Inovação }\end{array}$ \\
\hline $\begin{array}{l}\text { Minguela-Rata, } \\
\text { Fernandez- } \\
\text { Menendez e Fossas- } \\
\text { Olalla (2014) }\end{array}$ & $\begin{array}{l}\text { - Inovação do produto } \\
\text { - Grau de inovação do produto }\end{array}$ & 5-Inovação \\
\hline Rosli e Sidek (2007) & $\begin{array}{l}\text { - Desempenho da firma } \\
\text {-Retorno das vendas; } \\
\text {-Retorno nos ativos; } \\
\text {-Lucratividade; } \\
\text {-Fatia de mercado; } \\
\text {-Receita de vendas; } \\
\text {-Produtividade laboral; } \\
\text {-Empregabilidade }\end{array}$ & 1-Custo \\
\hline $\begin{array}{l}\text { Ndubisi e Iftikhar } \\
\text { (2012) }\end{array}$ & - Desempenho de qualidade ${ }^{4}$ & 4-Qualidade \\
\hline $\begin{array}{l}\text { O'Dwyer e Ledwith } \\
(2010)\end{array}$ & $\begin{array}{l}\text { - Desempenho organizacional } \\
\text {-Crescimento de vendas; } \\
\text {-Lucro; } \\
\text {-Sucesso de novos produtos }{ }^{5} \text { - } \\
\text {-Fatia de vendas de novos produtos; } \\
\text {-Fatia de mercado; } \\
\text {-ROI ou IRR }\end{array}$ & 5-Inovação \\
\hline Odoom (2016) & $\begin{array}{l}\text { - Margem de lucro; } \\
\text { - Fatia de mercado; } \\
\text { - Volume de vendas; } \\
\text { - Base de consumidor; } \\
\text { - Desenvolvimento de novos produtos }{ }^{5}\end{array}$ & 5-Inovação \\
\hline $\begin{array}{l}\text { Pantouvakis e } \\
\text { Patsiouras (2016) }\end{array}$ & - Satisfação do consumidor ${ }^{4}$ & 4-Qualidade \\
\hline $\begin{array}{l}\text { Papastathopoulos e } \\
\text { Beneki (2010) }\end{array}$ & $\begin{array}{l}\text { - Melhoria da produtividade }{ }^{1} \text {; } \\
\text { - Melhoria de procedimentos de produção já existentes }{ }^{4} \text {; } \\
\text { - Redução dos custos de trabalho }{ }^{1}\end{array}$ & $\begin{array}{l}\text { 1-Custo } \\
\text { 4-Qualidade }\end{array}$ \\
\hline $\begin{array}{l}\text { Papula, Volná e } \\
\text { Hul'vej (2013) }\end{array}$ & $\begin{array}{l}\text { - Desempenho da inovação } \\
\text {-Inovação do produto ou do processo (PPI); } \\
\text {-Inovação organizacional ou em marketing (MOI) }\end{array}$ & 5-Inovação \\
\hline $\begin{array}{l}\text { Parida e Örtqvist } \\
(2015)\end{array}$ & - Desempenho da inovação ${ }^{5}$ & 5-Inovação \\
\hline $\begin{array}{l}\text { Prajapati e Biswas } \\
\text { (2011) }\end{array}$ & $\begin{array}{l}\text { - Desempenho } \\
\text {-Crescimento de vendas; } \\
\text {-Qualidade do produto ; } \\
\text {-Desenvolvimento de novos produtos }{ }^{5} ; \\
\text {-Serviço do consumidor; } \\
\text {-Desenvolvimento de novo design }\end{array}$ & $\begin{array}{l}\text { 4-Qualidade } \\
\text { 5-Inovação }\end{array}$ \\
\hline $\begin{array}{l}\text { Rahman, } \\
\text { Laosirihongthong e } \\
\text { Sohal (2010) }\end{array}$ & $\begin{array}{l}\text { - Desempenho operacional } \\
\text {-Entrega rápida comparada ao competidor }{ }^{2} ; \\
\text {-Custo unitário do produto em relação aos } \\
\text { concorrentes }^{1} ; \\
\text {-Produtividade total }{ }^{1} ; \\
\text {-Satisfação total do } \text { cliente }^{4}\end{array}$ & $\begin{array}{l}\text { 1-Custo } \\
\text { 2-Entrega } \\
\text { 4-Qualidade }\end{array}$ \\
\hline $\begin{array}{l}\text { Rawwas e lyer } \\
\text { (2013) }\end{array}$ & $\begin{array}{l}\text { - Desempenho operacional } \\
\text {-Lucro líquido; } \\
\text {-Interações sociais e satisfação; } \\
\text {-Adaptabilidade na adoção de novos produtos e }\end{array}$ & 5-Inovação \\
\hline
\end{tabular}




\begin{tabular}{|c|c|c|}
\hline Referência & $\begin{array}{l}\text { - Indicador de desempenho } \\
\text {-Dimensão }\end{array}$ & $\begin{array}{l}\text { Dimensão de } \\
\text { desempenho } \\
\text { operacional } \\
\text { identificada } \\
\text { 1-Custo } \\
\text { 2-Entrega } \\
\text { 3-Flexibilidade } \\
\text { 4-Qualidade } \\
\text { 5-Inovação }\end{array}$ \\
\hline & $\begin{array}{l}\text { mercados }{ }^{5} ; \\
\text {-Sincronização de esforços }\end{array}$ & \\
\hline Reade e Lee (2016) & $\begin{array}{l}\text { - Comportamento inovador do colaborador } \\
\text {-Geração de ideia; } \\
\text {-Realização de ideia }\end{array}$ & 5-Inovação \\
\hline $\begin{array}{l}\text { Richey, Genchev e } \\
\text { Daugherty (2005) }\end{array}$ & $\begin{array}{l}\text { - Estratégico; } \\
\text { - Responsividade operacional2; } \\
\text { - Qualidade do serviço operacional }{ }^{4}\end{array}$ & $\begin{array}{l}\text { 2-Entrega } \\
\text { 4-Qualidade }\end{array}$ \\
\hline $\begin{array}{l}\text { Rodriguez e } \\
\text { Guzman (2013) }\end{array}$ & - Inovação ${ }^{5}$ & 5-Inovação \\
\hline $\begin{array}{l}\text { Rojas-Méndez, Kara } \\
\text { e Spillan (2005) }\end{array}$ & $\begin{array}{l}\text { - Desempenho organizacional } \\
\text {-Sucesso do produto }{ }^{5} ; \\
\text {-Retenção do consumidor; } \\
\text {-Qualidade do preço-produto }{ }^{4}\end{array}$ & $\begin{array}{l}\text { 4-Qualidade } \\
\text { 5-Inovação }\end{array}$ \\
\hline $\begin{array}{l}\text { Sheehan e Cooper } \\
\text { (2011) }\end{array}$ & $\begin{array}{l}\text { - Terceirização de recursos humanos; } \\
\text {-Treinamento e desenvolvimento; } \\
\text {-Recrutamento e seleção; } \\
\text {-Avaliação de desempenho; } \\
\text {-Remuneração por desempenho; } \\
\text {-Relações entre empregados; } \\
\text {-Remuneração administrativa; } \\
\text {-Sistema de informação de gerência de recursos } \\
\text { humanos; } \\
\text {-Gestão de mudanças } \\
\text { - Eficiência da organização } \\
\text {-Eficiência do desempenho organizacional total; } \\
\text {-Perspectiva de futuro; } \\
\text {-Qualidade de produtos e serviços } \\
\text {-Liderança na indústria } \\
\text { - Desempenho financeiro percebido } \\
\text {-Lucratividade organizacional; } \\
\text {-ROI; } \\
\text {-Metas financeiras internas }\end{array}$ & 4-Qualidade \\
\hline $\begin{array}{l}\text { Sheng e Song } \\
(2013)\end{array}$ & - Produtividade total da empresa ${ }^{1}$ & 1-Custo \\
\hline $\begin{array}{l}\text { Singh, Khamba e } \\
\text { Nanda (2017) }\end{array}$ & $\begin{array}{l}\text { - Desempenho industrial da firma } \\
\text {-Desempenho do produto; } \\
\text {-Desempenho de vendas; } \\
\text {-Desempenho de inovação }{ }^{5}\end{array}$ & 5-Inovação \\
\hline $\begin{array}{l}\text { Sinha, Garg e Dhall } \\
(2016)\end{array}$ & $\begin{array}{l}\text { - Desempenho organizacional } \\
\text {-Resultados de consumidor } \\
\text {-Resultados de processo; } \\
\text {-Resultados de empregado }\end{array}$ & 4-Qualidade \\
\hline $\begin{array}{l}\text { Siqueira e Cosh } \\
(2008)\end{array}$ & $\begin{array}{l}\text { - Top desempenhadores } \\
\text {-Produtividade }^{1}\end{array}$ & 1-Custo \\
\hline $\begin{array}{l}\text { Soni, Lilien e Wilson } \\
\text { (1993) }\end{array}$ & $\begin{array}{l}\text {-Inovação } \\
\text {-Inovação de melhoria; } \\
\text {-Inovação de imitação }\end{array}$ & 5-Inovação \\
\hline
\end{tabular}




\begin{tabular}{|c|c|c|}
\hline Referência & $\begin{array}{l}\text { - Indicador de desempenho } \\
\text {-Dimensão }\end{array}$ & $\begin{array}{l}\text { Dimensão de } \\
\text { desempenho } \\
\text { operacional } \\
\text { identificada } \\
\text { 1-Custo } \\
\text { 2-Entrega } \\
\text { 3-Flexibilidade } \\
\text { 4-Qualidade } \\
\text { 5-Inovação }\end{array}$ \\
\hline & $\begin{array}{l}\text { - Desempenho } \\
\text {-Vendas; } \\
\text {-Crescimento de vendas }\end{array}$ & \\
\hline $\begin{array}{l}\text { Sorooshian et al. } \\
\text { (2011) }\end{array}$ & $\begin{array}{l}\text { - Desempenho financeiro } \\
\text {-Retorno sobre ativos; } \\
\text {-Mudanças nas vendas } \\
\text { - Desempenho operacional } \\
\text {-Qualidade do produto }{ }^{4} \\
\text {-Habilidade de mudança rápida no volume de } \\
\text { produção }{ }^{3} \\
\text {-Desempenho de habilidade on-time }{ }^{2} ; \\
\text {-Satisfação do consumidor }\end{array}$ & $\begin{array}{l}\text { 2-Entrega } \\
\text { 3-Flexibilidade } \\
\text { 4-Qualidade }\end{array}$ \\
\hline $\begin{array}{l}\text { Subramaniam et al. } \\
\text { (2011) }\end{array}$ & $\begin{array}{l}\text { - Específicos da organização } \\
\text {-Qualidade percebida do produto } \\
\text {-Custo percebido de produção } \\
\text { - Relativos ao mercado } \\
\text {-Fatia de mercado percebida; } \\
\text {-Vendas percebidas } \\
\text { - Desempenho organizacional total }\end{array}$ & $\begin{array}{l}\text { 1-Custo } \\
\text { 4-Qualidade }\end{array}$ \\
\hline $\begin{array}{l}\text { Sukwadi, Wee e } \\
\text { Yang (2013) }\end{array}$ & $\begin{array}{l}\text { - Desempenho da pequena e média empresa } \\
\text {-Retorno sobre investimento; } \\
\text {-Crescimento de vendas; } \\
\text {-Conhecimento e experiência no negócio; } \\
\text {-Habilidade de fornecer produtos ou serviços }{ }^{2} ; \\
\text {-Capacidade de desenvolver novos produtos e } \\
\text { processos } \\
\text {-Habilidade de gerenciar e trabalhar em grupo; } \\
\text {-Produtividade da força de trabalho }{ }^{1} ; \\
\text {-Responsabilidade da empresa }\end{array}$ & $\begin{array}{l}\text { 1-Custo } \\
\text { 2-Entrega } \\
\text { 5-Inovação }\end{array}$ \\
\hline Tai et al. (2012) & - Qualidade do produto 4 & 4-Qualidade \\
\hline $\begin{array}{l}\text { Tejada e Moreno } \\
(2013)\end{array}$ & $\begin{array}{l}\text { • Atividade de inovação } \\
\text {-Inovação de mercado; } \\
\text {-Inovação organizacional; } \\
\text {-Inovação do produto; } \\
\text {-Inovação do processo }\end{array}$ & 5-Inovação \\
\hline $\begin{array}{l}\text { Theriou e } \\
\text { Chatzoudes (2015) }\end{array}$ & $\begin{array}{l}\text { - Desempenho da firma } \\
\text {-Crescimento de vendas; } \\
\text {-Crescimento da receita; } \\
\text {-Crescimento do número de empregados; } \\
\text {-Margem de lucro líquido; } \\
\text {-Crescimento da inovação de produtos e serviços }{ }^{5} \text {; } \\
\text {-Qualidade e variedade de produtos e serviços }{ }^{4} ; \\
\text {-Adoção de novas tecnologias } \\
\text {-Satisfação do consumidor }\end{array}$ & $\begin{array}{l}\text { 4-Qualidade } \\
\text { 5-Inovação }\end{array}$ \\
\hline $\begin{array}{l}\text { Tomlinson e Fai } \\
(2013)\end{array}$ & $\begin{array}{l}\text { - Inovação } \\
\text {-Inovação do produto; } \\
\text {-Inovação do processo }\end{array}$ & 5-Inovação \\
\hline $\begin{array}{l}\text { Tsaur e Wang } \\
\text { (2011) }\end{array}$ & $\begin{array}{l}\text { - Desempenho } \\
\text {-Eficiência dos custo de suprimentos }{ }^{1} \text {; } \\
\text {-Produtividade de operações }{ }^{1} ; \\
\text {-Preços do produto }\end{array}$ & 1-Custo \\
\hline
\end{tabular}




\begin{tabular}{|c|c|c|}
\hline Referência & $\begin{array}{l}\text { - Indicador de desempenho } \\
\text {-Dimensão }\end{array}$ & $\begin{array}{l}\text { Dimensão de } \\
\text { desempenho } \\
\text { operacional } \\
\text { identificada } \\
\text { 1-Custo } \\
\text { 2-Entrega } \\
\text { 3-Flexibilidade } \\
\text { 4-Qualidade } \\
\text { 5-Inovação }\end{array}$ \\
\hline Ukenna et al. (2010) & $\begin{array}{l}\text { - Desempenho financeiro } \\
\text {-Produtividade do colaborador }{ }^{1} ; \\
\text {-Taxas de defeito; } \\
\text {-Fatia de mercado } \\
\text { - Desempenho não-financeiro } \\
\text {-Melhoria de fluxo de trabalho; } \\
\text {-Inovação } \\
\text {-Satisfação do consumidor } \\
\text {-Desenvolvimento de habilidades; } \\
\text {-Capital humano }\end{array}$ & $\begin{array}{l}\text { 1-Custo } \\
\text { 4-Qualidade } \\
\text { 5-Inovação }\end{array}$ \\
\hline $\begin{array}{l}\text { Urban e Greyling } \\
(2015)\end{array}$ & $\begin{array}{l}\text { - Desempenho da inovação }{ }^{5} \\
\text {-Inovação do produto; } \\
\text {-Inovação do processo; } \\
\text {-Vendas de novos produtos e serviços }\end{array}$ & 5-Inovação \\
\hline $\begin{array}{l}\text { Verbano e Crema } \\
(2016)\end{array}$ & $\begin{array}{l}\text { - Desempenho da inovação }{ }^{5} \\
\text {-Inovação incremental; } \\
\text {-Inovação radical }\end{array}$ & 5-Inovação \\
\hline Yam et al. (2004) & $\begin{array}{l}\text { - Taxa de inovação }{ }^{5} \\
\text {-Crescimento de vendas; } \\
\text {-Competitividade do produto } \\
\text { (separadamente) }\end{array}$ & 5-Inovação \\
\hline Duan e Yu (2016) & $\begin{array}{l}\text { - Desempenho da firma } \\
\text {-Crescimento de vendas; } \\
\text {-Crescimento da receita; } \\
\text {-Crescimento do lucro; } \\
\text {-ROI; } \\
\text {-Crescimento no número de empregados; } \\
\text {-Desenvolvimento de novos produtos; } \\
\text {-Desenvolvimento de mercado; } \\
\text {-Satisfação do consumidor }{ }^{4} ; \\
\text {-Imagem social; } \\
\text {-Qualidade dos funcionários }\end{array}$ & 4-Qualidade \\
\hline Yun et al. (2016) & $\begin{array}{l}\text { - Desempenho da inovação } \\
\text {-Volume de negócios da empresa relativo a produtos } \\
\text { novos para o mercado mundial; } \\
\text {-Volume de negócios referente a produtos novos para a } \\
\text { empresa; } \\
\text {-Volume de novos negócios referente a produtos } \\
\text { melhorados }\end{array}$ & 5-Inovação \\
\hline Zhou et al. (2017) & $\begin{array}{l}\text { - Desempenho da inovação } \\
\text {-Número de patentes; } \\
\text {-Número de novos produtos; } \\
\text {-Fatia de mercado; } \\
\text {-Taxa de sucesso da inovação }\end{array}$ & 5-Inovação \\
\hline
\end{tabular}




\section{APÊNDICE III - Questionário}

\section{Apresentação}

Sua empresa foi selecionada pelo SEBRAE para participar de uma pesquisa realizada em conjunto com a PUC-Rio, cujo objetivo é identificar os fatores determinantes para o desempenho dos serviços em empresas do Estado do Rio de Janeiro. O formulário leva aproximadamente 7 minutos para ser preenchido e, para isso, é necessário que seja respondido pelo(a) principal dirigente da empresa ou funcionário que tenha profundo conhecimento da mesma. Toda informação fornecida é estritamente confidencial e anônima. Os resultados desta pesquisa serão disponibilizados para as empresas participantes.

Figura 10 - Apresentação do questionário Fonte: Autora (2018). 
2. Perfil do respondente

O objetivo desta seção é identificar o perfil do respondente do questionário.

*1. Qual o seu cargo na empresa?

*2. Há quantos anos ocupa esse cargo?

Atente para o fato de que o tempo na empresa deve ser maior que o tempo ocupando o cargo atua.

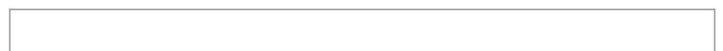

*3. Há quantos anos trabalha na empresa?

Atente para o fato de que o tempo na empresa deve ser maior que o tempo ocupando o cargo atual.

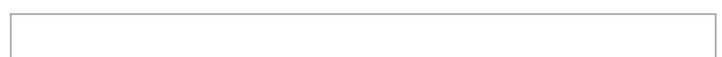

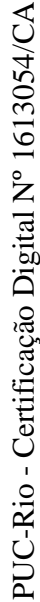

Figura 11 - Perfil do respondente

Fonte: Autora (2018). 
3. Perfil da empresa

O objetivo desta seção é identificar o segmento e tempo de atuação da sua empresa.

*4. A qual desses segmentos a sua empresa pertence?

*5. Qual a principal atividade realizada pela empresa?

*6. Quantos funcionários trabalham na empresa?

* 7. Qual a data de início das atividades da empresa?

Data

DD/MM/AAAA

* 8. Qual o faturamento anual da empresa?

Até $\mathrm{R} \$ 60.000,00$

De $R \$ 60.000,01$ até $R \$ 360.000,00$

De $R \$ 360.000,01$ até $R \$ 3.600 .000,00$

De $R \$ 360.000,01$ até $\mathrm{R} \$ 35.000 .000,00$

Superior a $\mathrm{R} \$ 35.000 .000,00$

Figura 12 - Perfil da empresa

Fonte: Autora (2018). 
4. Orientação de mercado

* 9 . Sobre a atividade principal da sua empresa, marque o quanto você concorda ou discorda das afirmações abaixo

Discordo totalmente Discordo parcialmente Indiferente $\quad \begin{gathered}\text { Concordo } \\ \text { parcialmente }\end{gathered}$ Concordo totalmente

Tratatamos a satisfação

do cliente como um

objetivo do negócio

○

$\bigcirc$

Monitoramos

constantemente o nivel

de compromisso para

atender às necessidade

do cliente

Desenvolvemos

vantagem competitiva

visando satisfazer as

necessidades do cliente

Compartilhamos

regularmente dentro da

empresa as informações

dos concorrentes

Respondemos

rapidamente às açõe

dos concorrentes

O

0

0

Discutimos

frequentemente os

pontos fortes e as

estratégias dos

concorrentes

Comunicamos

frequentemente as

experiências de sucesso

e de fracasso entre

todos os departamentos

Integramos todos os

departamentos para

satisfazer os clientes

0

O

0

O

Todos na empresa são

encorajados a

compartilhar

informações entre si

0

0

0

0

0

Encorajamos

funcionários de

diferentes áreas

funcionais a

compartilharem recursos

(pessoas, materiais,

equipamentos)

Figura 13 - Caracterização da empresa quanto à orientação ao mercado Fonte: Autora (2018). 
5. Esforços de inovação

* 10. Considerando novos serviços como quaisquer alterações feitas em serviços já existentes ou a criação de um serviço totalmente inédito, marque o quanto você concorda ou discorda das afirmações abaixo

\begin{tabular}{|c|c|c|c|c|}
\hline & Discordo totalmente Discordo parcialmente & Indiferente & $\begin{array}{l}\text { Concordo } \\
\text { parcialmente }\end{array}$ & Concordo totalmente \\
\hline \multicolumn{5}{|l|}{$\begin{array}{l}\text { Aplicamos orçamento } \\
\text { suficiente para o } \\
\text { desenvolvimento de } \\
\text { novas ideias de serviços }\end{array}$} \\
\hline \multicolumn{5}{|l|}{$\begin{array}{l}\text { Aplicamos tempo e } \\
\text { recursos suficientes para } \\
\text { o desenvolvimento de } \\
\text { novos serviços. }\end{array}$} \\
\hline \multicolumn{5}{|l|}{$\begin{array}{l}\text { Incentivamos os } \\
\text { funcionários a } \\
\text { desenvolverem novas } \\
\text { ideias de serviços }\end{array}$} \\
\hline $\begin{array}{l}\text { Fornecemos } \\
\text { recompensa adequada } \\
\text { aos funcionários para } \\
\text { testarem novas ideias }\end{array}$ & 0 & 0 & 0 & 0 \\
\hline & & & & \\
\hline & & & & \\
\hline & & & & \\
\hline & & & & \\
\hline & & & & \\
\hline & & & & \\
\hline & & & & \\
\hline & & & & \\
\hline & & & & \\
\hline & & & & \\
\hline & & & & \\
\hline
\end{tabular}

Figura 14 - Caracterização da empresa quanto aos esforços de inovação Fonte: Autora (2018). 
6. Objetivo de desempenho

* 11. Como as alternativas abaixo se posicionariam num ranking do que é mais importante para o seu negócio se manter competitivo? Sendo $1^{\circ}$ o mais importante e $5^{\circ}$ o menos importante.

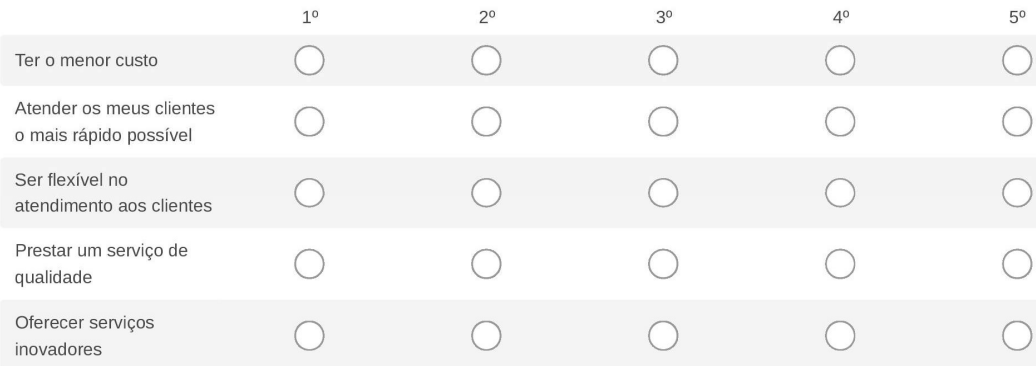

Figura 15 - Ordenamento dos objetivos de desempenho Fonte: Autora (2018). 
7. Desempenho do negócio

* 12. E como se encontra o desempenho atual da empresa quando comparado ao do principal concorrente?

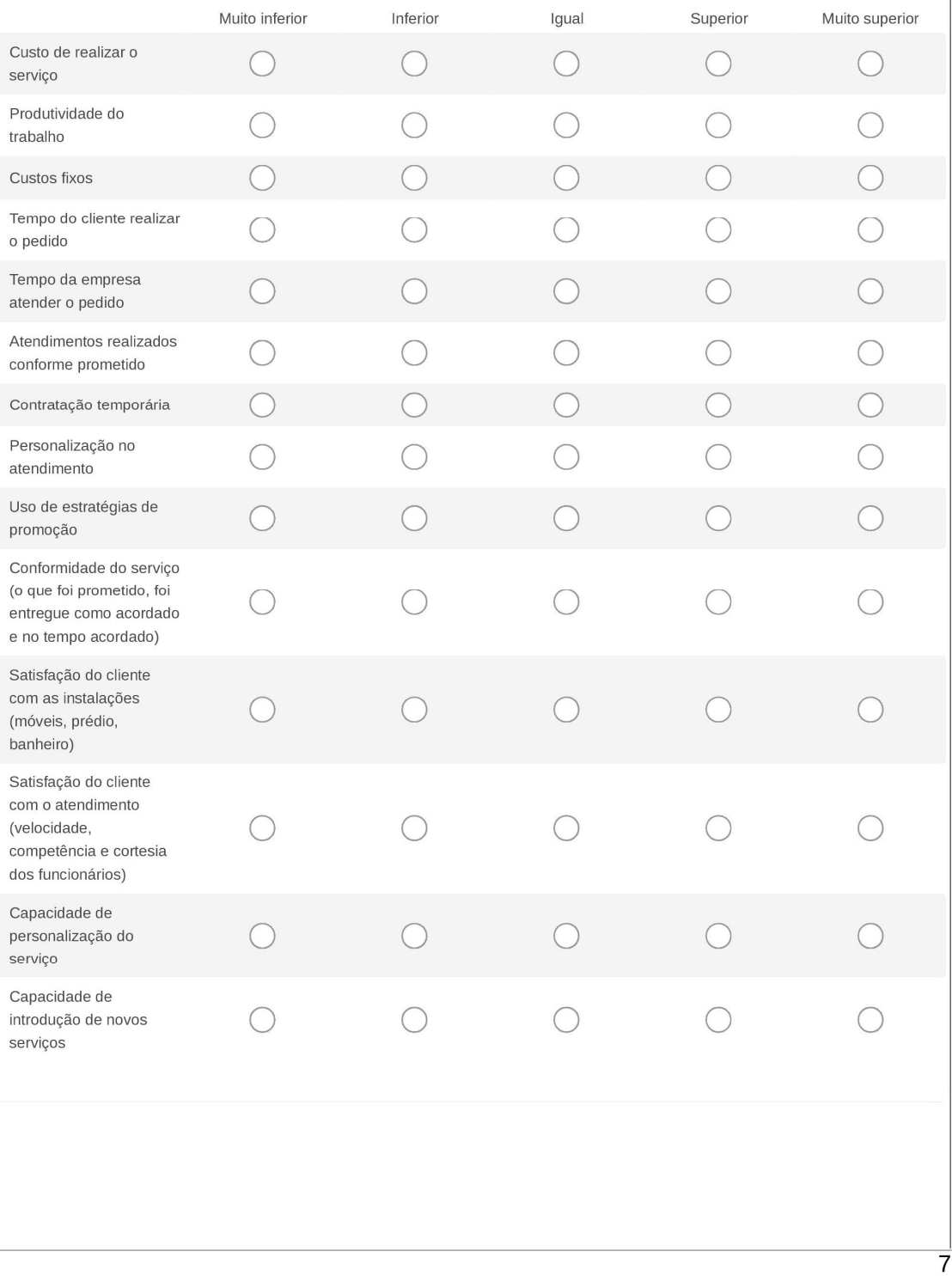

Figura 16 - Avaliação do desempenho operacional Fonte: Autora (2018). 
8. Agradecimento pela participação

Este estudo está focado em empresas com faturamento diferente do que a sua se enquadra, por isso não podemos continuar a pesquisa com a sua empresa.

De qualquer forma, agradecemos o seu interesse em participar!

Figura 17 - Agradecimento pela participação na pesquisa Fonte: Autora (2018). 
9. Agradecimento

Agradecemos a sua participação em nossa pesquisa!

13. Caso deseje obter o retorno desta pesquisa, insira seu email abaixo.

Figura 18 - Oferta de retorno dos resultados da pesquisa Fonte: Autora (2018). 


\section{APÊNDICE IV - Escalas de fatores de desempenho operacional}

\begin{tabular}{|c|c|c|}
\hline $\begin{array}{r}\text { Dimensão de } \\
\text { desempenho } \\
\text { operacional }\end{array}$ & Escala & Referência \\
\hline \multirow[t]{23}{*}{ 1-Custos } & -Baixo custo & Badri, Davis e Davis (2000) \\
\hline & $\begin{array}{l}\text {-Competitividade das estratégias } \\
\text { competitivas }\end{array}$ & Amir, Auzair e Amiruddin (2016) \\
\hline & -Custo & $\begin{array}{l}\text { da Silveira e Sousa (2010); Gaur, } \\
\text { Vasudevan e Gaur (2011); Gui-Lin, Xiao- } \\
\text { Hong e Guo-Qun (2008) }\end{array}$ \\
\hline & -Custo percebido de produção & Subramaniam et al. (2011) \\
\hline & $\begin{array}{l}\text {-Custo unitário do produto em relação aos } \\
\text { concorrentes }\end{array}$ & $\begin{array}{l}\text { Rahman, Laosirihongthong e Sohal } \\
(2010)\end{array}$ \\
\hline & -Eficiência do trabalho & Kongmanila e Takahashi (2010) \\
\hline & -Eficiência dos custos de suprimentos & Tsaur e Wang (2011) \\
\hline & $\begin{array}{l}\text {-Eficiência na manufatura de produtos } \\
\text { e/ou prestação de serviços }\end{array}$ & Malmström e Wincent (2012) \\
\hline & $\begin{array}{l}\text {-Ineficiência (custo de produtos vendidos } \\
\text { por colaborador) }\end{array}$ & Djupdal e Westhead (2015) \\
\hline & -Melhoria da produtividade & Papastathopoulos e Beneki (2010) \\
\hline & -Poupança de custo & Adawiyah et al. (2015) \\
\hline & -Produção/custo de operação & Agyapong, Agyapong e Poku (2017) \\
\hline & -Produtividade & $\begin{array}{l}\text { Gholami et al. (2013); Hilmi et al. (2010); } \\
\text { Jing (2017); Jones et al. (2013); Siqueira } \\
\text { e Cosh (2008) }\end{array}$ \\
\hline & -Produtividade da força de trabalho & Sukwadi, Wee e Yang (2013) \\
\hline & -Produtividade de capital & Martinez-Caro e Cegarra-Navarro (2010) \\
\hline & -Produtividade de operações & Tsaur e Wang (2011) \\
\hline & -Produtividade do colaborador & Ukenna et al. (2010) \\
\hline & -Produtividade do trabalho & Correia e Petiz (2006) \\
\hline & -Produtividade laboral & $\begin{array}{l}\text { Ali e Shabir (2017); Augusto, Lisboa e } \\
\text { Yasin (2014); Rosli e Sidek (2007) }\end{array}$ \\
\hline & -Produtividade total & $\begin{array}{l}\text { Rahman, Laosirihongthong e Sohal } \\
\text { (2010) }\end{array}$ \\
\hline & -Produtividade total da empresa & Sheng e Song (2013) \\
\hline & -Redução dos custos de trabalho & Papastathopoulos e Beneki (2010) \\
\hline & -Redução nos custos de produção & Mahmood e Mohd Rosli (2013) \\
\hline \multirow[t]{11}{*}{ 2-Entrega } & $\begin{array}{l}\text {-Competitividade das estratégias } \\
\text { competitivas }\end{array}$ & Amir, Auzair e Amiruddin (2016) \\
\hline & -Desempenho de habilidade on-time & Sorooshian et al. (2011) \\
\hline & -Entrega & $\begin{array}{l}\text { Badri, Davis e Davis (2000); da Silveira e } \\
\text { Sousa (2010); Gaur, Vasudevan e Gaur } \\
\text { (2011) }\end{array}$ \\
\hline & $\begin{array}{l}\text {-Entrega rápida comparada ao } \\
\text { competidor }\end{array}$ & $\begin{array}{l}\text { Rahman, Laosirihongthong e Sohal } \\
(2010)\end{array}$ \\
\hline & $\begin{array}{l}\text {-Habilidade de fornecer produtos ou } \\
\text { serviços }\end{array}$ & Sukwadi, Wee e Yang (2013) \\
\hline & -Leadtime reduzido na produção & Adawiyah et al. (2015) \\
\hline & -Prontidão de entrega & Biju e Bhasi (2014) \\
\hline & -Redução de leadtime & Biju e Bhasi (2014) \\
\hline & -Responsividade operacional & Richey, Genchev e Daugherty (2005) \\
\hline & -Tempo & Gui-Lin, Xiao-Hong e Guo-Qun (2008) \\
\hline & -Velocidade de servir os clientes & Agyapong, Agyapong e Poku (2017) \\
\hline \multirow[t]{4}{*}{$\begin{array}{l}\text { 3- } \\
\text { Flexibilidade }\end{array}$} & $\begin{array}{l}\text {-Capacidade para gerenciar variadas } \\
\text { necessidades de clientes/mercado }\end{array}$ & Agyapong, Agyapong e Poku (2017) \\
\hline & $\begin{array}{l}\text {-Competitividade das estratégias } \\
\text { competitivas }\end{array}$ & Amir, Auzair e Amiruddin (2016) \\
\hline & -Diversificação de produto e serviço & Massaro, Dumay e Bagnoli (2015) \\
\hline & $\begin{array}{l}\text {-Extensão da flexibilidade no processo de } \\
\text { entrega de produto / serviço }\end{array}$ & Agyapong, Agyapong e Poku (2017) \\
\hline
\end{tabular}




\begin{tabular}{|c|c|c|}
\hline $\begin{array}{c}\text { Dimensão de } \\
\text { desempenho } \\
\text { operacional }\end{array}$ & Escala & Referência \\
\hline & -Flexibilidade & $\begin{array}{l}\text { Adawiyah et al. (2015); Badri, Davis e } \\
\text { Davis (2000); da Silveira e Sousa } \\
\text { (2010); Gaur, Vasudevan e Gaur (2011) }\end{array}$ \\
\hline & $\begin{array}{l}\text {-Habilidade de mudança rápida no } \\
\text { volume de produção }\end{array}$ & Sorooshian et al. (2011) \\
\hline \multirow[t]{19}{*}{ 4-Qualidade } & $\begin{array}{l}\text {-Competitividade das estratégias } \\
\text { competitivas }\end{array}$ & Amir, Auzair e Amiruddin (2016) \\
\hline & -Desempenho de qualidade & Ndubisi e Iftikhar (2012) \\
\hline & -Extensão da falha no produto / serviço & Agyapong, Agyapong e Poku (2017) \\
\hline & $\begin{array}{l}\text {-Melhoria de procedimentos de produção } \\
\text { já existentes }\end{array}$ & Papastathopoulos e Beneki (2010) \\
\hline & -Perspectiva do consumidor & Khalique e Pablos (2015) \\
\hline & -Qualidade & $\begin{array}{l}\text { Badri, Davis e Davis (2000); da Silveira e } \\
\text { Sousa (2010); Gaur, Vasudevan e Gaur } \\
\text { (2011); Gui-Lin, Xiao-Hong e Guo-Qun } \\
\text { (2008) }\end{array}$ \\
\hline & -Qualidade de produtos e serviços & Sheehan e Cooper (2011) \\
\hline & $\begin{array}{l}\text {-Qualidade de produtos e serviços } \\
\text { desenvolvidos pela firma }\end{array}$ & Malmström e Wincent (2012) \\
\hline & -Qualidade do preço-produto & Rojas-Méndez, Kara e Spillan (2005) \\
\hline & -Qualidade do produto & $\begin{array}{l}\text { Fan et al. (2013); Prajapati e Biswas } \\
\text { (2011); Sorooshian et al. (2011); Tai et } \\
\text { al. (2012) }\end{array}$ \\
\hline & -Qualidade do serviço operacional & Richey, Genchev e Daugherty (2005) \\
\hline & $\begin{array}{l}\text {-Qualidade e variedade de produtos e } \\
\text { serviços }\end{array}$ & Theriou e Chatzoudes (2015) \\
\hline & -Qualidade percebida do produto & Subramaniam et al. (2011) \\
\hline & $\begin{array}{l}\text {-Quão consistentemente as necessidades } \\
\text { do cliente são atendidas }\end{array}$ & Agyapong, Agyapong e Poku (2017) \\
\hline & -Resultados de consumidor & Sinha, Garg e Dhall (2016) \\
\hline & -Satisfação & $\begin{array}{l}\text { Gui-Lin, Xiao-Hong e Guo-Qun (2008) } \\
\text { Hosseini e Eskandari (2013) }\end{array}$ \\
\hline & -Satisfação do consumidor & $\begin{array}{l}\text { Augusto, Lisboa e Yasin (2014); Duan e } \\
\text { Yu (2016); Fening, Pesakovic e Amaria } \\
\text { (2008); Gholami et al. (2013); Hilmi et al. } \\
\text { (2010); Jing (2017); Johns, Avcí e } \\
\text { Karatepe (2004); Mahmood e Mohd } \\
\text { Rosli (2013); Mahmood et al. (2017); } \\
\text { Pantouvakis e Patsiouras (2016); } \\
\text { Sorooshian et al. (2011); Theriou e } \\
\text { Chatzoudes (2015); Ukenna et al. (2010) }\end{array}$ \\
\hline & -Satisfação total do cliente & $\begin{array}{l}\text { Rahman, Laosirihongthong e Sohal } \\
(2010)\end{array}$ \\
\hline & -Serviço do consumidor & Prajapati e Biswas (2011) \\
\hline \multirow[t]{10}{*}{ 5-Inovação } & $\begin{array}{l}\text {-Adaptabilidade na adoção de novos } \\
\text { produtos e mercados }\end{array}$ & Rawwas e lyer (2013) \\
\hline & -Adoção de novas tecnologias & Theriou e Chatzoudes (2015) \\
\hline & -Atividade de inovação & Heimonen (2012) \\
\hline & $\begin{array}{l}\text {-Capacidade de desenvolver novos } \\
\text { produtos e processos }\end{array}$ & Sukwadi, Wee e Yang (2013) \\
\hline & $\begin{array}{l}\text {-Competitividade das estratégias } \\
\text { competitivas }\end{array}$ & Amir, Auzair e Amiruddin (2016) \\
\hline & -Comportamento inovador do colaborador & Reade e Lee (2016) \\
\hline & $\begin{array}{l}\text {-Crescimento da inovação de produtos e } \\
\text { serviços }\end{array}$ & Theriou e Chatzoudes (2015) \\
\hline & -Desempenho da inovação & $\begin{array}{l}\text { Hu e Mathews (2009); Jo, Park e Kang } \\
\text { (2016); Parida e Örtqvist (2015) }\end{array}$ \\
\hline & $\begin{array}{l}\text {-Desempenho da inovação (porcentagem } \\
\text { da receita gerada através da venda de } \\
\text { produtos inovados no volume total de } \\
\text { vendas) }\end{array}$ & Subrahmanya (2013) \\
\hline & -Desempenho de inovação & Singh, Khamba e Nanda (2017) \\
\hline
\end{tabular}




\begin{tabular}{|c|c|c|}
\hline $\begin{array}{l}\text { Dimensão de } \\
\text { desempenho } \\
\text { operacional }\end{array}$ & Escala & Referência \\
\hline & -Desempenho tecnológico & Chung, Bae e Kim (2003) \\
\hline & -Desenvolvimento de novo design & Prajapati e Biswas (2011) \\
\hline & -Desenvolvimento de novos produtos & $\begin{array}{l}\text { Bae e Chung (2001); Liu e Chen (2015); } \\
\text { Odoom (2016); Prajapati e Biswas } \\
\text { (2011) }\end{array}$ \\
\hline & -Diversificação de produto e serviço & Massaro, Dumay e Bagnoli (2015) \\
\hline & $\begin{array}{l}\text {-Eficiência no desenvolvimento de } \\
\text { produtos e serviços }\end{array}$ & Malmström e Wincent (2012) \\
\hline & -Fatia de mercado & Zhou et al. (2017) \\
\hline & -Grau de inovação do produto & $\begin{array}{l}\text { Minguela-Rata, Fernandez-Menendez e } \\
\text { Fossas-Olalla (2014) }\end{array}$ \\
\hline & -Grau de novidade da inovação & Amara et al. (2008) \\
\hline & $\begin{array}{l}\text {-Grau em que o programa de } \\
\text { desenvolvimento de novos produtos } \\
\text { atingiu seu objetivo; }\end{array}$ & Markham e Lee (2014) \\
\hline & -Implementação da inovação & McAdam et al. (2010) \\
\hline & -Inovação & $\begin{array}{l}\text { Alam et al. (2016); Amara et al. (2008); } \\
\text { Gholami et al. (2013); Gui-Lin, Xiao- } \\
\text { Hong e Guo-Qun (2008); Hosseini e } \\
\text { Eskandari (2013); Keizer, Dijkstra e } \\
\text { Halman (2002); Laforet (2009); } \\
\text { Rodriguez e Guzman (2013); Ukenna et } \\
\text { al. (2010) }\end{array}$ \\
\hline & -Inovação (vendas inovadoras relativas) & Ebersberger e Herstad (2013) \\
\hline & -Inovação de entrada aberta & Huang, Lai e Huang (2015) \\
\hline & -Inovação de imitação & Soni, Lilien e Wilson (1993) \\
\hline & -Inovação de melhoria & Soni, Lilien e Wilson (1993) \\
\hline & -Inovação de mercado & Tejada e Moreno (2013) \\
\hline & -Inovação do mercado & Medrano e Olarte-Pascual (2016) \\
\hline & -Inovação do processo & $\begin{array}{l}\text { Jha e Bosel (2016); Tejada e Moreno } \\
\text { (2013); Tomlinson e Fai (2013); Urban e } \\
\text { Greyling (2015) }\end{array}$ \\
\hline & -Inovação do produto & $\begin{array}{l}\text { Jha e Bosel (2016); Minguela-Rata, } \\
\text { Fernandez-Menendez e Fossas-Olalla } \\
\text { (2014); Tejada e Moreno (2013); } \\
\text { Tomlinson e Fai (2013); Urban e } \\
\text { Greyling (2015) }\end{array}$ \\
\hline & $\begin{array}{l}\text {-Inovação do produto ou do processo } \\
\text { (PPI) }\end{array}$ & Papula, Volná e Hul'vej (2013) \\
\hline & -Inovação incremental & Verbano e Crema (2016) \\
\hline & -Inovação organizacional & Tejada e Moreno (2013) \\
\hline & $\begin{array}{l}\text {-Inovação organizacional ou em } \\
\text { marketing (MOI) }\end{array}$ & Papula, Volná e Hul'vej (2013) \\
\hline & -Inovação radical & Verbano e Crema (2016) \\
\hline & -Introdução da internet & Aragon-Correa e Cordon-Pozo (2005) \\
\hline & -Número de novos produtos & Zhou et al. (2017) \\
\hline & -Número de patentes & Zhou et al. (2017) \\
\hline & -Política de sucesso e inovação & Markic et al. (2011) \\
\hline & -Proporção de inovação & Guan et al. (2006) \\
\hline & $\begin{array}{l}\text {-Sucesso da unidade de negócio de } \\
\text { desenvolvimento de novos produtos }\end{array}$ & Markham e Lee (2014) \\
\hline & -Sucesso de mercado; & Markham e Lee (2014) \\
\hline & -Sucesso de novos produtos & $\begin{array}{l}\text { Droge, Calantone e Harmancioglu } \\
\text { (2008); O'Dwyer e Ledwith (2010) }\end{array}$ \\
\hline & -Sucesso do produto & Rojas-Méndez, Kara e Spillan (2005) \\
\hline & -Sucesso financeiro & Markham e Lee (2014) \\
\hline & -Sucesso percebido de novos produtos & Mendes e Ganga (2013) \\
\hline & -Sucesso total do programa; & Markham e Lee (2014) \\
\hline & -Taxa de inovação & Yam et al. (2004) \\
\hline & $\begin{array}{l}\text { - Taxa de introdução de novos } \\
\text { produtos/serviços no mercado }\end{array}$ & Agyapong, Agyapong e Poku (2017) \\
\hline & -Taxa de sucesso da inovação & Zhou et al. (2017) \\
\hline
\end{tabular}




\begin{tabular}{|c|c|c|}
\hline $\begin{array}{c}\text { Dimensão de } \\
\text { desempenho } \\
\text { operacional }\end{array}$ & Escala & Referência \\
\hline & -Tempo de desenvolvimento; & Markham e Lee (2014) \\
\hline & $\begin{array}{l}\text {-Vantagem comparativa relevada pela } \\
\text { tecnologia }\end{array}$ & Mahmood e Mitchell (2004) \\
\hline & -Vendas de novos produtos e serviços & Urban e Greyling (2015) \\
\hline & $\begin{array}{l}\text {-Volume de negócios da empresa relativo } \\
\text { a produtos novos para o mercado mundial }\end{array}$ & Yun et al. (2016) \\
\hline & $\begin{array}{l}\text {-Volume de negócios referente a produtos } \\
\text { novos para a empresa }\end{array}$ & Yun et al. (2016) \\
\hline & $\begin{array}{l}\text {-Volume de novos negócios referente a } \\
\text { produtos melhorados }\end{array}$ & Yun et al. (2016) \\
\hline
\end{tabular}

